\title{
WestVirginiaUniversity
}

THE RESEARCH REPOSITORY @ WVU

Graduate Theses, Dissertations, and Problem Reports

2013

\section{Folding Solid-Membrane Wing Structure for a Micro Air Vehicle}

Joe D. Allen Jr.

West Virginia University

Follow this and additional works at: https://researchrepository.wvu.edu/etd

\section{Recommended Citation}

Allen, Joe D. Jr., "Folding Solid-Membrane Wing Structure for a Micro Air Vehicle" (2013). Graduate Theses, Dissertations, and Problem Reports. 559.

https://researchrepository.wvu.edu/etd/559

This Thesis is protected by copyright and/or related rights. It has been brought to you by the The Research Repository @ WVU with permission from the rights-holder(s). You are free to use this Thesis in any way that is permitted by the copyright and related rights legislation that applies to your use. For other uses you must obtain permission from the rights-holder(s) directly, unless additional rights are indicated by a Creative Commons license in the record and/ or on the work itself. This Thesis has been accepted for inclusion in WVU Graduate Theses, Dissertations, and Problem Reports collection by an authorized administrator of The Research Repository @ WVU. For more information, please contact researchrepository@mail.wvu.edu. 


\title{
Folding Solid-Membrane Wing Structure for a Micro Air Vehicle
}

\author{
Joe D. Allen, Jr.
}

Thesis submitted

to the Benjamin M. Statler College of Engineering and Mineral Resources at West Virginia University

\author{
in partial fulfillment of the requirements for the degree of \\ Master of Science in \\ Mechanical Engineering
}

\author{
Wade W. Huebsch, Ph.D., Co-Chair \\ John L. Loth, Ph.D., Co-Chair \\ Patrick H. Browning, Ph.D.
}

Department of Mechanical and Aerospace Engineering

\author{
Morgantown, West Virginia \\ 2013
}

Keywords: Micro Air Vehicle, Unmanned Air Vehicle, Low Reynolds Number Flight, Stowable Wing, Aircraft Design, Wind Tunnel, Experimental Evaluation, Wing Deployment Mechanism, Folding Wing

Copyright 2013 Joe D. Allen, Jr. 


\section{Abstract \\ Folding Solid-Membrane Wing Structure for a Micro Air Vehicle \\ Joe D. Allen, Jr.}

The design of a solid-membrane folding wing for use on a tube launched micro air vehicle (MAV), and experimental wind tunnel results of the wing integrated on an engineering MAV model are presented herein. Due to the sizing and performance requirements of the MAV, the wing must provide sufficient wing area while minimizing its stowed footprint. Many current available methods for folding the wing for such a MAV sacrifice aerodynamic efficiency or are cost prohibitive. The solid-membrane wing design presented blends elements of a solid semirigid wing with those of a membrane wing. This provides the aerodynamic efficiency of a wing with conventional airfoils and reduces the required storage volume of the wing when folded. In order to demonstrate the performance benefits of the wing, the wing was integrated via 3D modeling into an engineering MAV model along with other MAV components including tail control fins, actuators, and other useful payloads. Wind tunnel testing over the anticipated flight regime was also conducted to evaluate the L/D performance of the solid-membrane winged MAV model to that of a conventional solid winged MAV model. The results indicate the solidmembrane folding wing design has satisfactory aerodynamic performance at a lower cost. 


\section{Acknowledgements}

I would like to thank several individuals and institutions for their support, counsel, and assistance in completing this work. Everyone mentioned made it possible for me to complete this work and each helped in their own way.

Thank you:

To my wife, parents, and friends for your support during my educational and personal pursuits. The support and guidance you have provided me over the years has helped mold me into the person I am today and made completion of this work possible.

To the members of my graduate committee, Dr. Wade Huebsch, Dr. John Loth, and Dr. Patrick Browning, for all your hard work in advising me, guiding me, and teaching me over the years. Your counsel has helped me grow both professionally and personally over the years and I feel privileged to have gotten the opportunity to work with each of you.

To the faculty, staff, and my colleagues at WVU for their assistance in completing various aspects of the work, especially in being a sounding board for new ideas, for an extra hand when it was needed, for helping produce the models, and much more.

Lastly, to ARDEC for providing the funding for this project and for the opportunity to develop the new wing folding technology presented herein. 


\section{Table of Contents}

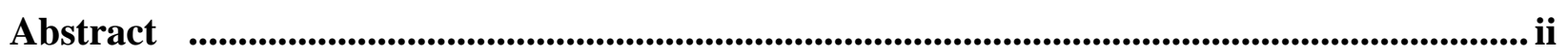

Acknowledgements ........................................................................................................................................ iii

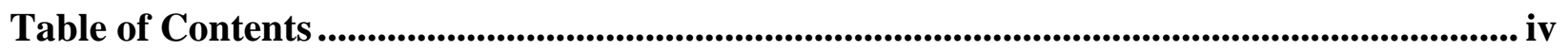

List of Figures................................................................................................................................................. vii

List of Tables ................................................................................................................................. $\mathrm{x}$

List of Symbols and Abbreviations ......................................................................................................... xi

Chapter 1. Problem Statement and Thesis Outline ....................................................................... 1

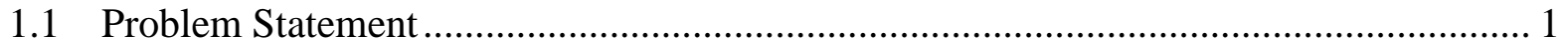

Chapter 2. Prior Art \& Technology Review ............................................................................. 1

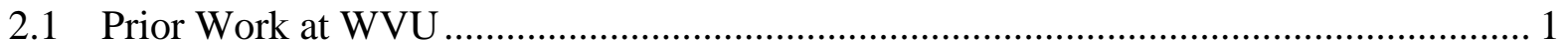

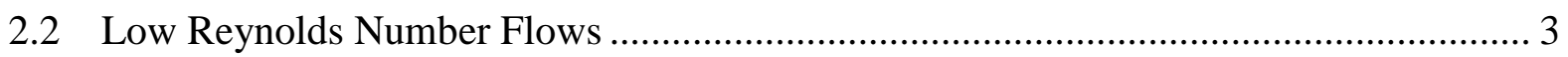

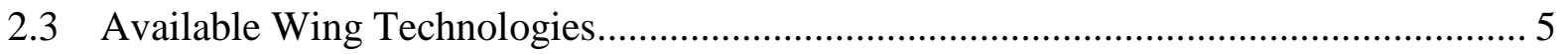

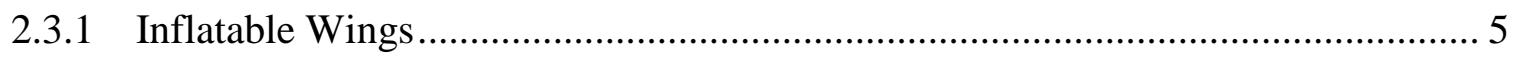

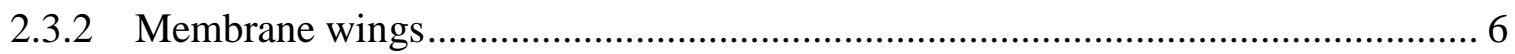

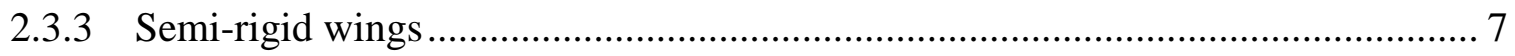

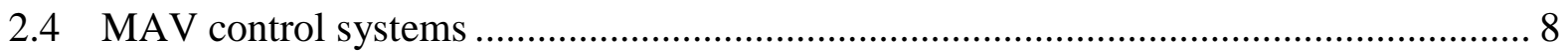

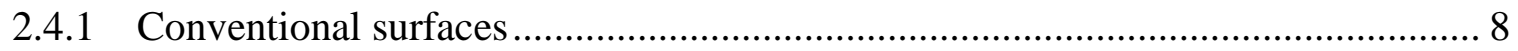

2.4.2 Flight control utilizing surface morphing \& smart materials ............................... 9

2.5 MAV and UAV Systems with Applicable Technologies ............................................... 11

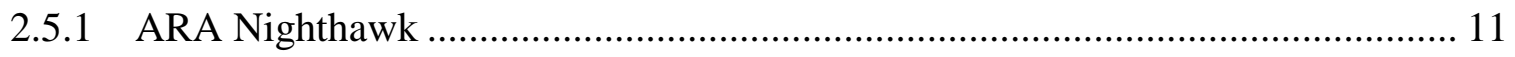

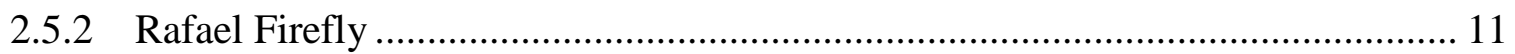

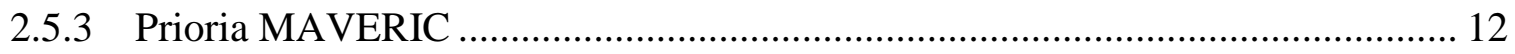

2.5.4 Aerovironment Switchblade ..................................................................... 12

2.5.5 Aerovironment Nano Hummingbird........................................................... 13

2.5.6 Aerovironment Black Widow ........................................................................ 13

Chapter 3. Considered Design Concepts and Selection............................................................ 14

3.1 Considered Concepts, Characteristics, and Preferred Embodiments.............................. 14

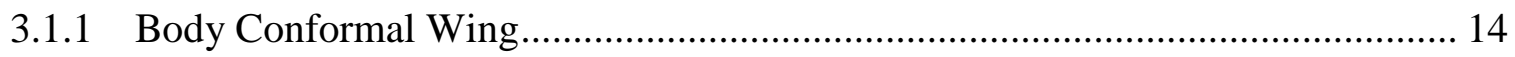

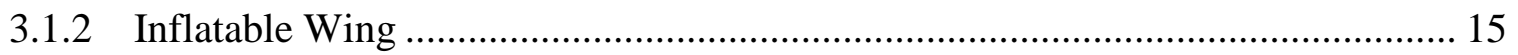

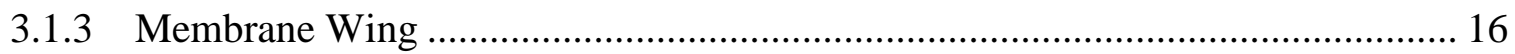

3.1.4 Composite Leaf Spring Wing …………………........................................ 18

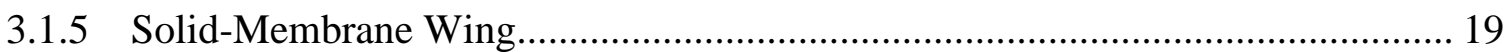

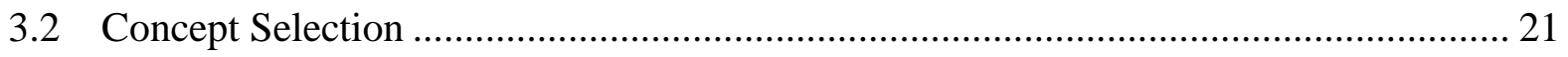

Chapter 4. Design of the Solid-Membrane Wing and Mechanism........................................ 23 


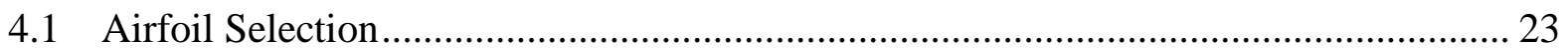

4.1.1 Comparison of NACA 0009 and Modified NACA 0009 Airfoils........................ 23

4.2 Wing Sizing and Performance Estimates................................................................. 24

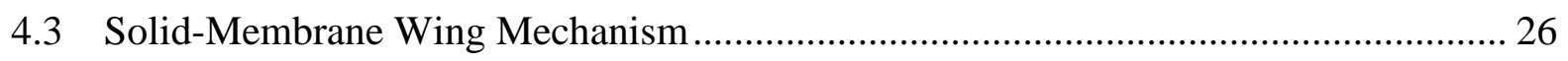

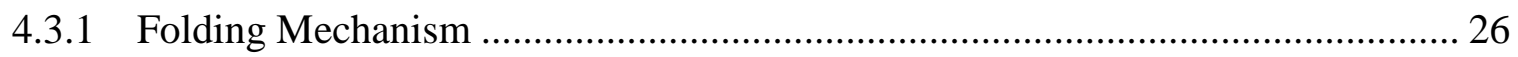

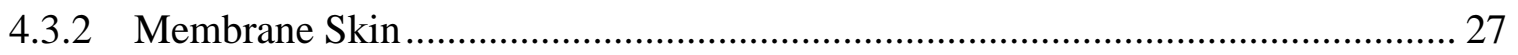

4.3.3 Release and Locking Mechanism ..................................................................... 27

4.3.4 Folding Wing Proof of Concept Model ............................................................... 27

4.4 Engineering Solid-Membrane Wing MAV Model ....................................................... 28

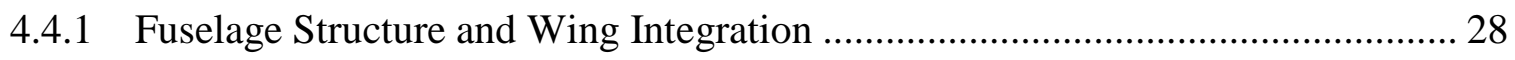

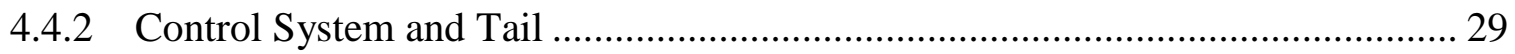

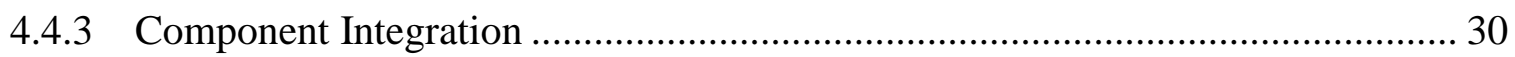

4.5 Final Estimated Performance Parameters ................................................................. 31

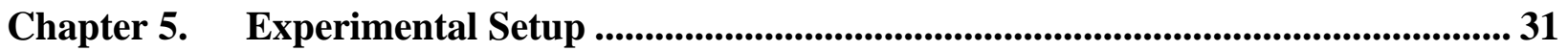

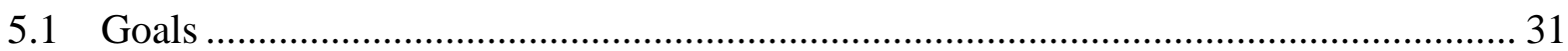

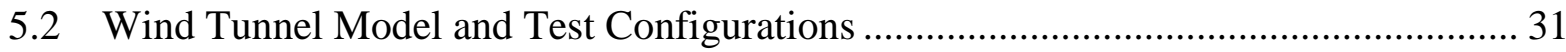

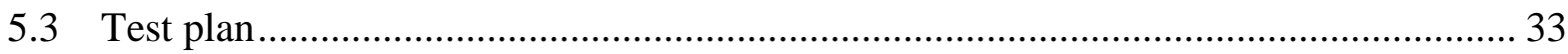

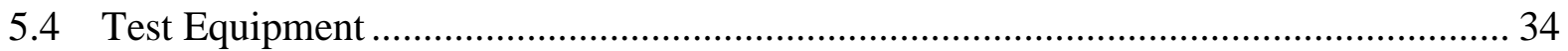

5.4.1 WVU Closed Loop Sub-Sonic Wind Tunnel.................................................. 34

5.4.2 Test Sting and Three-Component Balance …………......................................... 34

5.4.3 High Speed Camera ……………………………….......................................... 35

5.4.4 Data Acquisition and Processing …………………......................................... 36

Chapter 6. Data Analysis \& Discussion...................................................................................... 36

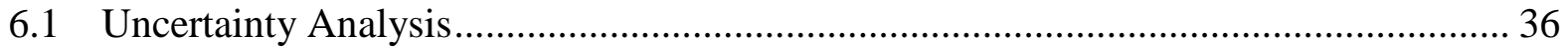

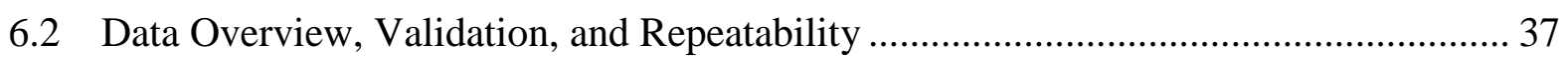

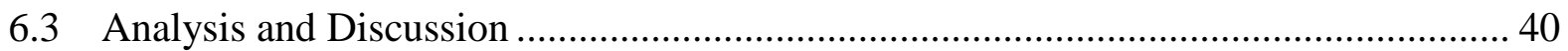

Chapter 7. Summary and Recommendations.............................................................................. 49

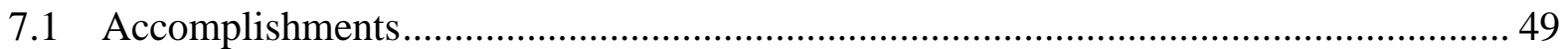

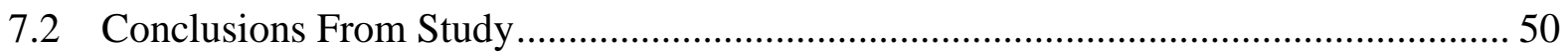

7.3 Recommendations for Future Work............................................................................... 50

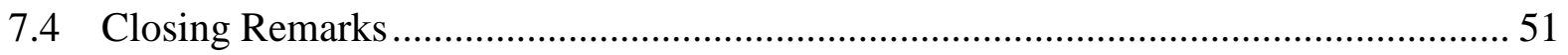

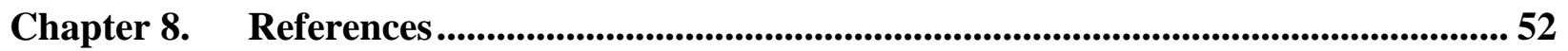

Appendix A: Full Test Plan.................................................................................................................. 55

Appendix B: Data Analysis Codes....................................................................................................... 58

Wind Tunnel Data Averaging and Calibration Code............................................................ 58

Wind Tunnel Data Averaging and Calibration Test Code................................................. 59

Wind Tunnel Data Averaging and Force Computation Code.................................................... 61

Appendix C: Method for Forming and Application of Membrane Wing Skins..................... 68 
Appendix D: Three-Component Balance Calibration..................................................................... 70

Appendix E: Uncertainty Analysis.................................................................................................... 71

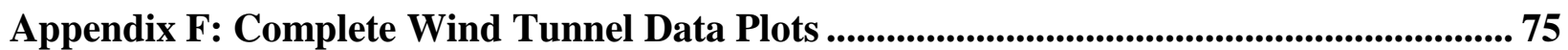

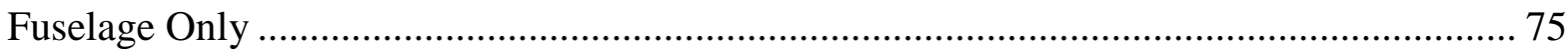

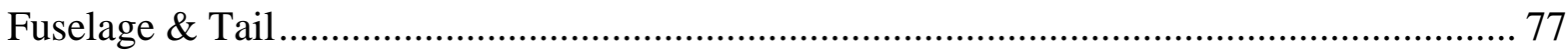

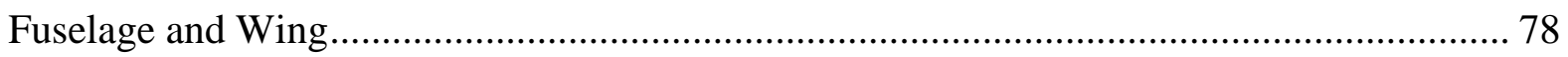

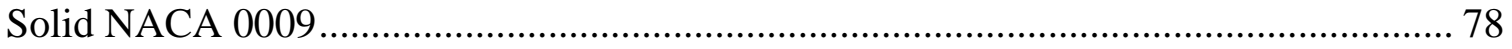

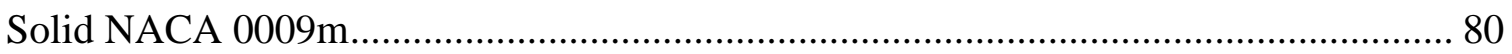

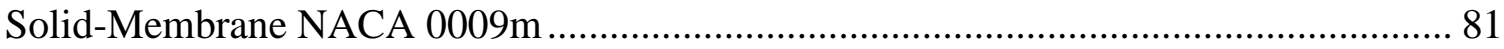

Partial Deployment Cases - Solid-Membrane NACA 0009m ........................................... 83

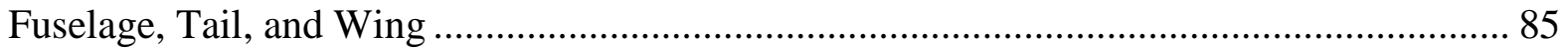

Solid NACA 0009

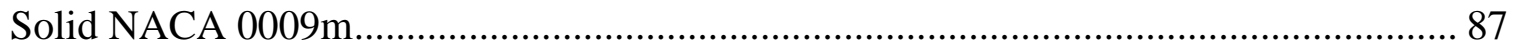

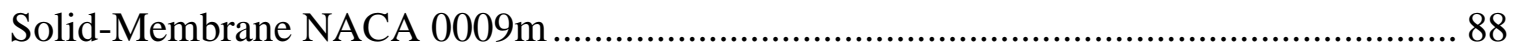




\section{List of Figures}

Figure 2-1 Mr. Hamburg's Initial Left Spring Wing Concepts (1) .......................................... 1

Figure 2-2 Mr. Hamburg's Initial Wrapped Membrane Wing Concept (1) ................................ 2

Figure 2-3 Mr. Hamburg's Initial Solid Wrapped Wing Concept (1) ......................................... 2

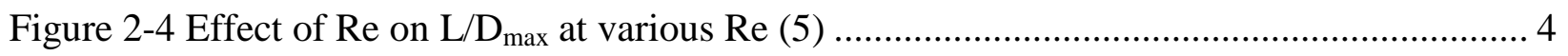

Figure 2-5 An ILC Dover Inflatable Wing Stowed (left) and Deployed (right) (7) .................... 5

Figure 2-6 Membrane Wing Concept Presented by Clarkson University (19)........................... 7

Figure 2-7 Load alleviating wing (left) and load agumentation wing (right) (16) ..................... 7

Figure 2-8 A 2.9 gram nano linear servo (left) and a 6 gram super sub micro servo (right) (22) .. 8

Figure 2-9 Dr. Richard Guiler's Morphing Wing Flight Test Vehicle, the Habicht II (23)........... 9

Figure 2-10 Morphing wing tip components from the Habicht II flight test vehicle (23)........... 10

Figure 2-11 Virginia Tech fully adaptive aircraft model (left) and twist mechanism (right) (24) 10

Figure 2-12 Nighthawk MAV with folding wings(18).................................................... 11

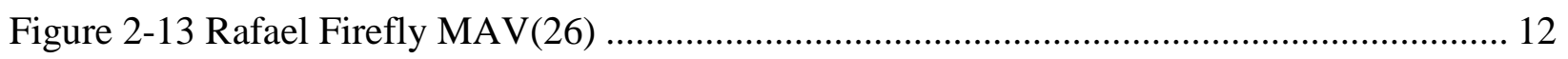

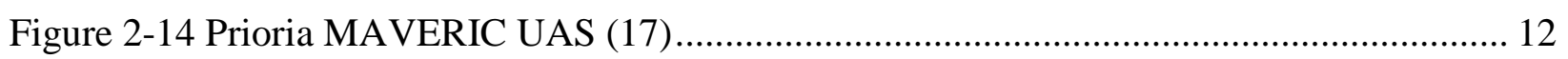

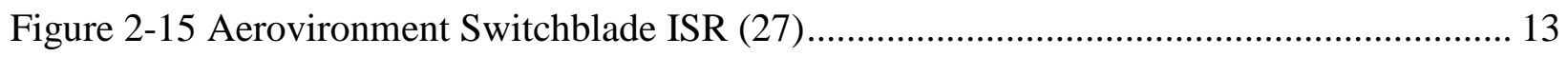

Figure 2-16 Aerovironment Nano Hummingbird (29) ......................................................... 13

Figure 2-17 Aerovironment Black Widow MAVs(30).......................................................... 13

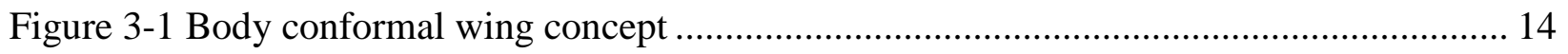

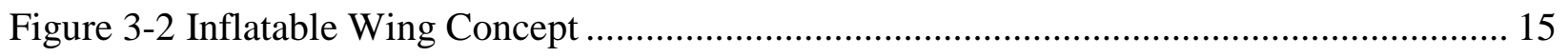

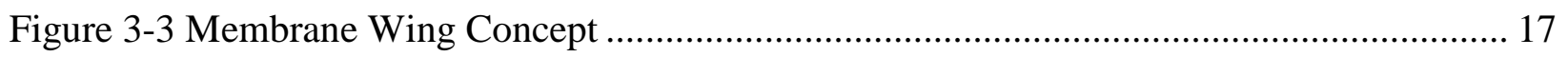

Figure 3-4 The Composite Leaf Spring MAV concept ........................................................ 18

Figure 3-5 Mr. Hamburg's Leaf Spring Embodiment (left) (28) \& the new Embodiment (right) 18

Figure 3-6 Solid-Membrane Wing Concept ......................................................................... 20

Figure 4-1 NACA 0009 (blue) and modified NACA 0009 (red) airfoils .................................. 23

Figure 4-2 XFLR 5 2D Lift Polar for NACA 0009 and modified NACA 0009 airfoils ............. 24

Figure 4-3 XFLR 5 2D Drag Polar for NACA 0009 and modified NACA 0009 airfoils ............ 24

Figure 4-4 XFLR 5 2D L/D Polar for NACA 0009 and modified NACA 0009 airfoils............. 24

Figure 4-5 Basic wing mechanism in the open position (left) and the closed position (right) ..... 26

Figure 4-6 Wing Leading edge and trailing edge elements with springs ................................. 26

Figure 4-7 Wing release and locking mechanism with the wing in the open and locked state... 27 
Figure 4-8 Folding Wing Proof of Concept Model Stowed (left) and Deployed (right)............. 28

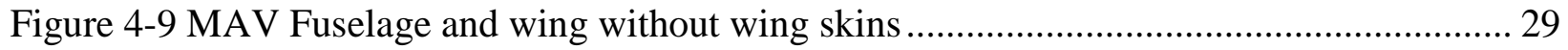

Figure 4-10 MAV Fuselage Structure with outer skin removed............................................ 29

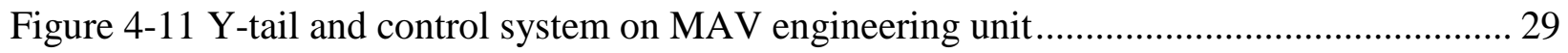

Figure 4-12 Final rendering of the engineering MAV model with all system components. ........ 30

Figure 5-1 Wind tunnel model with solid NACA 0009 wings installed ................................... 32

Figure 5-2 Primary Test Section of the WVU Closed Loop Subsonic Wind Tunnel.................. 34

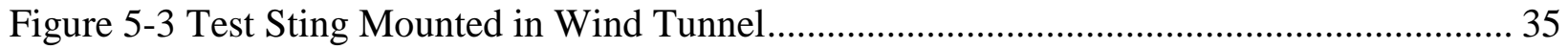

Figure 5-4 Three-component balance assembly (left) mounted under the wind tunnel (right) .... 35

Figure 6-1 Lift and Drag data comparison at $\mathrm{Re}=250,000$ between data for a baseline fuselage in the ARDEC wind tunnel and the solid-membrane wing MAV fuselage. ................... 38

Figure 6-2 Repeatability plots for Fuselage, Tail, and Wing Configurations at $\mathrm{Re}=125,000 \ldots . . .39$

Figure 6-3 Repeatability plots for Fuselage only Configuration at $\mathrm{Re}=250,000 \ldots \ldots \ldots \ldots \ldots \ldots \ldots . . . . . . . . . .39$

Figure 6-4 Fuselage, Tail, and Solid-Membrane Wing $C_{L}, C_{D}$, and $L / D$ data with vertical error

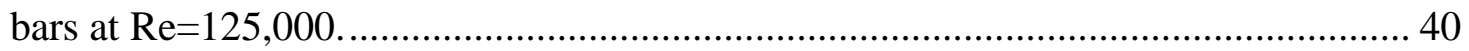

Figure 6-5 Lift, Drag, \& L/D Polars for the Fuselage \& Solid NACA 0009 Wing Configuration 42

Figure 6-6 Fuselage \& Wing and Fuselage, Wing, \& Tail Configuration Results at $\mathrm{Re}=125,000$.

Figure 6-7 Lift, Drag, and L/D Comparison of Fuselage, Fuselage \& Tail, Fuselage \& SolidMembrane Wing, and Fuselage, Tail, \& Solid-Membrane Wing Configurations. ...... 45

Figure 6-8 Fuselage and Wing Full, Partial, and Failed TE Deployment Comparison ............... 47

Figure C-1 Sample Membrane Wing Skin Material Pattern (Not to Scale) ............................... 68

Figure D-1 Lift (top left), Drag (top right), and Moment (bottom) Load Cell Calibration Curves

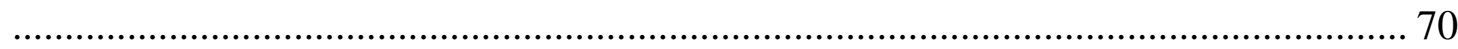

Figure F-1 Fuselage Only - Lift, Drag, and L/D Polars..................................................... 75

Figure F-2 Fuselage Only- Lift, Drag, and L/D Polars from Repeatability Testing at Re=250,000

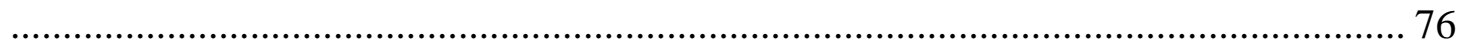

Figure F-3 Fuselage \& Tail - Lift, Drag, and L/D Polars .................................................... 77

Figure F-4 Fuselage \& Solid NACA 0009 Wing - Lift, Drag, and L/D Polars .......................... 78 
Figure F-5 Fuselage \& Solid NACA 0009 Wing - Lift, Drag, and L/D Polars from Repeatability

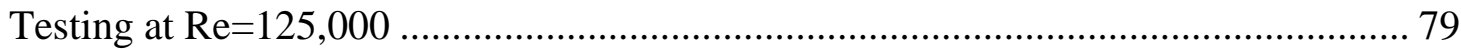

Figure F-6 Fuselage \& Solid NACA 0009m Wing - Lift, Drag, and L/D Polars ........................... 80

Figure F-7 Fuselage \& Solid-Membrane NACA 0009m Wing - Lift, Drag, and L/D Polars ...... 81

Figure F-8 Fuselage \& Solid-Membrane NACA 0009m Wing - Lift, Drag, and L/D Polars from

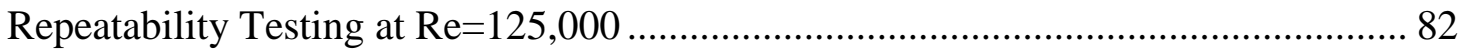

Figure F-9 Fuselage \& Solid-Membrane NACA 0009m Wing - Partial Trailing Edge Element

Deployment - Lift, Drag, and L/D Polars...................................................................... 83

Figure F-10 Fuselage \& Solid-Membrane NACA 0009m Wing - No Trailing Edge Element Deployment - Lift, Drag, and L/D Polars.................................................................... 84

Figure F-11 Fuselage, Tail, \& Solid NACA 0009 Wing - Lift, Drag, and L/D Polars................... 85

Figure F-12 Fuselage, Tail, \& Solid NACA 0009 Wing - Lift, Drag, and L/D Polars from

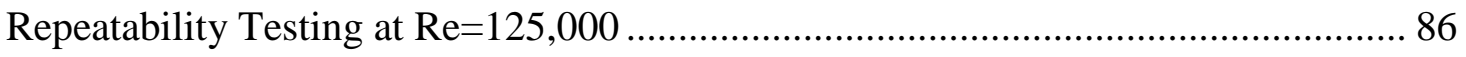

Figure F-13 Fuselage, Tail, \& Solid NACA 0009m Wing - Lift, Drag, and L/D Polars .............. 87

Figure F-14 Fuselage, Tail, \& Solid-Membrane NACA 0009m Wing - Lift, Drag, and L/D Polars

Figure F-15 Fuselage, Tail, \& Solid-Membrane NACA 0009m Wing - Lift, Drag, and L/D Polars from Repeatability Testing at $\mathrm{Re}=125,000$ 89 


\section{List of Tables}

Table 3-1 Solid Body Conformal Wing Concept Pros and Cons .................................................. 15

Table 3-2 Inflatable Wing Concept Pros and Cons ............................................................................. 16

Table 3-3 Membrane Wing Concept Pros and Cons ………......................................................... 17

Table 3-4 Pros and Cons for the Composite Leaf Spring Wing Concept........................................ 19

Table 3-5 Solid-membrane wing advantages and disadvantages ................................................. 20

Table 3-6 Description of Concept Selection Figures of Merit........................................................ 22

Table 3-7 FOM for Wing Concept Selection............................................................................ 22

Table 4-1 Solid-Membrane Wing Parameters ................................................................................ 25

Table 4-2 Solid-Membrane Wing Performance Estimates - Wing Only ....................................... 25

Table 4-3 Prototype Component List......................................................................................... 30

Table 4-4 Solid-Membrane Wing MAV Performance Estimates................................................... 31

Table 6-1 Uncertainty Results (Maximum Uncertainties)............................................................... 37

Table 6-2 Solid-Membrane Wing MAV Performance Estimates................................................... 43

Table 6-3 Fuselage \& Fully Deployed Wing Membrane Skin High Speed Video Frame Captures

Table 6-4 Fuselage and Wing Partial Trailing Edge Deployment High Speed Video Frame

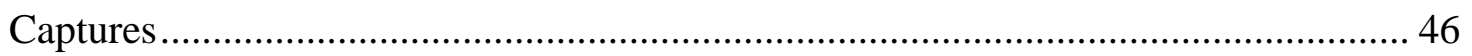

Table 6-5 Fuselage and Wing Failed Trailing Edge Deployment High Speed Video Frame Captures................................................................................................................ 48

Table A-1 Wind Tunnel Test Plan Configuration Descriptions ..................................................... 55

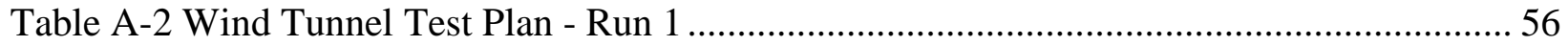

Table A-3 Wind Tunnel Test Plan - Run 2 ……………….......................................................... 57

Table A-4 Wind Tunnel Test Plan - Run 3 …………………………………....................... 57

Table D-1 Derived k-matrix from load cell calibration ................................................................... 70

Table E-1 Parameter Values Used in Uncertainty Analysis ............................................................... 74

Table E-2 Experimental Measurement Uncertainty ......................................................................... 74 


\section{List of Symbols and Abbreviations}

$\begin{array}{cl}\text { AR } & \text { Aspect Ratio } \\ \text { AoA } & \text { Angle of Attack } \\ \text { b } & \text { Span } \\ \mathrm{C}_{\mathrm{D}} & \text { 3-D Drag Coefficient } \\ \mathrm{C}_{\mathrm{d}} & \text { 2-D Drag Coefficient } \\ \mathrm{C}_{\mathrm{L}} & \text { 3-D Lift Coefficient } \\ \mathrm{C}_{\mathrm{l}} & \text { 2-D Lift Coefficient } \\ \mathrm{C}_{\mathrm{MAC}} & \text { Mean aerodynamic chord } \\ \mathrm{C}_{\mathrm{r}} & \text { Root Chord Length } \\ \mathrm{C}_{\mathrm{t}} & \text { Tip Chord Length } \\ \mathrm{CFD} & \text { Computational Fluid Dynamics } \\ \mathrm{CG} & \text { Center of gravity } \\ \mathrm{D} & \text { Drag } \\ \mathrm{fps}_{\mathrm{f}} & \text { Frames per second } \\ \mathrm{F}_{\mathrm{D}} & \text { Recorded drag force } \\ \mathrm{F}_{\mathrm{L}} & \text { Recorded lift force } \\ \mathrm{g} & \text { Gravitational acceleration on } \\ & \text { Earth } \\ \mathrm{h}_{\mathrm{w}} & \text { Tunnel head pressure } \\ \mathrm{L} & \text { Lift } \\ \text { L/D } & \text { Lift to drag ratio } \\ \text { LE } & \text { Leading Edge }\end{array}$

$\begin{array}{cl}\text { MAC } & \text { Mean Aerodynamic Chord } \\ \text { MAV } & \text { Micro Aerial Vehicle } \\ \rho & \text { Density } \\ \rho_{\mathrm{w}} & \text { Density of water } \\ \mathrm{q} & \text { Dynamic Pressure } \\ \mathrm{Re} & \text { Reynolds Number } \\ \mathrm{S} & \text { Area } \\ \mathrm{T} & \text { Temperature } \\ \mathrm{TE} & \text { Trailing Edge } \\ \mathrm{U} & \text { Uncertainty } \\ \mathrm{UAS} & \text { Unmanned Aerial System } \\ \mathrm{UAV} & \text { Unmanned Aerial Vehicle } \\ \mathrm{UV} & \text { Ultra Violet } \\ \mu & \text { Kinematic Viscosity } \\ \mathrm{V} & \text { Velocity } \\ \text { Vol } & \text { Volume } \\ \mathrm{W} / \mathrm{S} & \text { Wing loading } \\ \text { WVU } & \text { West Virginia University } \\ \Lambda_{\mathrm{LE}} & \text { Leading edge sweep angle } \\ \lambda & \text { Wing taper ratio } \\ \omega_{\mathrm{X}} & \text { Precision error of x }\end{array}$




\section{Chapter 1. Problem Statement and Thesis Outline}

\subsection{Problem Statement}

In 2008, West Virginia University was awarded a multi-million dollar contract to develop a small projectile launched unpowered MAV for the U.S. Army Armament Research Development and Engineering Center (ARDEC). This small MAV was to have a maximum outer diameter of 40mm, a maximum length of $171.5 \mathrm{~mm}$, a maximum launch weight of 220 grams, and be able to withstand a 15,000+ G acceleration launch. The minimum range of the MAV was to be $585 \mathrm{~m}$ including the initial flight phase at which the MAV was ascending in altitude.

The constraints defined above limited the total weight and size of a stowed wing and mechanism if any volume and weight were to remain for flight control systems, cameras, telemetry systems, and other payloads. As a result, the research and concept development process concentrated on developing a combination solid-membrane wing design that strikes a balance between maintaining the aerodynamic performance of wing utilizing a full airfoil profile with the packing efficiency to maintain enough internal volume in the MAV to place the required payloads and components.

\section{Chapter 2. Prior Art \& Technology Review}

\subsection{Prior Work at WVU}

Prior conceptual and preliminary design work was completed at WVU by Mr. Shanti Hamburg and is documented in his thesis(1). In his work, Mr. Hamburg laid the foundation for the development of the design presented in this work by performing some initial sizing, performing trade studies, comparing airfoils using CFD, and analyzing the MAV mission profiles considered. He also developed and presented the initial leaf spring, membrane, and solid wing concepts, presented in Figure 2-1, Figure 2-2, and Figure 2-3, respectively.

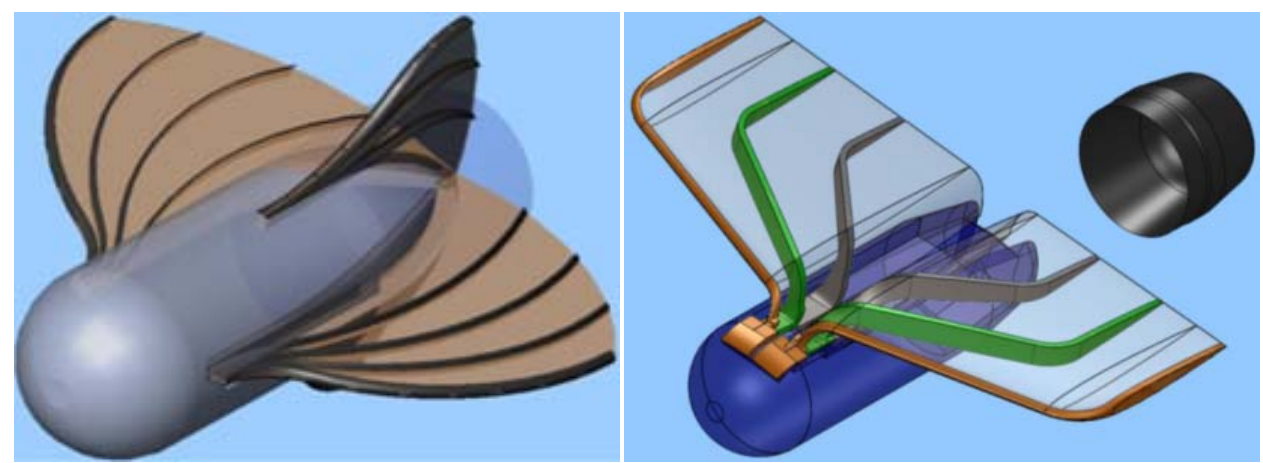

Figure 2-1 Mr. Hamburg's Initial Left Spring Wing Concepts (1) 


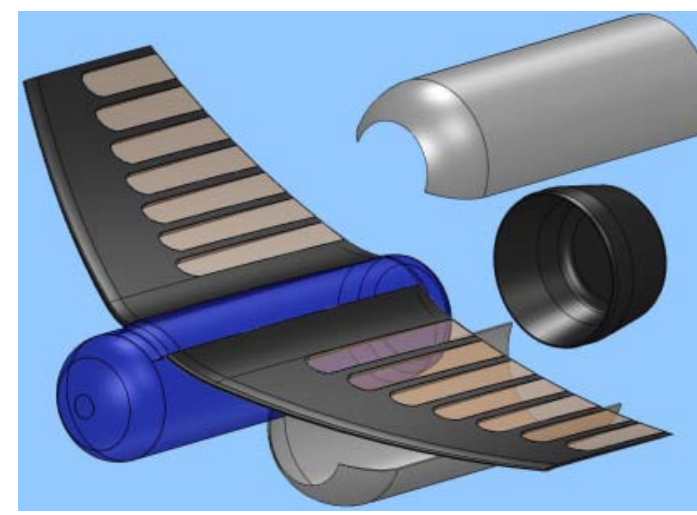

Figure 2-2 Mr. Hamburg's Initial Wrapped Membrane Wing Concept (1)

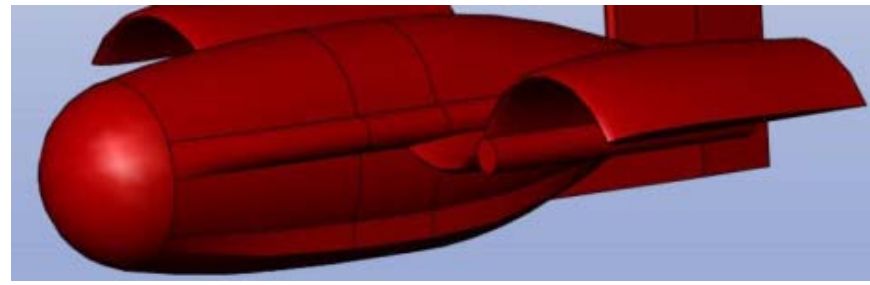

Figure 2-3 Mr. Hamburg's Initial Solid Wrapped Wing Concept (1)

Mr. Hamburg also completed work to determine the initial conditions at which the MAV's primary flight surfaces would deploy and the gliding phase of flight would begin. He used classical ballistics along with a custom MATLAB code to determine the optimal launch angles to maximize endurance. From his analysis, he discovered that for maximum range, it was best to launch at high incidence angles ( $>75^{\circ}$ ) to achieve higher altitudes and to optimize the MAV to fly at lower speeds $(<20 \mathrm{~m} / \mathrm{s})$ at the resulting apex of the ballistic trajectory (1). This resulted in larger required wing areas to provide a sufficient vehicle $\mathrm{L} / \mathrm{D}$ at these lower speeds (1).

In his thesis, Mr. Hamburg also performed a sensitivity study of a vehicle's L/D with respect to wing AR. Initially, he theorized that due to the low Re region the MAV would be operating in, it may be beneficial to use a larger chord wing with a lower AR to increase the chordwise Re thereby increasing the wing's performance (1). During his sensitivity analysis using CFD simulations, he was able to prove this to be true by showing that a wing with $A R=2.0$ and $\operatorname{Re} \approx 127 \mathrm{k}$ could achieve a maximum $\mathrm{L} / \mathrm{D} \approx 14.5$, where as another wing with $\mathrm{AR}=4.0$ and $\operatorname{Re} \approx 90 \mathrm{k}$, a maximum $L / D \approx 11.5$ could be achieved (1). This demonstrated that by reducing the AR by $50 \%$, the vehicle's L/D could be increased by more than $20 \%$.

Mr. Hamburg performed additional studies to determine the effects on the L/D ratio imposed by the wing loading (W/S), wing leading edge sweep angle $\left(\Lambda_{\mathrm{LE}}\right)$, and the wing taper ratio $(\lambda)$. The results showed that increasing the wing loading and reducing the taper ratio had a positive effect on increasing the wing $\mathrm{L} / \mathrm{D}$, and that varying the leading edge sweep between $0^{\circ}$ and $30^{\circ}$ did not have a significant effect on the L/D (1). 


\subsection{Low Reynolds Number Flows}

Similar to the concepts presented in Mr. Hamburg's work, the MAV system presented in this work is operating with an average Re between 75,000 to 150,000 . Flow at these Re is generally considered a low Re flow, although the definition at which point a Re is considered as either a low, medium, or high Re is not clear. For this work, it is assumed that the accepted range of low Re external flow is defined as any external flow with a $\mathrm{Re}<500,000$ (2). This places the MAV design in question in the lower end of low Re flow, necessitating a good understanding of low Re flow to successfully design a functional wing and folding mechanism.

The effects of low Re on a flow cannot be discussed effectively without first discussing the composition and characteristics of external flows. Going back to the basics, there are two important regions of flow around a body moving in a fluid: the boundary layer near the body and the region outside of this boundary layer. By definition, the boundary layer is the region in the flow from the surface of a body where the local velocity is or is nearly 0 until the region in which the local velocity is equal to $99 \%$ of the free stream velocity relative to the body. The thickness of a boundary layer ranges from fractions of an inch to many inches thick depending on the specific properties of both the body and fluid around the body. For the purpose of discussing low Re flow, and most other flows as well, only the boundary layer region is of any concern here.

Breaking things down further, there are two primary types of flow within the boundary layer. The first type, laminar flow, is a smooth low energy flow that is highly susceptible to the effects of adverse pressure gradients. Turbulent flow, the second flow type, is generally an unsteady, higher energy flow that is less susceptible to the effects of adverse pressure gradients. In a higher Re flow over a wing with a conventional non-laminar flow airfoil, laminar flow is only maintained until around $20 \%-40 \%$ of the chord length back from the leading edge before the flow either separates and reattaches as a turbulent flow or transitions directly to turbulent flow

(2). In lower Re flows, the entire flow field around a wing before full separation occurs may be laminar.

Laminar flows generally result in lower drag and lower lift forces, which in turn result in lower $\mathrm{L} / \mathrm{D}$ values than can be achieved when the Re is high enough for the flow to transition to turbulent. For laminar flow at low Re, the drag of an airfoil or wing is often higher than the drag of the same surface operating at a higher Reynolds number, due in part to the formation of laminar separation bubbles along the surface of the airfoil (3). These laminar separation bubbles 
often form in front of the airfoil separation point, and as shown by Liebeck and Blackwelder, the separation bubbles can be affected by external stimuli in the flow field around the airfoil itself , increasing or decreasing airfoil performance as desired (3).

At low Re, the formation of separation bubbles generally leads to complete flow separation (i.e. stall) rather than flow reattachment and/or transition of the flow to turbulent flow (2). This means that increasing the vehicle AoA relative the flow can cause the wing to stall sooner, and unlike flow at higher Re, it can also take significant decreases in AoA before the flow will reattach (2), (1). This creates additional difficulties that must be accounted for when designing a MAV wing and when collecting data at low Re. This is especially true since most of the readily available airfoil data is for airfoils operating at high Re.

It is possible to improve airfoil performance at low Re by forcing the flow, which is mostly laminar, to trip to turbulent. This effectively prevents the flow from detaching from the surface of the airfoil when adverse pressure gradients on the airfoil are encountered, reducing drag and increasing lift (4). Various methods exist to force the flow to transition to turbulent from laminar, including the introduction of turbulators to the surface, increasing the surface roughness, applying Gurney flaps, or a combination of the above. It has been shown experimentally that an airfoil with a rough surface operating at low Re has a higher L/D than a smooth airfoil, as shown in Figure 2-4 (5), and that the application of trailing edge devices at low Re, such as regular trailing edge and Gurney flaps, can increase the overall wing L/D as well (6).

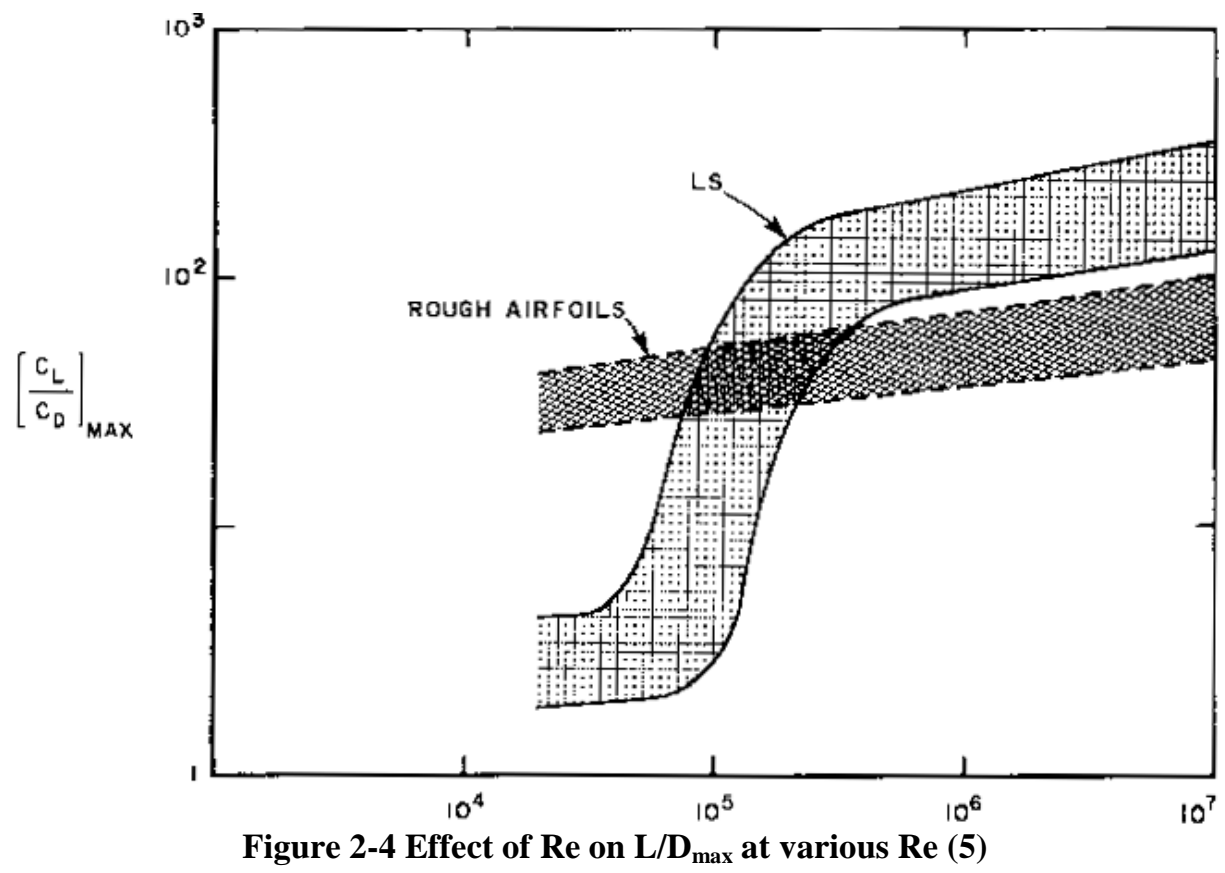




\subsection{Available Wing Technologies}

\subsubsection{Inflatable Wings}

Inflatable wings are structures that are inflated using gases from a pressure vessel, a compressor, or a gas generator. They have been used and tested in various vehicles since the early 1950's, including manned and unmanned aircraft, munitions, and lighter than air vehicles (7). These wings can safely be stowed in spaces with as little as one tenth the volume of the inflated wing itself (7), making inflatable wings especially useful when it comes to minimizing the required stowage volume. To give a visual sense of the packing efficiency of an inflatable wing, an inflatable wing in the stowed and deployed states from ILC Dover is presented in Figure 2-5.
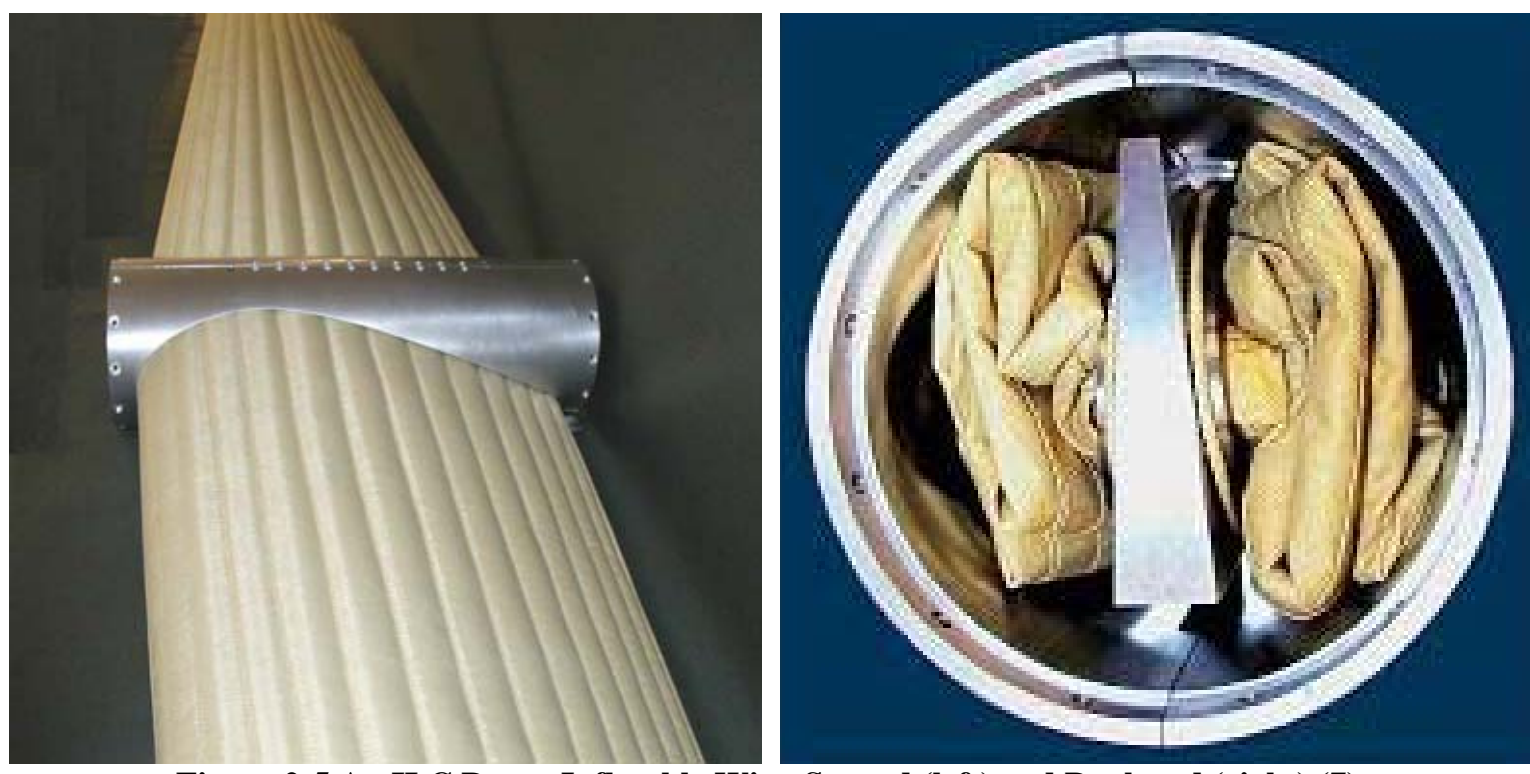

Figure 2-5 An ILC Dover Inflatable Wing Stowed (left) and Deployed (right) (7)

The internal structure of inflatable wings usually consists of a series of structural tubes or a compartmentalized internal structure, which spans the entire wing and stiffens when pressurized. Wing skins are then wrapped around the internal structure to provide the airfoil shape (7). Through both wind tunnel and flight tests, the wings have been proven to be very rugged and strong. Much research has been performed by others to develop accurate models for calculating structural loads (9) (10) (11) (12). Additionally, unlike traditional wings with solid structures, when an inflatable wing bends or "fails" under high flight loads, it can recover its structural strength when those flight loads are relaxed or the pressure inside the wing is increased (13). 
Inflatable wings can also be rigidized by pre-impregnating a catalyst sensitive epoxy in a fabric layer below the wing skins. Upon exposure to the curing catalyst, such as a particular chemical or UV light, the impregnated epoxy cures yielding a rigid wing structure without the need to maintain system pressure (7). Experimental data presented by Adherent Technologies, Inc. from 2005, indicated that less than five seconds may be required for a UV activated resin system to reach a $90 \%$ cure (14).

The deployment rate of inflatable wings can vary from less than a second to several seconds or more, depending on the size and desired deployment dynamics (15). For a conventional takeoff or launched aircraft, the wing inflation system can be a separate piece of ground support equipment, but for a projectile launched transforming vehicle, the system must be carried within the vehicle. Inflation methods include the utilization of pressurized gas canisters, onboard compressors, or chemical gas generators, all of which can quickly consume available weight and volume of the system; potentially so much so that the advantages provided by the low packing volume of the wing itself are outweighed by the volume and weight of the inflation system.

\subsubsection{Membrane wings}

Membrane wings are flexible wings that are rigid enough to resist aerodynamic forces and provide lift while retaining the flexibility required to allow the wing to conform to its environment. In addition, membrane wings are often also lighter than their conventional counterparts (16). In some applications, such as on the Prioria MAVERICK and ARA Nighthawk, the membrane wing is flexible enough laterally to wrap around the fuselage, yet strong enough to avoid buckling when loaded in flight (17) (18) (19). In other applications, the wing is comprised of a flexible membrane skin wrapped around a more rigid frame, such as those being studied by researchers at the University of Florida and University of Michigan studying flow control and load alleviation/augmentation technologies (16).

A wing design concept of consequence for a MAV with a similar mission profile originated at Clarkson University and is presented in Figure 2-6. The wing is essentially a cambered flat plate that can be flattened via a sprung mechanism and rolled around the fuselage. Although the wing performed well during testing once it was fully deployed, it was discovered during dynamic deployment testing that at high angles of attack or velocities, a successful full deployment of the wing was difficult to achieve (19). The research team at Clarkson University theorized that this was likely due to a lack of sufficient lateral stiffness in the wing, and that it could be overcome 
by stiffening up the wing with additional structures or by using leaf springs, stiffeners, or memory alloys (19).

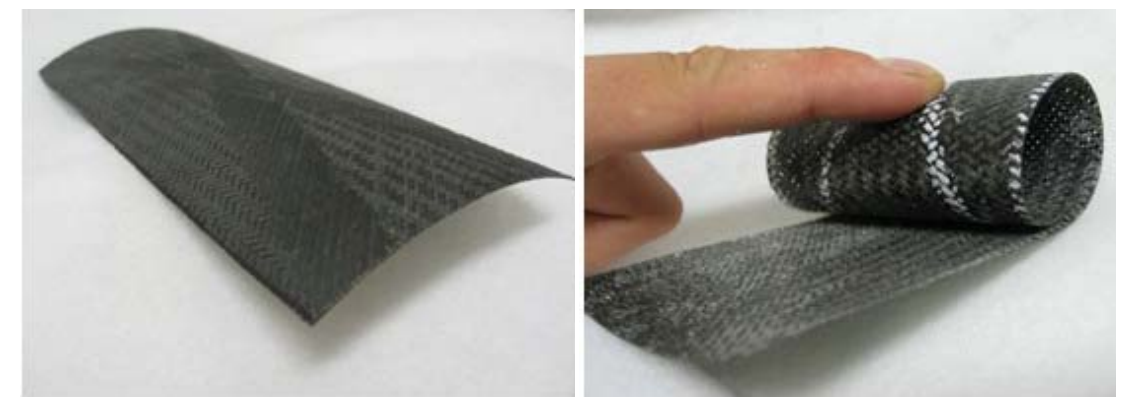

Figure 2-6 Membrane Wing Concept Presented by Clarkson University (19)

Rigid membrane wings incorporating flow control technologies have also been developed and tested. Two designs with active flow control of particular interest are shown in Figure 2-7. The design on the left features a load alleviating wing design that allows the wing to conform to the flow, thereby decreasing drag and the slope of the lift curve while increasing the stall AoA. The design on the right, featuring a load augmentation wing, is designed to allow the wing to conform to the flow based on the exerted aerodynamic loads leading to a decreased stall angle, increased lift, and increased pitching moment (16).
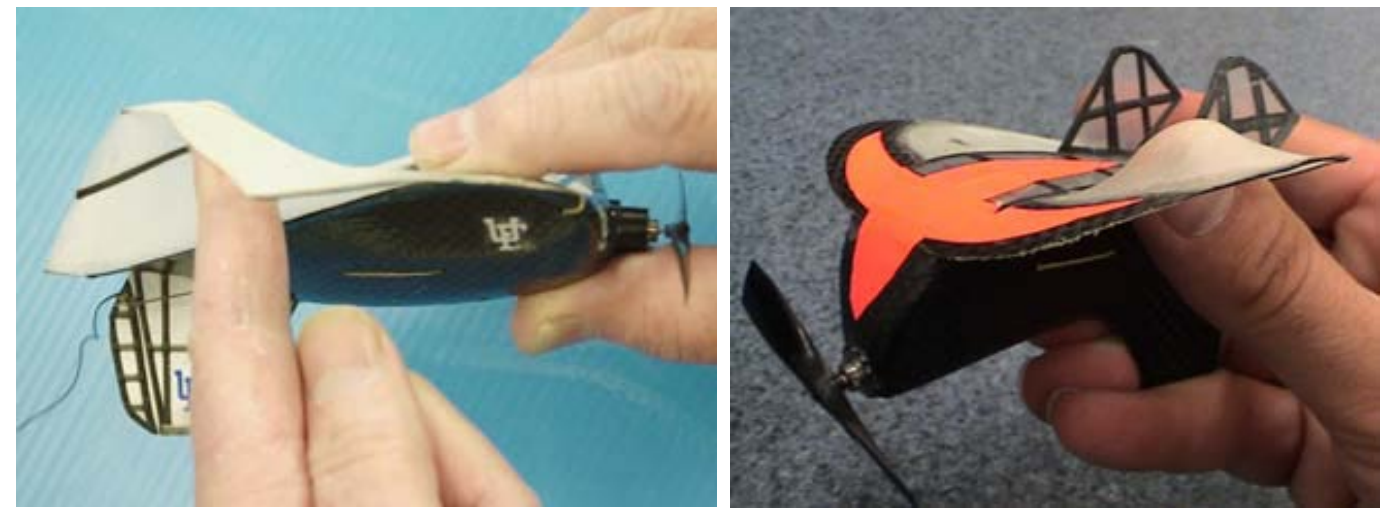

Figure 2-7 Load alleviating wing (left) and load agumentation wing (right) (16)

\subsubsection{Semi-rigid wings}

Probably the most common and oldest wing type in use today is the semi-rigid or solid wing. These wings provide a stiff wing structure that maintains an accurate airfoil profile throughout its entire span. The vast majority of aircraft today use this type of wing, and they have also been used as the primary flight surfaces on other vehicles, including military missiles, rockets, torpedoes, and submersibles among others. When used on missiles and rockets, these semi-rigid wings often take the form of fins, which can be stowed during storage and launch until the missile exits a launch tube (20) (21) . 
The mechanisms and control systems for these fins and deployable wings are often mechanically complex and difficult to cost effectively scale down for use on a MAV. Additionally, the maximum size of the deployed surfaces is significantly limited by both the body diameter and length, as well as the desired location of the vehicle's center of gravity. When stowed, semi-rigid wings also tend to consume large amounts of internal volume (1). Additionally, the rigidity of solid wings operating at low Re tend to promote the formation of adverse pressure gradients, which can significantly decrease flight vehicle performance.

\subsection{MAV control systems}

Although the development and testing of a MAV control system is outside the purview of this work, it is necessary to put some forethought into the available methods if an effective wing is to be developed. In the following text, two of the most promising methods of achieving flight control for the MAV system presented are discussed and reviewed.

\subsubsection{Conventional surfaces}

Traditional actuator/surface controls for small remotely controlled and autonomous aircraft use a servo actuator (essentially an electric motor), to move a hinged control surface. The behavior and effectiveness of traditional control surfaces are well understood and the servos used are often very reliable. Commercially produced servos, such as those shown in Figure 2-8, are available off the shelf from a variety of companies, and come in a variety of sizes from nano ( $<10 \mathrm{oz}^{*}$ in of torque) to giant scale servos ( $>250 \mathrm{oz} *$ in of torque) flying $1 / 4$ scale and larger aircraft. Most of the servos available are rotary actuators with a servo arm attached, but linear actuators are also available, such as those used in the ultra-micro class of R/C aircraft similar in size to the MAV under development.

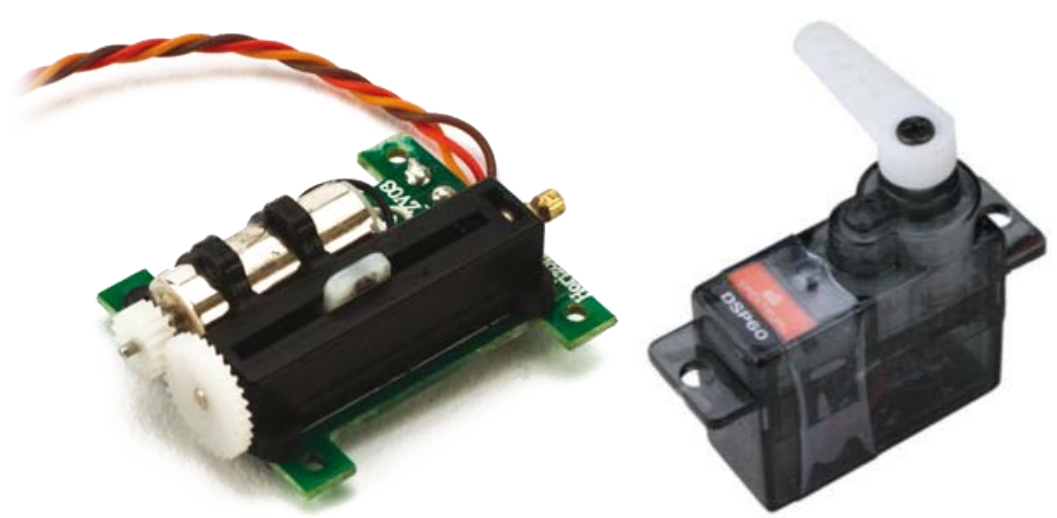

Figure 2-8 A 2.9 gram nano linear servo (left) and a 6 gram super sub micro servo (right) (22) 


\subsubsection{Flight control utilizing surface morphing \& smart materials}

Another potential control method is the concept of flight control through the use of morphing surfaces. This concept is mostly inspired by nature, and various methods to morph surfaces have been developed including the use of servos, flexible materials, pneumatic actuators, and smart piezoelectric sensitive materials. Unfortunately, it appears that the integration, development, and testing of piezoelectric sensitive materials for achieving control is still in its early stages and not applicable to the current MAV design. Some of the more promising applications of existing technologies to morphing surfaces are outlined and discussed below to show the benefits a morphing surface can provide.

While working on his dissertation at WVU, Dr. Richard Guiler performed a study on flight control of a tailless flying wing utilizing wing tip morphing. His project culminated with the design, assembly, and successful flight test of a seven foot span model that implemented wing tip morphing by using "fingers" and a control rod for flight control as presented in Figure 2-9 and Figure 2-10 (23). Dr. Guiler was able to show through wind tunnel testing that the tip vortex of the morphing wing was less pronounced than that produced by a wing with a traditional elevon control surface. Additionally, during flight testing of the seven foot span model, the test pilot was unable to force the aircraft to enter a tip stall, and noted that the morphing surface provided an equivalent roll response with approximately $2 / 3$ the pitch response when compared to a traditional elevon on a similar flying wing model (23).

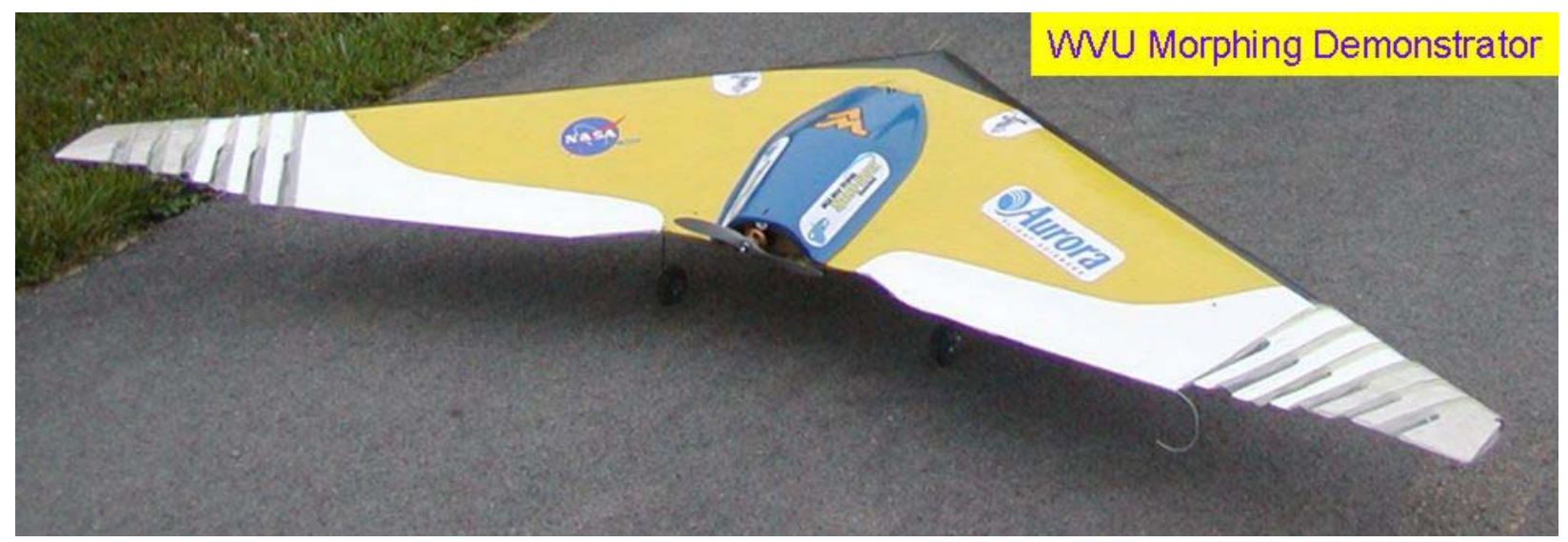

Figure 2-9 Dr. Richard Guiler's Morphing Wing Flight Test Vehicle, the Habicht II (23). 


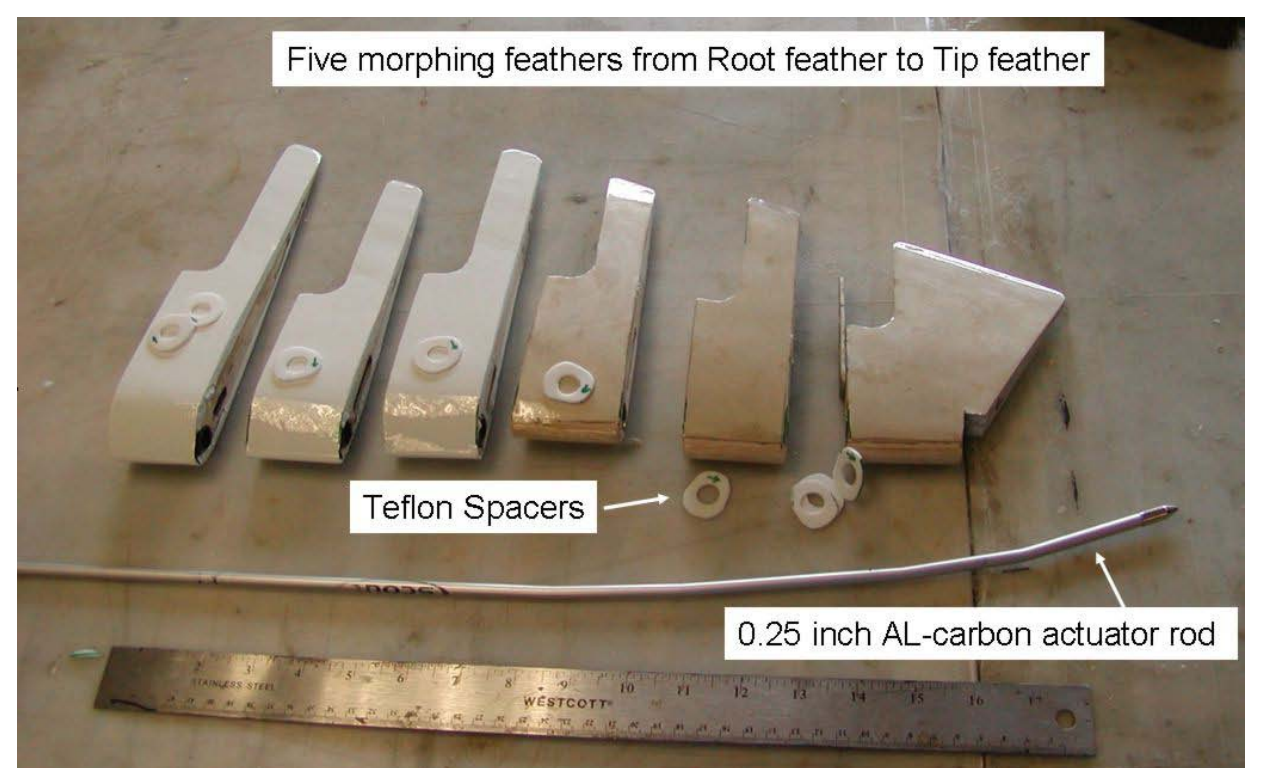

Figure 2-10 Morphing wing tip components from the Habicht II flight test vehicle (23).

At Virginia Tech, a fully adaptive aircraft and control system was developed and tested in their wind tunnel facility. This wind tunnel model featured a variable sweep wing with variable wing tip lengths, twisting wing tips for control, and an extendable/retractable tail. For controlling wing twist, a pneumatic actuator was used along with a geared drive system attached to a keyed rod. This rod connected to the tip wing rib and allowed for the wing tip to be twisted, providing a morphing wing tip for roll control (24). The Virginia Tech adaptive aircraft configuration wind tunnel model and twist mechanism are shown in Figure 2-11. A benefit of a fully adaptive system to the MAV designed in this work is that it would allow the wing to be optimized for high or low speed flight profiles on-the-fly by the flight control system onboard, allowing the MAV to fly at the optimal L/D ratio over a wider range of the flight envelope.
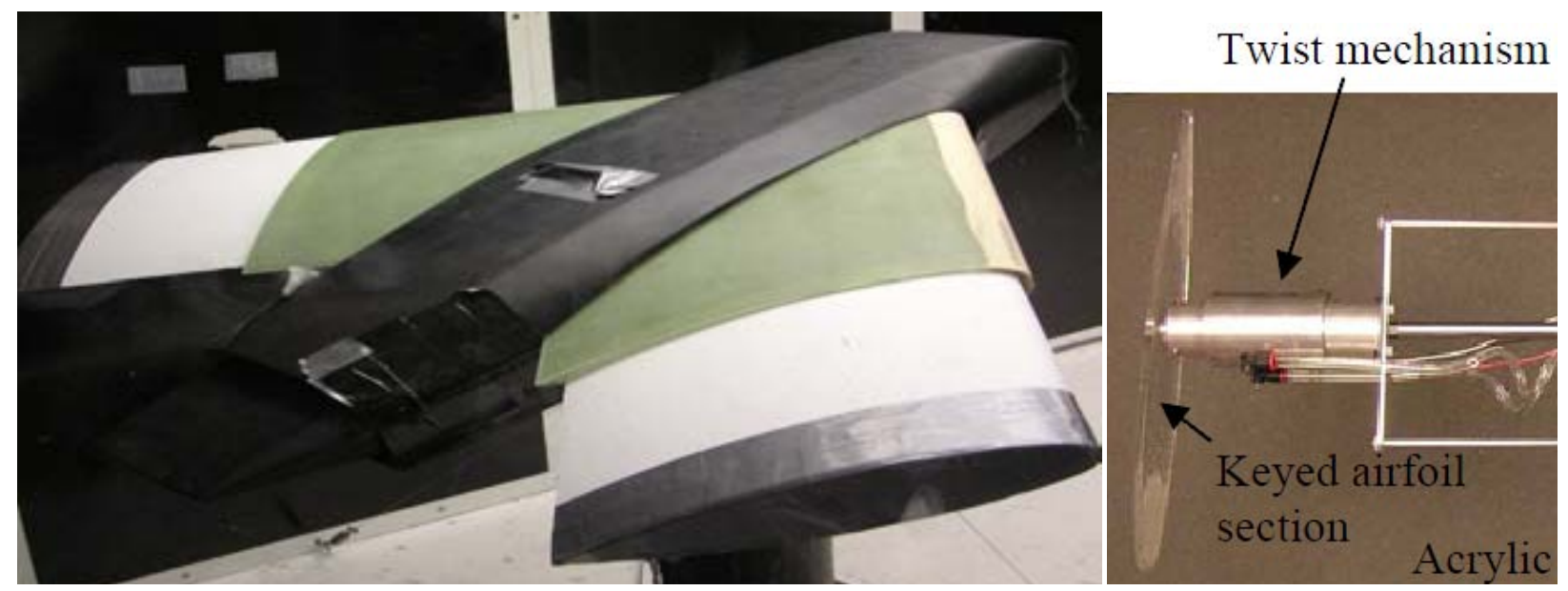

Figure 2-11 Virginia Tech fully adaptive aircraft model (left) and twist mechanism (right) (24) 
Unfortunately, a control system using similar components described above would be difficult to implement in a wing for a MAV with folding surfaces while maintaining sufficient amounts of internal storage volume. However, this difficulty should be reduced or eliminated entirely in the future as advancements in the development and testing of piezoelectric sensitive materials with respect to achieving flight control are reached.

\subsection{MAV and UAV Systems with Applicable Technologies}

To gain insight and to aid in brainstorming for further concept development, a quick survey of small MAV and UAV systems with applicable technologies was completed. Many of these systems are too large or fragile for the task at hand, but most demonstrated useful technologies that could potentially be applied to the MAV described in this work. The survey presented is certainly not all inclusive, but the systems presented provide a general overview of available technologies that have been successfully demonstrated.

\subsubsection{ARA Nighthawk}

The first of these systems is the ARA Nighthawk. It features a flexible, carbon fiber membrane wing that can partially wrap around the aircraft fuselage for stowage and transport, yet deploys quickly and easily for flight when launched from a six inch diameter tube. The system also features the ability for the MAV to be flown under auto, including takeoff and landing, or manually (18).

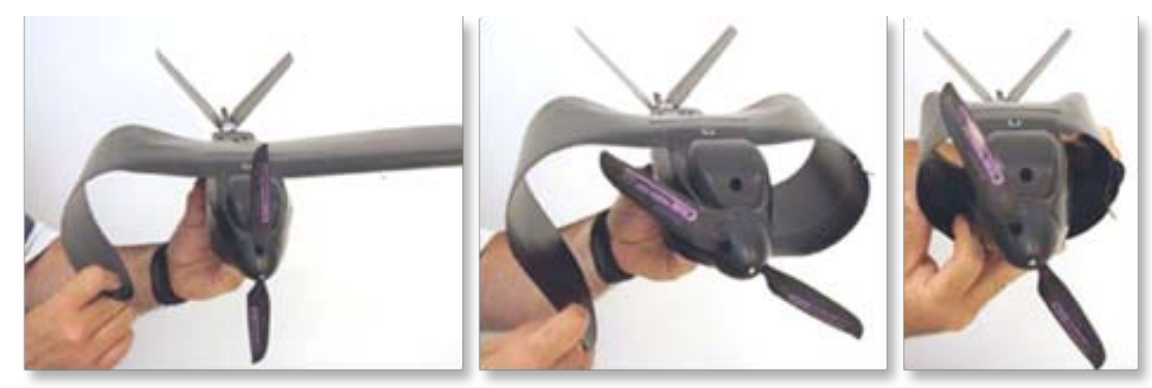

Figure 2-12 Nighthawk MAV with folding wings(18)

\subsubsection{Rafael Firefly}

The Rafael Firefly is a small MAV launched from a $40 \mathrm{~mm}$ M203 grenade launcher. Its purpose is to provide surveillance video from a stable platform using two cameras transmitted back to a pocket PC on the battlefield. Firefly is $38 \mathrm{~mm}$ in diameter, a length of $155 \mathrm{~mm}$, and a weight of 145 grams. The folding tail fins provide stability, while a folding body conformal 
wing provides extra lift and gliding time for gathering video. The maximum range of Firefly is $600 \mathrm{~m}$ with a maximum flight time of 8 seconds(25).

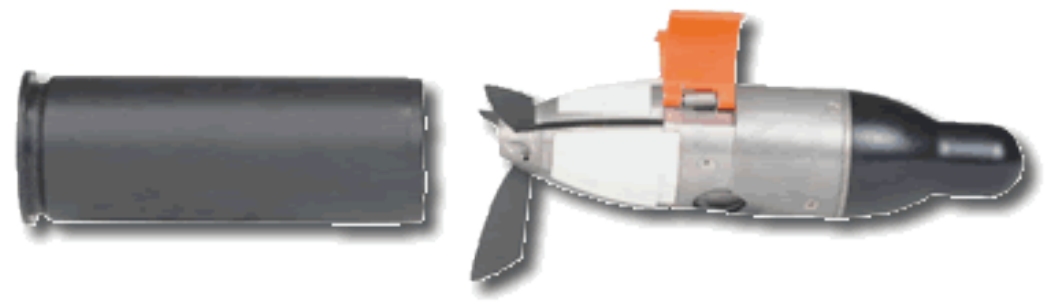

Figure 2-13 Rafael Firefly MAV(26)

\subsubsection{Prioria MAVERIC}

The Prioria MAVERIC UAV's wings are foldable and can be wrapped around the fuselage. This allows the UAV to be stored in a six inch tube, from which it is easily launched or removed and subsequently hand launched. MAVERIC flies fully autonomously and has a flight duration of 45 to 90 minutes. For flight, the user indicates, in real time, navigation points and the area where the UAV is to land. A claimed benefit by Prioria of its MAVERIC bendable wing is that the wings function as a dampening mechanism via "adaptive washout" to minimize the effects of gusting winds on small UAVs(17).

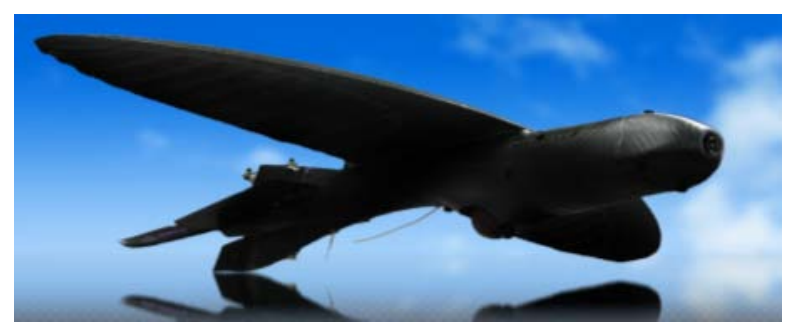

Figure 2-14 Prioria MAVERIC UAS (17)

\subsubsection{Aerovironment Switchblade}

The Aerovironment Switchblade is an expendable, compact, and fully scalable solution that can be launched from a multitude of platforms on the ground and in the air. It is designed to be capable of fully autonomous flight, striking targets with minimal collateral damage, and gathering and transmitting intelligence, reconnaissance, and surveillance information back to the warfighter beyond their visual line of sight (27). The Switchblade is also a low cost solution, and features a quiet, yet effective, electric propulsion system to make detection more difficult, allowing the UAS to fly and/or glide to targets. For easy stowage, transport, and launch, the Switchblade's solid geometry wings fold up below the fuselage(28). 


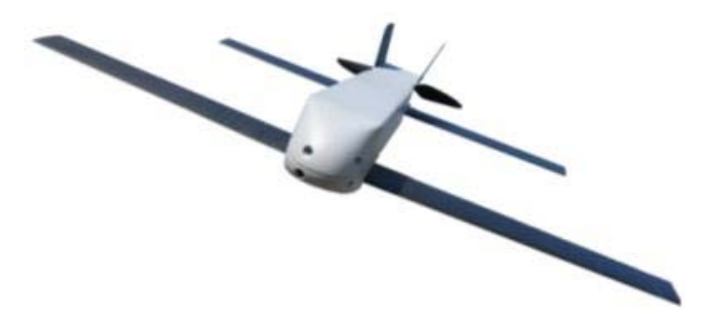

Figure 2-15 Aerovironment Switchblade ISR (27)

\subsubsection{Aerovironment Nano Hummingbird}

This MAV was developed as part of a phase II contract from DARPA to develop a UAS capable of both indoor and outdoor flight. Some features of the Nano Hummingbird include the ability to hover for eight minutes using an internal power source, the ability to hover and maintain relative position in wind with side gusts of up to five mph, the capability of precision indoor and outdoor flight by a pilot using only a video feed, and the ability to transition between hovering, forward moving flight, and back to hovering (29). This technology demonstrates the feasibility of miniaturizing the necessary electronics for use in a small folding wing MAV.

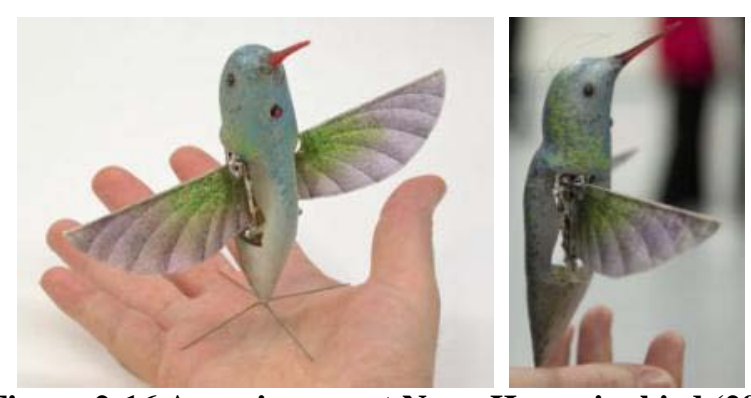

Figure 2-16 Aerovironment Nano Hummingbird (29)

\subsubsection{Aerovironment Black Widow}

The Black Widow was the first fully operational MAV system and was developed by Aerovironment for a DARPA sponsored project. It features a six inch wingspan, a weight of three ounces, stability augmentation, a range of over one mile, and a flight duration of around thirty minutes. The Black Widow onboard electronics includes a micro camera with radio downlink that transmits the video feed as well as other sensor data (30).

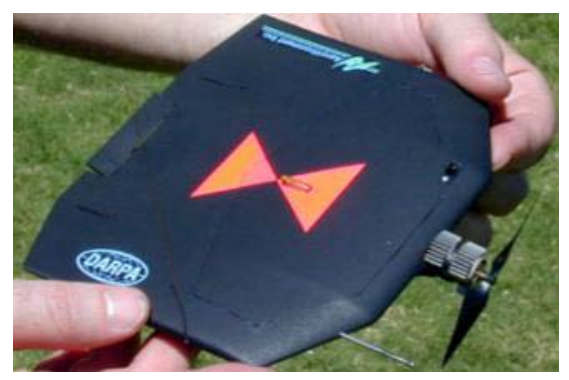

Figure 2-17 Aerovironment Black Widow MAVs(30) 


\section{Chapter 3. Considered Design Concepts and Selection}

\subsection{Considered Concepts, Characteristics, and Preferred Embodiments}

Initially, several concepts were developed and considered for use including semi-rigid solid wings, membrane wings, inflatable wings, and concepts that blend the others together. In the anteceding sections, each of the main concepts considered is presented along with some advantages and disadvantages of each design.

\subsubsection{Body Conformal Wing}

The body conformal wing concept presented in Figure 3-1 expands on the solid wing concept demonstrated by the Rafael Firefly (3) which was developed further by Mr. Hamburg during his design work (1). In this concept, the wing is formed by flat plates curved to match the fuselage contours, allowing the wing to be folded up around the outside of the fuselage. Deployment of the wing could also expose inlets for ducting to an internal propulsion system or provide cooling for onboard electronics such as batteries and transmitters.

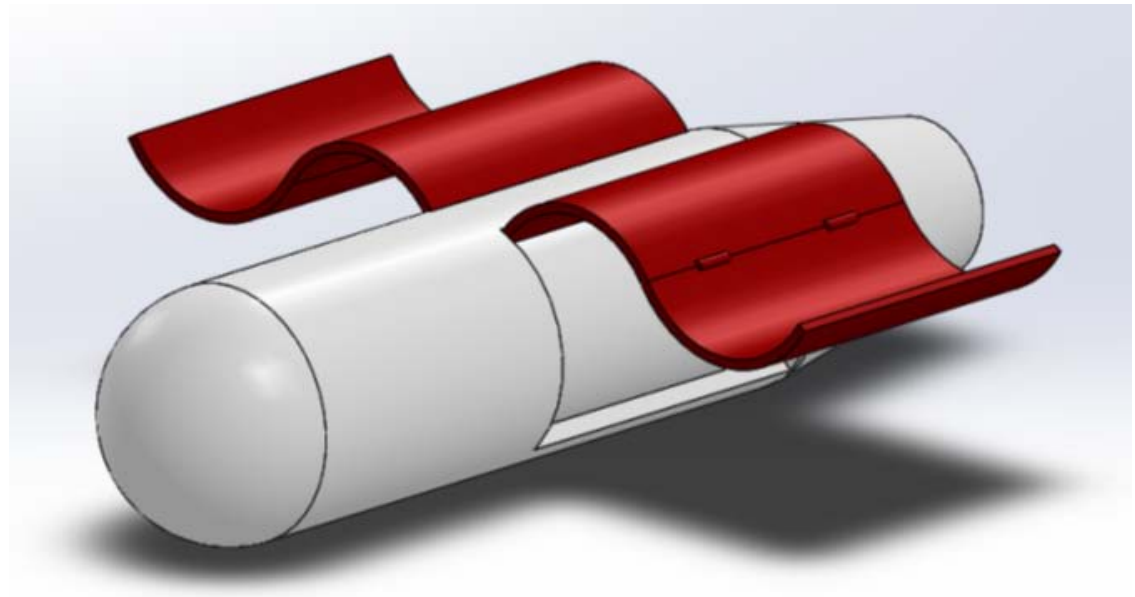

Figure 3-1 Body conformal wing concept

Internal volume efficiency of this design is also maximized with over $150 \mathrm{~cm}^{3}$ available for installation of payloads and control systems. Unfortunately volume comes at the cost of aerodynamic efficiency of the uncambered flat plates (31) used instead of cambered flat plate or conventional airfoils used in other concepts. Additionally, locking mechanisms for such a wing could also become rather complex due to the small size of the mechanisms required. Further pros and cons of the design concept are summarized in Table 3-1. 
Table 3-1 Solid Body Conformal Wing Concept Pros and Cons

\begin{tabular}{|c|c|}
\hline Pros & Cons \\
\hline Cheap to produce & $\begin{array}{c}\text { Low aerodynamic efficiency due to flat plate } \\
\text { airfoils and increased surface area for an } \\
\text { equivalent projected wing area }\end{array}$ \\
\hline Versatile design & $\begin{array}{c}\text { Very thin wing yielding sub-optimal } \\
\text { performance }\end{array}$ \\
\hline $\begin{array}{c}\text { Maximizes the availability of usable } \\
\text { internal volume }\end{array}$ & $\begin{array}{c}\text { Has a double shell on sections of the } \\
\text { fuselage, increasing weight }\end{array}$ \\
\hline $\begin{array}{c}\text { Easily stored for long periods of time } \\
\text { without significant risk to functionality }\end{array}$ & $\begin{array}{c}\text { May require a protection sleeve on launch to } \\
\text { prevent damage to the wings }\end{array}$ \\
\hline
\end{tabular}

\subsubsection{Inflatable Wing}

This concept, presented in Figure 3-2, incorporates an inflatable wing structure inflated by either a compressed gas or a chemical gas generator. Due to the packing efficiency of inflatable wings, the wing can be placed nearly anywhere along the fuselage body vertically, but using a mid to high wing design, as shown, allows for increased stability. It also provides ample amounts of volume forward, below, and behind the wing to house the inflation system, control systems, and payloads. An inflatable wing design could also easily lend itself to utilization of morphing control techniques for flight control and flow control.

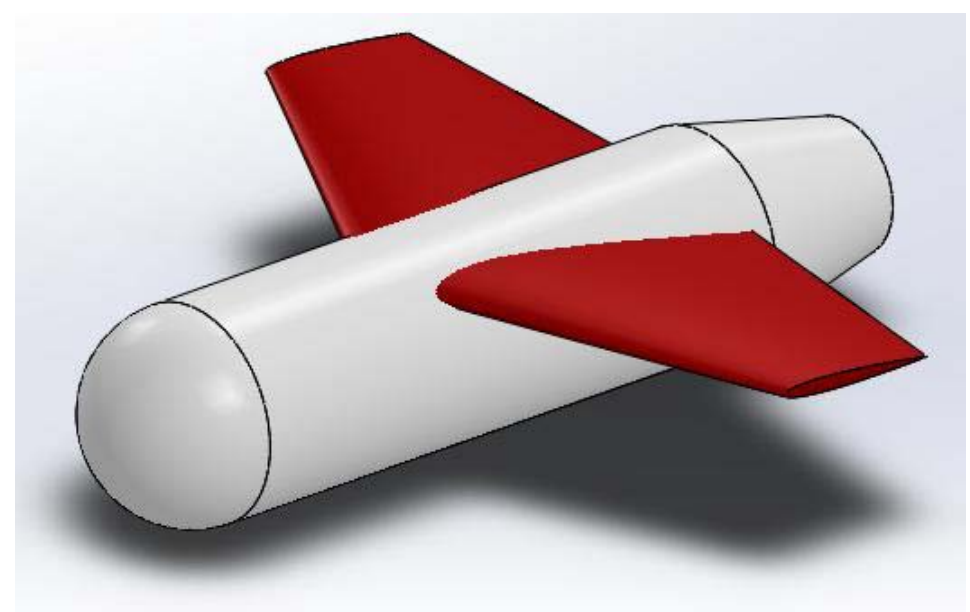

Figure 3-2 Inflatable Wing Concept

Like the Body Conformal Solid Wing concept presented earlier, the inflatable wing concept retains large quantities of internal volume, in excess of $150 \mathrm{~cm}^{3}$, when the inflation system is not included in the volumetric packing requirements of the wing. The inclusion of an inflation system, however, would reduce this advantage slightly while reducing the available weight for flight control systems, and other payloads. 
Given its numerous positives, there is one major negative with regards to an inflatable wing: the development cost. After consultation with representative from ILC Dover, it was determined that development of a single test wing with an inflation system could cost in excess of twenty thousand dollars and take several months. The representative also indicated that they couldn't guarantee success as a wing on this scale hadn't been attempted before. Additional pros and cons are summarized in Table 3-2.

Table 3-2 Inflatable Wing Concept Pros and Cons

\begin{tabular}{|c|c|}
\hline $\begin{array}{c}\text { Pros } \\
\text { flight controls and other payloads }\end{array}$ & Cons \\
\hline Variable speed deployment & $\begin{array}{c}\text { High development risk - would potentially } \\
\text { be the smallest inflatable wing attempted }\end{array}$ \\
\hline $\begin{array}{c}\text { Aerodynamic resistance to wind gusts via } \\
\text { active flow control }\end{array}$ & $\begin{array}{c}\text { For an unrigidized wing, the pressure } \\
\text { membrane is highly susceptible to puncture } \\
\text { or material degradation while in storage }\end{array}$ \\
\hline $\begin{array}{c}\text { Wing morphing control could potentially } \\
\text { easily be integrated }\end{array}$ & \\
\hline
\end{tabular}

\subsubsection{Membrane Wing}

The membrane wing concept in Figure 3-3 is similar to the concept developed by Clarkson University for a similar MAV, although the presented concept was developed independently and concurrently after researching the Nighthawk MAV and Maverick UAS. For storage, the wing would wrap around the outside of the fuselage and be covered by a protective shell to prevent damage during launch. Near the apex of its flight, the shell would then be released allowing the wings to open. Again, as with the inflatable wing concept, a membrane wing is a strong candidate for using wing morphing technologies to achieve directional control as opposed to conventional control systems. 


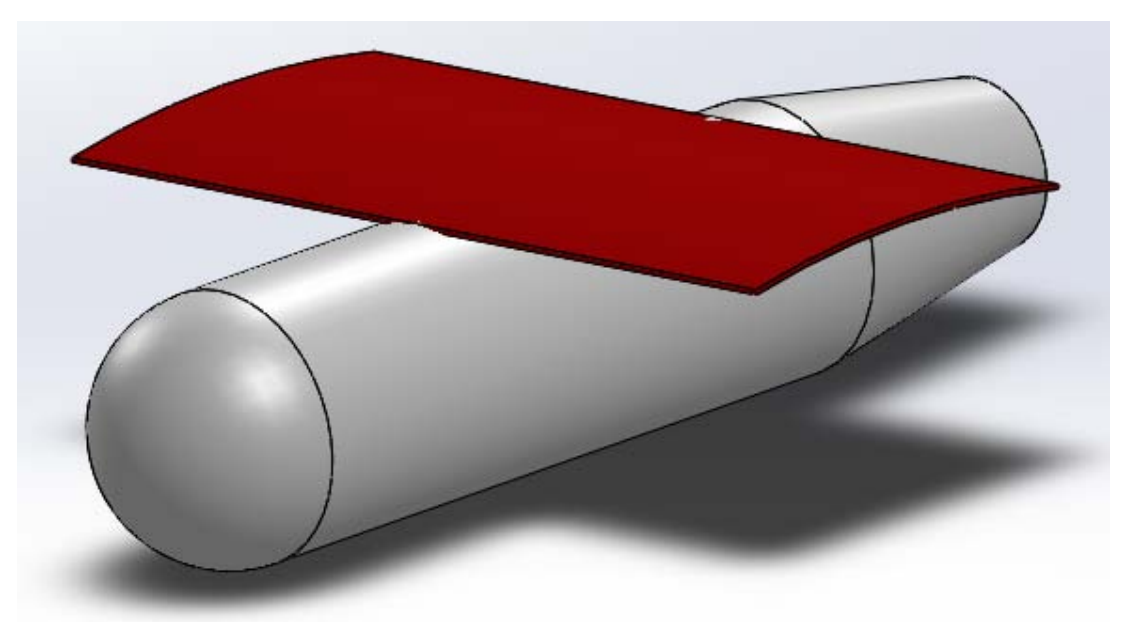

Figure 3-3 Membrane Wing Concept

Like both the body conformal and inflatable wing concepts, the membrane wing concept has a relatively large amount of internal volume for installation of flight controls and payloads. The flexibility inherent in a membrane wing design may also reduce the effect of wind gusts on the flight path through the use of active flow control as described by Stanford et. al (16). Some additional concerns with a membrane wing structure that would need to be addressed include creep in the wing structure and material longevity while the MAV is in long term storage. Also, the deployment dynamics and ability of the wing to deploy under varying conditions would need to be extensively studied, as evidenced by the results of the deployment testing of the Clarkson University MAV (19). A more complete list of the major pros and cons relating to the membrane wing concept is summarized in Table 3-2.

Table 3-3 Membrane Wing Concept Pros and Cons

\begin{tabular}{|c|c|}
\hline $\begin{array}{c}\text { Maximization of available volume for flight } \\
\text { controls and other payloads }\end{array}$ & $\begin{array}{c}\text { Medium-high risk design due to additional } \\
\text { testing and design required to ensure safe } \\
\text { deployment over a large range of } \\
\text { deployment conditions }\end{array}$ \\
\hline $\begin{array}{c}\text { Aerodynamic resistance to wind gusts via } \\
\text { active flow control }\end{array}$ & $\begin{array}{c}\text { Mechanical creep of the wing in storage } \\
\text { could alter the wing properties and } \\
\text { negatively affect the control system }\end{array}$ \\
\hline $\begin{array}{c}\text { A sleeve to protect the wing during launch } \\
\text { and the initial flight phase would need to be } \\
\text { included thereby increasing the system } \\
\text { weight via the sleeve and an ejection system }\end{array}$ \\
\hline $\begin{array}{c}\text { Good lateral stability from a natural } \\
\text { dihedral from the structure when loaded }\end{array}$ & \\
\hline
\end{tabular}




\subsubsection{Composite Leaf Spring Wing}

The composite leaf spring wing concept, shown in Figure 3-4, was originally developed and first presented by Shanti Hamburg in his thesis in 2010 at West Virginia University. Mr. Hamburg originally envisioned a wing structure, shown in Figure 3-5, comprised of multiple composite leaf springs connected by a tensioned flexible skin to provide the wing's skin (25). The new proposed concept, also shown in Figure 3-5, draws from another of Mr. Hamburg's concepts and uses a single composite leaf spring located spanwise along the maximum t/c location with a collapsible foam leading edge. The new concept, also has an airfoil cross section to improve performance, while the original wing concept employed a flat plate cross section.

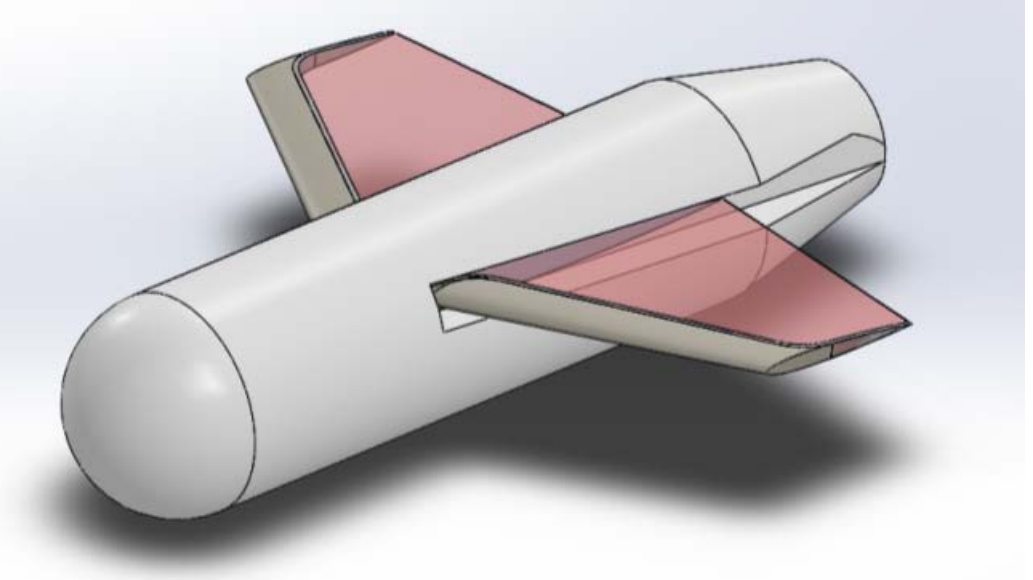

Figure 3-4 The Composite Leaf Spring MAV concept
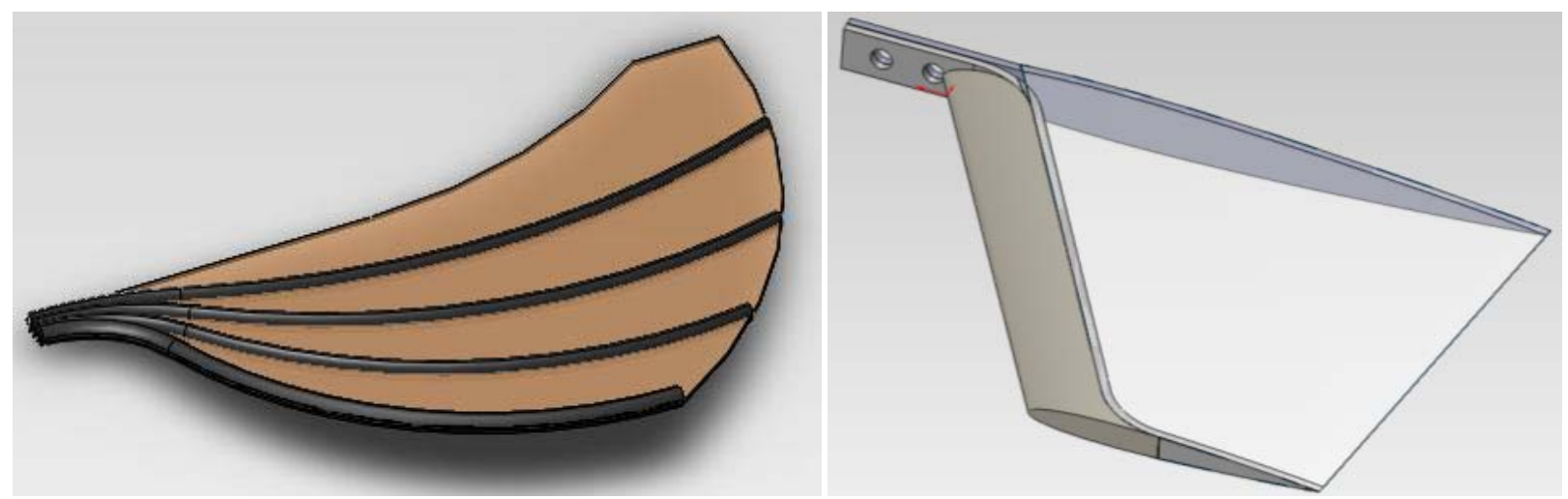

Figure 3-5 Mr. Hamburg's Leaf Spring Embodiment (left) (28) \& the new Embodiment (right)

As before, the leaf spring wing design would provide ample useable volume, albeit slightly less than previous concepts, inside the MAV fuselage for the placement of flight control systems and additional payloads. The design could also lend itself to the utilization of wing morphing for flight control via pull cables, smart materials, or leaf spring control rods inside the wings 
connected to traditional actuators. A compilation of various pros and cons for the leaf spring design is summarized in Table 3-4.

One major obstacle with the leaf spring wing concept not presented in Table 3-4 is the development of composite leaf springs with enough rigidity to support the weight of the MAV in flight while being flexible enough to collapse for storage. In the initial phases of research, the author invested a significant amount of time experimenting with epoxies, mix ratios, additives, weaves, and fabrics to determine how best to produce such a spring. The results of the testing showed only minimal success as once springs that were flexible enough to stow while retaining sufficient rigidity to resist flight loads were produced, mechanical creep while the springs were stressed became a major concern.

Table 3-4 Pros and Cons for the Composite Leaf Spring Wing Concept

\begin{tabular}{|c|c|}
\hline Pros & Cons \\
\hline $\begin{array}{c}\text { Relatively large amounts of useable volume } \\
\text { remains for flight controls and payloads }\end{array}$ & $\begin{array}{c}\text { Relatively high development costs required } \\
\text { for material and spring research and } \\
\text { development }\end{array}$ \\
\hline Quick surface deployment & $\begin{array}{c}\text { Very high risk design - development of } \\
\text { functional composite leaf springs }\end{array}$ \\
\hline $\begin{array}{c}\text { Possible application of morphing wing } \\
\text { technologies leading to improved } \\
\text { performance }\end{array}$ & $\begin{array}{c}\text { Leaf spring wing may not be rigid enough to } \\
\text { resist flight loads }\end{array}$ \\
\hline & $\begin{array}{c}\text { Shelf-life feasibility unknown due to creep } \\
\text { and material life cycles }\end{array}$ \\
\hline
\end{tabular}

\subsubsection{Solid-Membrane Wing}

The solid-membrane wing concept, shown in Figure 3-6, features a solid leading edge and trailing edge element with a membrane like skin stretched between the two components to form the upper and lower surfaces of the wing. This concept requires that much of the fuselage be separated into at least two compartments, which results in less available volume for positioning flight control systems and payloads. The significant advantage of this concept is that it blends the aerodynamic efficiency of a wing using a conventional airfoil with the increased packing efficiency of a membrane wing. 


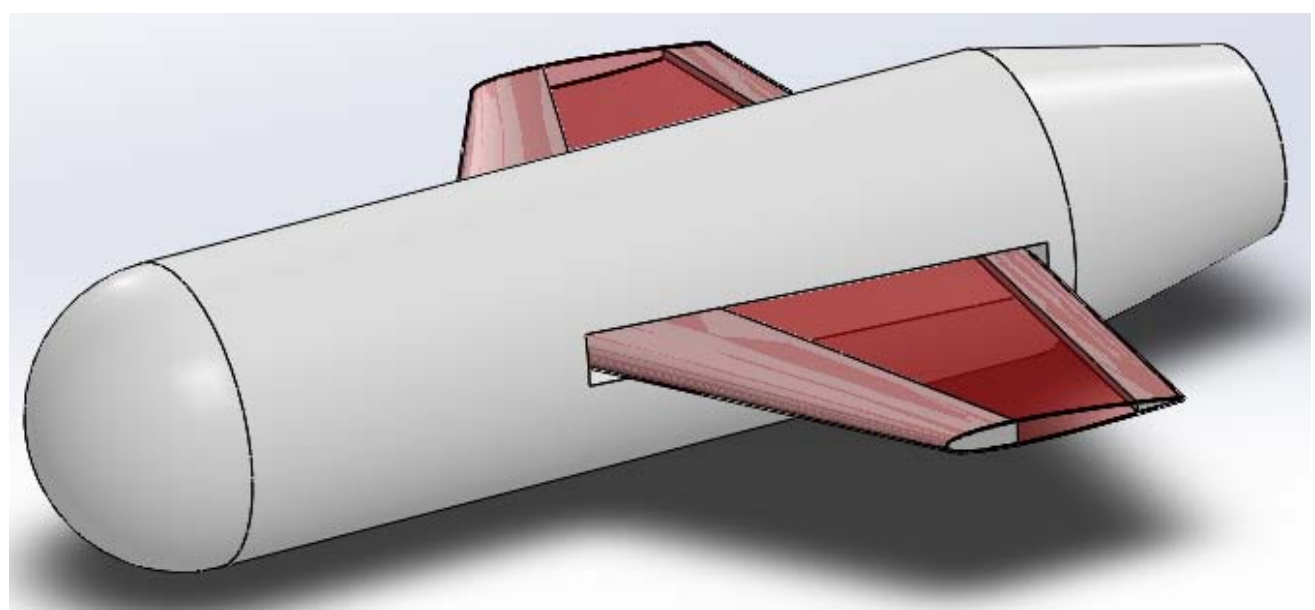

Figure 3-6 Solid-Membrane Wing Concept

The solid wing components are deployed by use of springs, causing the fabric covering to tense. This provides a flexible yet rigid membrane like wing structure. Due to the nature of the fabric skin, the profiles of the airfoils used need to be modified from their original shape. The shape of the original airfoil profile is maintained to the maximum t/c point via the forward solid element before the profile changes to have a straight line from this point until the trailing edge of the airfoil.

A major benefit to this design is the ability to pack a much larger wing inside a relatively small fuselage, allowing for improved performance. The system is also mechanically quite simple and robust, and it makes use of currently available and understood technologies and materials. Unfortunately, unlike the other concepts presented, this concept doesn't lend itself well to the application of wing morphing technologies. A more comprehensive list of pros and cons is summarized below in Table 3-5.

Table 3-5 Solid-membrane wing advantages and disadvantages

\begin{tabular}{|c|c|}
\hline Advantages & Disadvantages \\
\hline Low required storage volume & $\begin{array}{c}\text { Tolerances are difficult to achieve with } \\
\text { available equipment and methods }\end{array}$ \\
\hline Mechanically simple & $\begin{array}{c}\text { Fuselage is separated into multiple } \\
\text { compartments, complicating electronics and } \\
\text { system component location }\end{array}$ \\
\hline No "new" materials are needed & \\
\hline Low cost & \\
\hline
\end{tabular}




\subsection{Concept Selection}

In the previous section, several folding wing concepts were presented and discussed citing many pros and cons for each. A preliminary investigation into the costs and development time of each system was then completed. This investigation led to the removal of two concepts from consideration due to development cost and risk; the inflatable wing concept (cost and risk) and the composite leaf spring wing concept (cost, development difficulty, risk). The remaining three concepts were then compared, and a final down selection was completed utilizing a figure of merit analysis.

Five key figures of merit were identified for use during the down selection process based upon a review of the most important aspects of the design and the author's design experience. In random order of significance, the figures of merit are: design complexity/technical risk, usable internal volume, aerodynamic performance, system weight, and development time and cost. Each individual figure of merit is described in more detail in Table 3-6.

As described above, the selection process was completed by employing a standard figure of merit analysis which ranks each design in order from best to worst for each figure of merit with 1 being the best and 3 being the worst. Each figure of merit is also assigned a weighting factor which is indicative of the significance of each particular figure of merit relative to the other figures of merit. The final ranking for each concept is then determined by multiplying the figure of merit weighting factor by the concept ranking for each figure of merit.

Weighting factors for each figure of merit were selected by the author based on past design experience as well as a review of the design requirements and the potential effect of each figure of merit on satisfying the design requirements. Rankings were also determined somewhat arbitrarily based on the author's intuition and knowledge about the technologies utilized in each concept . The analysis showed the solid-membrane wing concept should be selected for further

development followed by the membrane wing and the solid body conformal wing concepts. The detailed results of the figure of merit analysis are presented below in Table 3-7. 
Table 3-6 Description of Concept Selection Figures of Merit

\begin{tabular}{|c|c|}
\hline Consideration & Description \\
\hline $\begin{array}{l}\text { Design complexity / } \\
\text { Technical Risk }\end{array}$ & $\begin{array}{l}\text { The complexity of developing a successful design should be as } \\
\text { low as possible to reduce the technical risk involved. This may } \\
\text { lead to a reliance on technologies more familiar to the } \\
\text { designer/team as well as the use of technologies in which more } \\
\text { technical support information is available. }\end{array}$ \\
\hline Usable Internal Volume & $\begin{array}{c}\text { For the current design, enough usable internal volume must be } \\
\text { available to efficiently place control system components and } \\
\text { payloads to complete the mission as well as to balance the MAV } \\
\text { center of gravity. }\end{array}$ \\
\hline $\begin{array}{l}\text { Aerodynamic } \\
\text { Performance }\end{array}$ & $\begin{array}{l}\text { The design must provide an adequate L/D to satisfy the mission } \\
\text { requirements and be able to perform well in a multitude of flight } \\
\text { conditions. }\end{array}$ \\
\hline System Weight & $\begin{array}{l}\text { The mechanism and wing should be as light as possible so as to } \\
\text { reduce launch loads and increase the available payload weight } \\
\text { capacity. }\end{array}$ \\
\hline $\begin{array}{c}\text { Development time \& } \\
\text { cost }\end{array}$ & $\begin{array}{l}\text { To keep costs down, the estimated required development time } \\
\text { should be as short as possible while delivering a system that } \\
\text { satisfies the mission requirements. }\end{array}$ \\
\hline
\end{tabular}

Table 3-7 FOM for Wing Concept Selection

\begin{tabular}{|c|c|c|c|c|}
\hline Figure of Merit & $\begin{array}{c}\text { Weighting } \\
\text { Factor }\end{array}$ & $\begin{array}{c}\text { Solid Body } \\
\text { Conformal } \\
\text { Wing }\end{array}$ & $\begin{array}{c}\text { Membrane } \\
\text { Wing }\end{array}$ & $\begin{array}{c}\text { Solid- } \\
\text { Membrane } \\
\text { Wing }\end{array}$ \\
\hline $\begin{array}{c}\text { Design Complexity / } \\
\text { Technical Risk }\end{array}$ & $15.0 \%$ & 1.0 & 3.0 & 2.0 \\
\hline Usable Internal Volume & $20.0 \%$ & 2.0 & 1.0 & 3.0 \\
\hline $\begin{array}{c}\text { Aerodynamic } \\
\text { Performance }\end{array}$ & $40.0 \%$ & 3.0 & 2.0 & 1.0 \\
\hline System Weight & $10.0 \%$ & 3.0 & 1.0 & 2.0 \\
\hline $\begin{array}{c}\text { Development time \& } \\
\text { cost }\end{array}$ & $15.0 \%$ & 1.0 & 3.0 & 2.0 \\
\hline Overall Score & $100.0 \%$ & 2.2 & 2.0 & 1.8 \\
\hline
\end{tabular}

Given the somewhat arbitrary nature in defining the figures of merit, the weight factors, and the rankings, a concept review was also held between the author and other members of the WVU research group working on the project to evaluate the designs. The conclusion drawn by the research team was in agreement with the results of the figure of merit analysis to continue development the solid-membrane wing. 


\section{Chapter 4. Design of the Solid-Membrane Wing and Mechanism}

The main goals of the folding wing mechanism design was to minimize the total number of moving parts and to minimize the volume of the folded wing. To achieve these goals, the design features a hollowed out leading edge element which the trailing edge element folds into when the wing is stowed, a combined release and locking mechanism, and a rip-stop nylon membrane skin. Also, before integration into an engineering MAV model, a proof of concept folding wing demonstrator was produced to prove the folding concept and test the mechanism.

\subsection{Airfoil Selection}

The NACA 0009 airfoil was selected as the base airfoil due to its symmetric profile and availability of CFD data. As presented in Chapter 3, the solid-membrane wing concept relies on the utilization of a simplified airfoil profile matching the original airfoil shape from the leading edge to the location of the airfoil maximum thickness before changing to a straight line profile connecting the profile at the $t / c_{\max }$ locations to the location of the original trailing edge. The modified NACA 0009 airfoil used is compared to the original NACA 0009 airfoil in Figure 4-1.

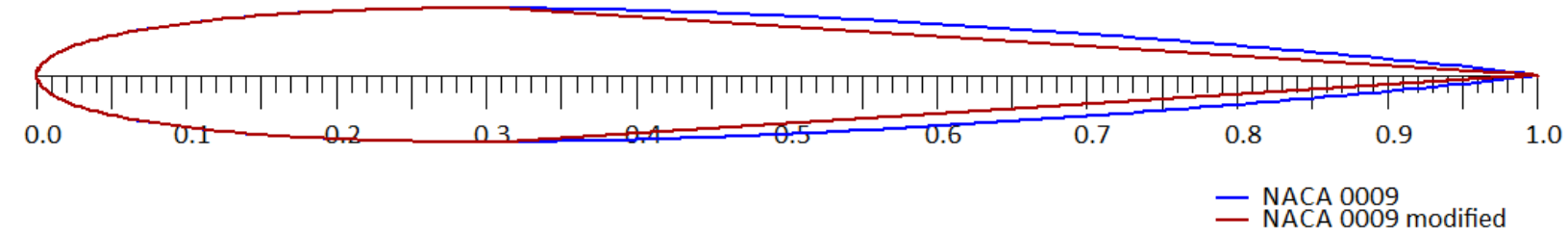

Figure 4-1 NACA 0009 (blue) and modified NACA 0009 (red) airfoils

\subsubsection{Comparison of NACA 0009 and Modified NACA 0009 Airfoils}

To estimate the effect of the airfoil modifications on the airfoil performance, lift, drag, and L/D polars were generated utilizing the inviscid flow X-Foil module built into XFLR5 with the results presented below in Figure 4-2, Figure 4-3, and Figure 4-4. The XFLR5 analysis showed that the performance of both the modified NACA 0009 and unmodified NACA 0009 airfoils should be very similar across the three Re tested. Although the computational solution indicated that the performance should be similar, the researcher's expectation was that the performance of the NACA 0009 airfoil would be superior to that of the modified NACA 0009 airfoil due to the sudden change in the airfoil profile aft of the $t / c_{\max }$ location on the upper and lower surfaces. This will most likely cause some sort of flow irregularities, especially at such low Re. Even so, it is expected that the modified airfoil will perform better than the cambered flat plate airfoil of a conventional thin membrane wing. 


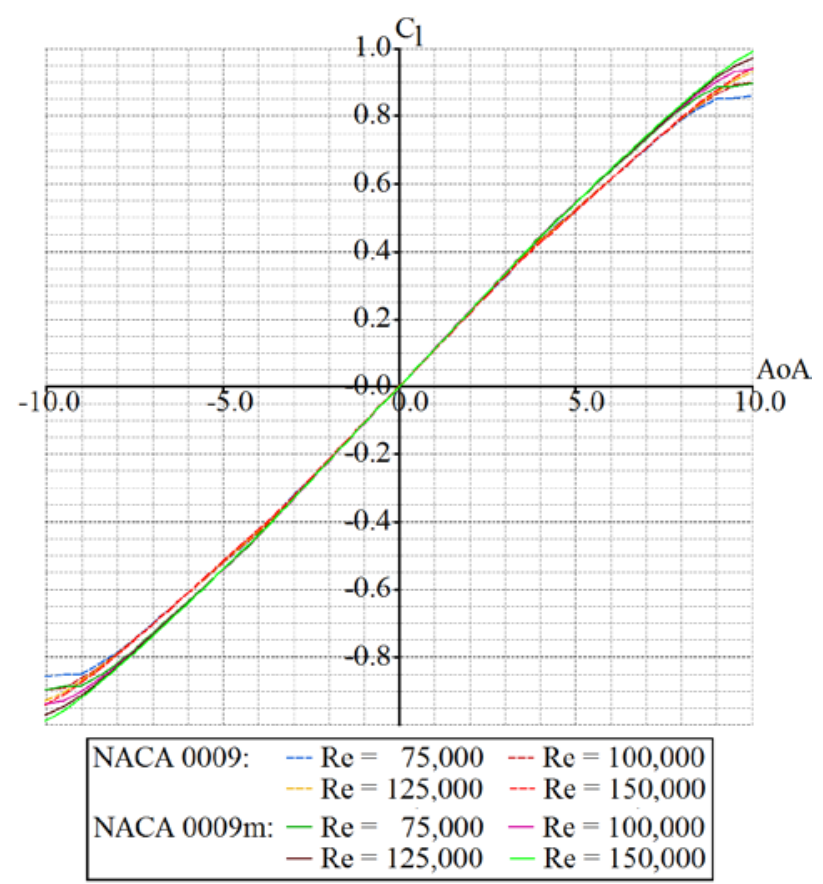

Figure 4-2 XFLR 5 2D Lift Polar for NACA 0009 and modified NACA 0009 airfoils

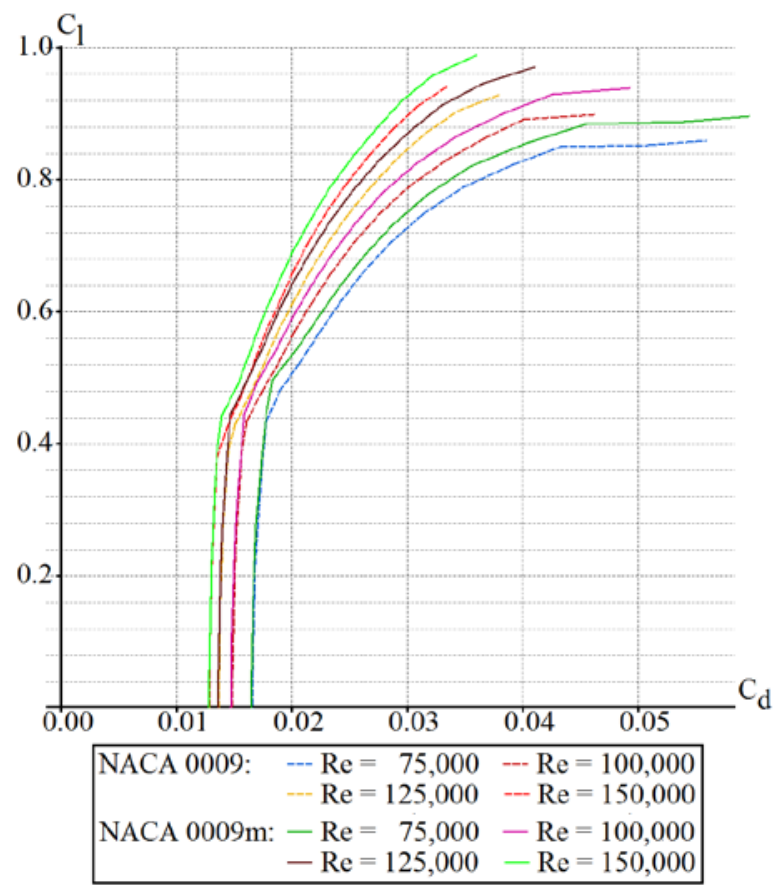

Figure 4-3 XFLR 5 2D Drag Polar for NACA 0009 and modified NACA 0009 airfoils

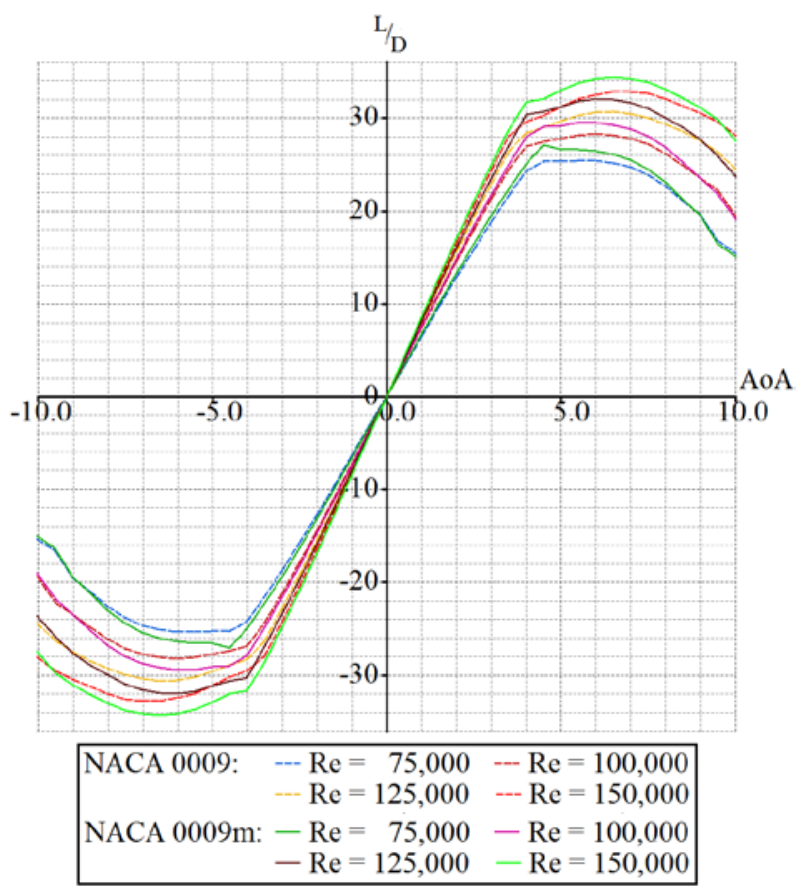

Figure 4-4 XFLR 5 2D L/D Polar for NACA 0009 and modified NACA 0009 airfoils

\subsection{Wing Sizing and Performance Estimates}

A detailed wing sizing and optimization study is outside the scope of this work, and as such, the wing aspect ratio (AR), taper ratio $(\lambda)$, leading edge sweep angle $\left(\Lambda_{\mathrm{LE}}\right)$, and wing loading (W/S) were selected based on the results from the L/D sensitivity studies presented in Mr. 
Hamburg's thesis as well as additional analysis work Mr. Hamburg completed after completion of his thesis. The resulting selected geometric wing parameters for the folding membrane wing are presented in Table 4-1.

Table 4-1 Solid-Membrane Wing Parameters

\begin{tabular}{|c|c|c|}
\hline Parameter & Value & Units \\
\hline Wing Area & 79.31 & $\mathrm{~cm}^{2}$ \\
\hline AR & 2.47 & - \\
\hline Span & 14.00 & $\mathrm{~cm}$ \\
\hline Taper Ratio & 0.42 & - \\
\hline Root Chord & 8.00 & $\mathrm{~cm}$ \\
\hline Tip Chord & 3.33 & $\mathrm{~cm}$ \\
\hline Mean Chord & 5.99 & $\mathrm{~cm}$ \\
\hline $\begin{array}{c}\text { LE sweep } \\
\text { angle }\end{array}$ & 30.00 & $\circ$ \\
\hline
\end{tabular}

To aid in evaluating the effectiveness of the wing design before proceeding with the development of the folding mechanism, general performance estimates were generated using classical aerodynamic theory. These performance estimates including L/D, glide angle, stall speed and other pertinent aerodynamic parameters are presented in Table 4-2.

Table 4-2 Solid-Membrane Wing Performance Estimates - Wing Only

\begin{tabular}{|c|c|c|}
\hline Parameter & Value & Units \\
\hline Wing loading & 247 & $\mathrm{~N} / \mathrm{m}^{2}$ \\
\hline$R e_{\text {STALL }}$ & 100,000 & - \\
\hline$C_{L_{S T A L L}}$ & 0.60 & - \\
\hline$C_{D_{\text {STALL }}}$ & 0.057 & - \\
\hline Stall Speed & 25.91 & $\mathrm{~m} / \mathrm{s}$ \\
\hline$R e_{\text {GLIDE }}$ & 125,000 & - \\
\hline$C_{L_{G L I D E}}$ & 0.22 & - \\
\hline$C_{D_{\text {GLIDE }}}$ & 0.013 & - \\
\hline Glide Speed & 30.00 & $\mathrm{~m} / \mathrm{s}$ \\
\hline Span efficiency & 0.90 & - \\
\hline Glide Angle & 3.30 & $\circ$ \\
\hline$L / D_{\text {wing }}$ & 17.33 & - \\
\hline
\end{tabular}




\subsection{Solid-Membrane Wing Mechanism}

\subsubsection{Folding Mechanism}

The wing mechanism for folding the main wings shown in Figure 4-5 and Figure 4-6 consists of a spring loaded hollowed out leading edge element, a carbon fiber tube reinforced sprung trailing edge element, and a ripstop nylon membrane skin. To fold, the trailing edge element folds forward and the leading edge element folds aft with the trailing edge element folding into the hollow interior of the leading edge element. A release and locking mechanism described in more detail later initiates deployment and also locks the wing in both the deployed and stowed positions.

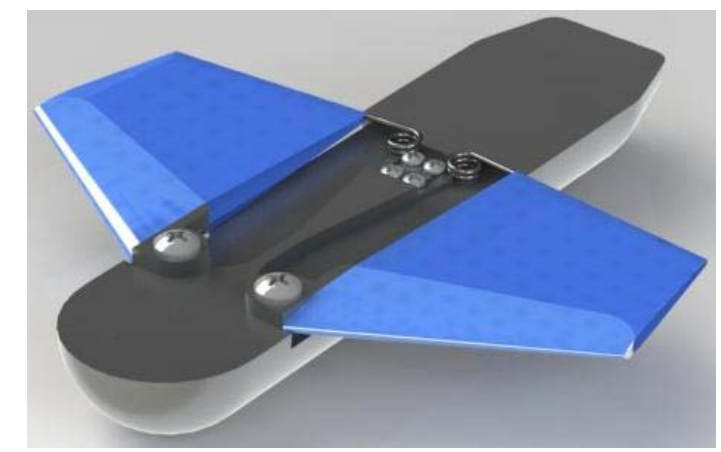

Figure 4-5 Basic wing mechanism in the open position (left) and the closed position (right)

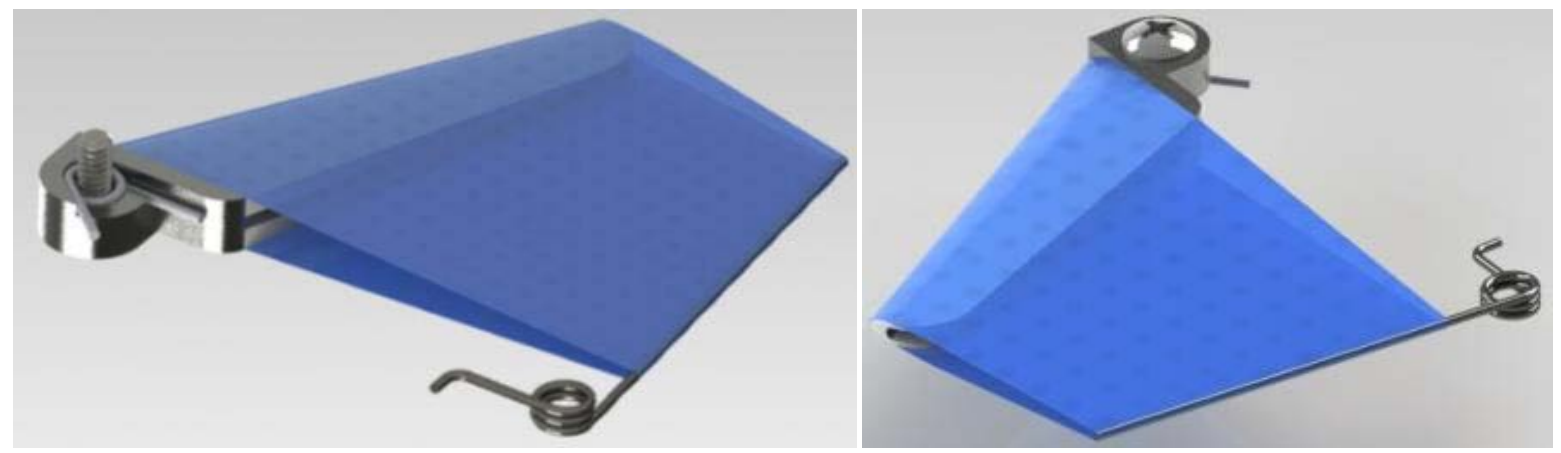

Figure 4-6 Wing Leading edge and trailing edge elements with springs

The leading edge element spring seen in the upper left of Figure 4-6 is countersunk into the element with the coil around the pivot shaft with the two ends resting against stops in both the wing and the fuselage. The trailing edge element is formed by the trailing edge deployment spring itself. Originally, the extension of the termination of the trailing edge spring was to form the element alone, but this proved to be too flexible to get a good even shape to the airfoil skin. A thin carbon tube (not shown) was then added over the section of the spring forming the trailing edge element to stiffen the trailing edge. 


\subsubsection{Membrane Skin}

Several materials were considered for use in forming the membrane skin around the wing including ripstop nylon, mylar, and latex. Ultimately, the ripstop nylon was chosen for its durability, resistance of the material to continue a tear if torn, and low amount of creep when loaded. A parachute grade $1.9 \mathrm{oz} / \mathrm{yd}^{2}$ coated rip stop nylon was also selected to reduce the likelihood of it sticking to itself and to reduce the risk of performance degradation due to flow leaking between the weave of the fabric.

\subsubsection{Release and Locking Mechanism}

In addition to the main wing mechanism, a release and locking mechanism shown in Figure 4-7 consisting of an actuator, pull cables, and spring loaded pins was developed. To deploy the wing, the pins retract and the spring loaded elements cause the wing to open. Once the wing is open, the spring loaded pins spring down against the inside edge of the leading edge element and prevent the wing from folding back into the fuselage..
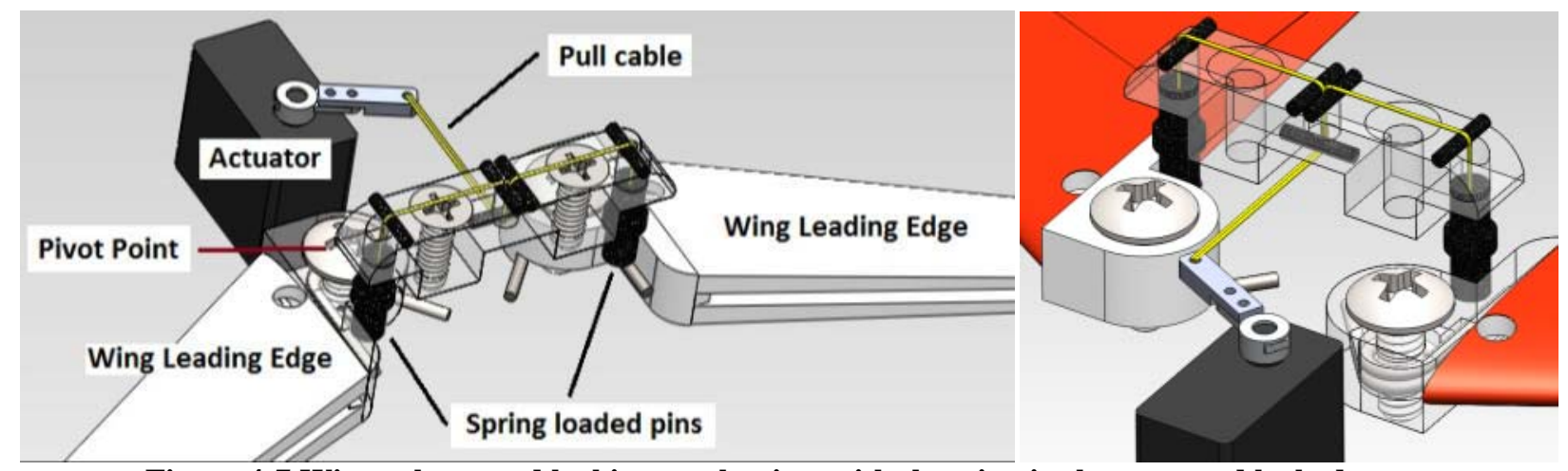

Figure 4-7 Wing release and locking mechanism with the wing in the open and locked state.

\subsubsection{Folding Wing Proof of Concept Model}

Before fully integrating the solid-membrane wing design into an engineering MAV model, a proof of concept model was developed with goals of 1.) proving the feasibility of the folding mechanism, and 2.) to identify where design modifications may be required. Major components were produced using ABS plastic parts printed on a 3D printer to reduce fabrication time, custom wound springs, and ripstop nylon wing skins. The completed model is shown in Figure 4-8 in both the stowed and deployed states. 

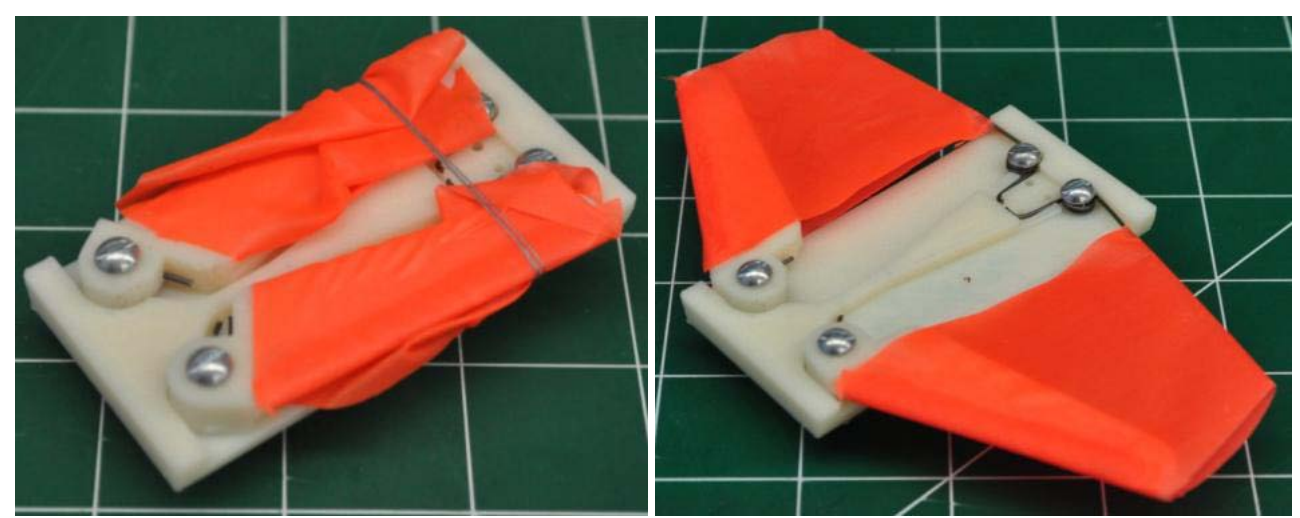

Figure 4-8 Folding Wing Proof of Concept Model Stowed (left) and Deployed (right)

During fabrication, one area that proved quite troublesome was the formation of consistent wing skins. Initially, the skins were wrapped around the deployed wing, but this proved difficult and it was nearly impossible to develop a consistent wing. Many other methods at forming the skin were also attempted, but the simplest solution developed involved utilizing a pattern to cut the wing skins and waxed moulds to wrap the skins around before bonding the seams together using a cyanoacrylate adhesive. This method, presented in Appendix C, resulted in consistent wing skins which could be easily fabricated and consistently installed to the wing.

\subsection{Engineering Solid-Membrane Wing MAV Model}

To further prove the feasibility of using the solid-membrane wing in the MAV design, an engineering model used for validating sufficient available volume for component integration was developed in CAD. Some work was also completed with regards to assembly of an engineering model utilizing a combination of 3D printed structural components, composite shells, fabric, springs, and fasteners. Major subsystem assemblies of the engineering model are described in more detail in the text below.

\subsubsection{Fuselage Structure and Wing Integration}

The fuselage shape was defined primarily by the baseline requirements and has an outer diameter of approximately $40 \mathrm{~mm}$ and a length of $171.5 \mathrm{~mm}$. The wing was integrated along the centerline of the fuselage so as to allow the CG location to be at the center of the main body. By being placed near the centerline, the wing essentially split the fuselage in 4 compartments to house components and payloads. The resulting MAV fuselage design as seen in Figure 4-9 and Figure 4-10 features a compartmentalized modular structure with aramid-composite skins bonded in place over the structure. 


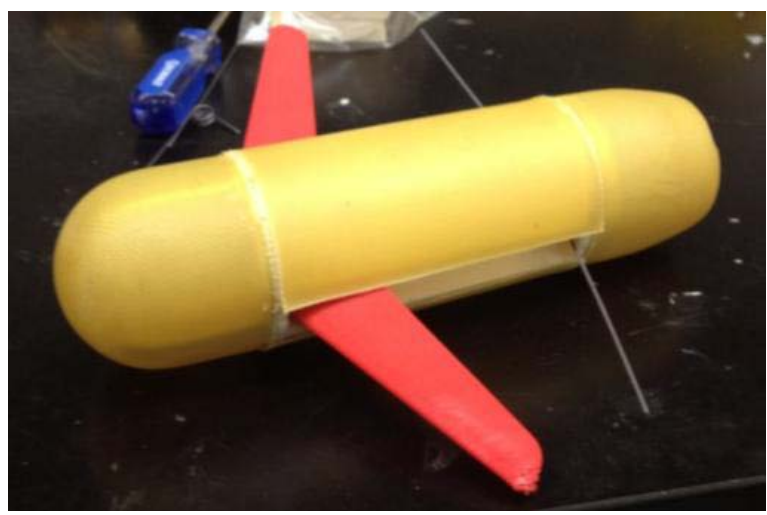

Figure 4-9 MAV Fuselage and wing without wing skins

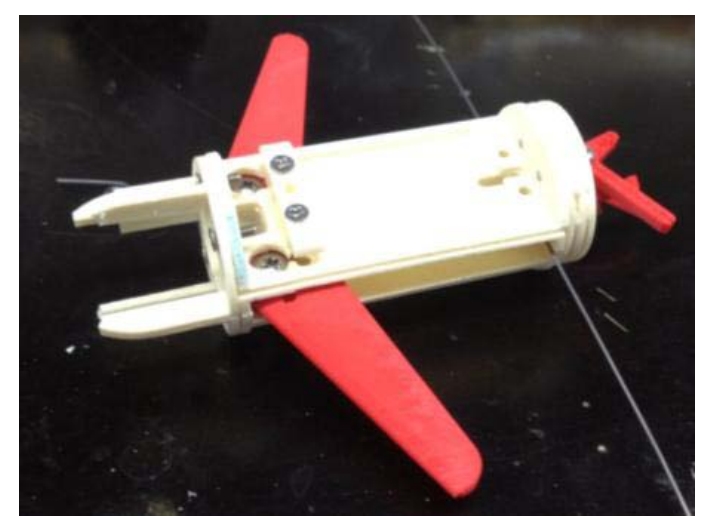

Figure 4-10 MAV Fuselage Structure with outer skin removed

\subsubsection{Control System and Tail}

It was decided that to rely on existing and fully developed control technologies, a full-flying y-tail would be installed on the engineering model. The aft compartment of the fuselage was therefore dedicated entirely to housing the folded tail fins and their pivot assemblies. Each control fin is a thin flat plate membrane-wing structure secured to a pivot assembly. For launch, the tail fins are rolled up and covered by a composite cover. Immediately after launch, the cover is ejected and the tail fins are deployed to aerodynamically stabilize the MAV during ascent before taking over to provide flight path control after deployment of the wings at the apex of the ballistic arc.

A detailed tail sizing or stability analysis for the engineering model was not completed since the engineering model's main goal was to prove the feasibility of fitting all the necessary control components into the fuselage around the solid-membrane wing concept. The resulting tail fins were sized to the maximum size that could be fit inside the aft compartment. A 3D rendering of the resulting tail attached to the completed engineering model is shown in Figure 4-11.

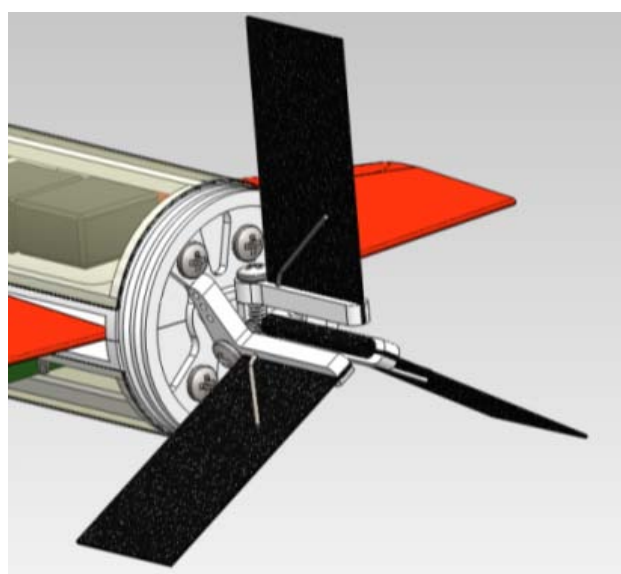

Figure 4-11 Y-tail and control system on MAV engineering unit 


\subsubsection{Component Integration}

Once the major structural and control surface subassemblies were completed, control system and payload components were integrated into the model including the wing release and locking mechanism, control surface actuators, payloads (camera, video tx, and simulated MAV controller), and a battery to provide power. More details on the components included in the model are tabulated in Table 4-3. The individual system components were selected based on their small size, performance, and cost relative to their capabilities to allow the MAV achieve the desired mission profile. The final design of the engineering MAV model is displayed in Figure 4-12. It should be noted that a significant amount of volume remains for further integration of additional payload components including more advanced flight controls.

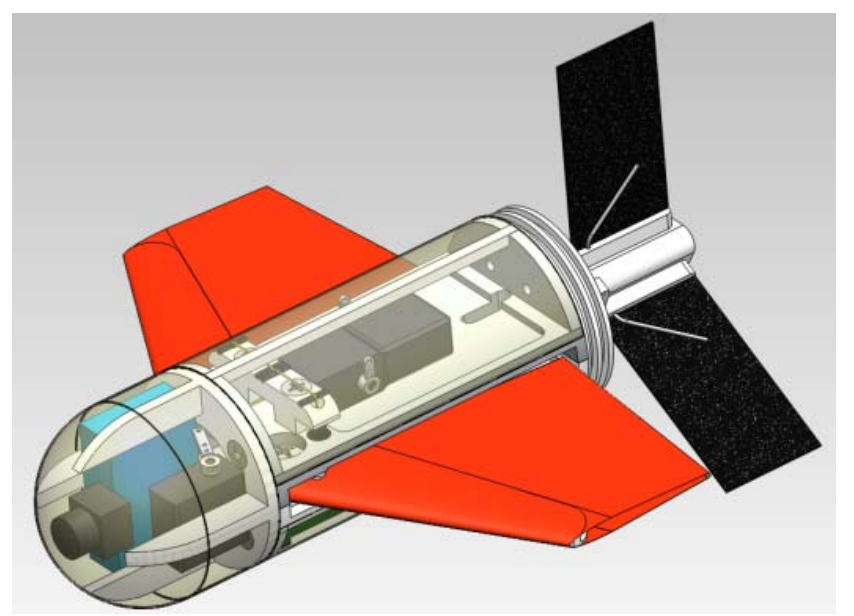

Figure 4-12 Final rendering of the engineering MAV model with all system components.

Table 4-3 Prototype Component List

\begin{tabular}{|c|c|c|c|}
\hline Component & Description & Qty & General Location \\
\hline Camera & DPC-001 Micro CMOS & 1 & Nose Assembly \\
\hline Video Transmitter & 900 MHz ATV AM Video Transmitter & 1 & $\begin{array}{c}\text { Main Fuselage } \\
\text { (bottom) }\end{array}$ \\
\hline Control Receiver & Simulated gumstick based autopilot & 1 & $\begin{array}{c}\text { Main Fuselage } \\
\text { (bottom) }\end{array}$ \\
\hline Battery & 2S 150 mAHr battery & 1 & Nose Assembly \\
\hline Tail Surface Actuators & Nuke 3 miniature servo & 3 & $\begin{array}{c}\text { Main Fuselage } \\
\text { (top and bottom) }\end{array}$ \\
\hline Wing Release Actuator & Nuke 3 miniature servo & 1 & Nose Assembly \\
\hline Tail Surfaces & Carbon Fiber Plate & 3 & Tail Assembly \\
\hline Tail Pivot Assemblies & Printed ABS Plastic & 3 & Tail Assembly \\
\hline $\begin{array}{c}\text { Wing and release } \\
\text { assembly }\end{array}$ & Solid Membrane Wing Assembly & 1 & $\begin{array}{c}\text { Main Fuselage } \\
\text { (Center) }\end{array}$ \\
\hline
\end{tabular}




\subsection{Final Estimated Performance Parameters}

Final estimated performance parameters of a MAV utilizing the fuselage and tail from the engineering MAV model were computed using classical aerodynamic theory. These parameters, appearing in Table 4-3Table 4-4, were used to evaluate whether a projectile launch MAV using the solid-membrane wing could satisfy the desired mission requirements. According to the estimations, the wing when installed in a MAV easily meets the minimum requirements.

Table 4-4 Solid-Membrane Wing MAV Performance Estimates

\begin{tabular}{|c|c|c|}
\hline Parameter & Value & Units \\
\hline Wing loading & 247 & $\mathrm{~N} / \mathrm{m}^{2}$ \\
\hline$R e_{\text {STALL }}$ & 100,000 & - \\
\hline$C_{L_{S T A L L}}$ & 0.60 & - \\
\hline$C_{D_{S T A L L}}$ & 0.048 & - \\
\hline Stall Speed & 25.91 & $\mathrm{~m} / \mathrm{s}$ \\
\hline$R e_{\text {GLIDE }}$ & 125,000 & - \\
\hline$C_{L_{G L I D E}}$ & 0.44 & - \\
\hline$C_{D_{\text {GLIDE }}}$ & 0.040 & - \\
\hline Glide Speed & 30.00 & $\mathrm{~m} / \mathrm{s}$ \\
\hline Span efficiency & 0.90 & - \\
\hline Glide Angle & -10.91 & $\circ$ \\
\hline$L / D_{M A V}$ & 5.19 & - \\
\hline
\end{tabular}

\section{Chapter 5. Experimental Setup}

\subsection{Goals}

The primary goal of the wind tunnel testing was to prove the feasibility of the solidmembrane wing to provide similar performance to that of a semi-rigid wing structure with full airfoils. Other goals included verification of the performance estimates, the development of a qualitative understanding of the individual contributions of the MAV components to the overall vehicle performance, an evaluation of the presence of flutter in the membrane skin of the wing, and determining the effects of partial deployments on the wing's performance.

\subsection{Wind Tunnel Model and Test Configurations}

Initial attempts to collect data using a full scale model proved to be troublesome after it was discovered the available three-component balance and load cells did not have the sensitivity to accurately measure the loads being exerted on the model. Balancing the sting arm and balance assembly also proved to be difficult with the full scale model due to the low weight of the model. 
Accurate calibration of the original model was also somewhat difficult since no provisions had been made in advance to provide mounting points for calibration equipment during model fabrication.

The solution to the aforementioned problems was to scale the model up in size by $50 \%$ so it matched the size of a different MAV model which was tested successfully with the available equipment and to use heavier materials when feasible. The resulting model, shown in Figure 5-1, was a $150 \%$ scale model with a solid aluminum fuselage and tail mount, interchangeable ABS plastic wings, and carbon fiber tail fins. Provisions for calibration mounting points were also included on the model to reduce the time required to accurately calibrate the load cells.

The interchangeable wings are easily replaced and are held into the body using flat head machine screws at the forward and aft ends of the wing modules. A plug was also produced to plug the gap in the fuselage when the wings were removed for the tests without wings. To reduce complexity of the model, the wing folding mechanism was omitted from the wing, but the membrane skin was retained. Additionally, to improve performance, the wing incidence was set to $+3^{\circ}$ based on the estimated glide lift coefficients of the wing by itself $\left(C_{L}=0.22\right)$ and wing and fuselage $\left(C_{L}=0.44\right)$. Lastly, so all the models had an equivalent surface roughness, the two sets of solid wing plugs were covered with the ripstop nylon membrane wing material.

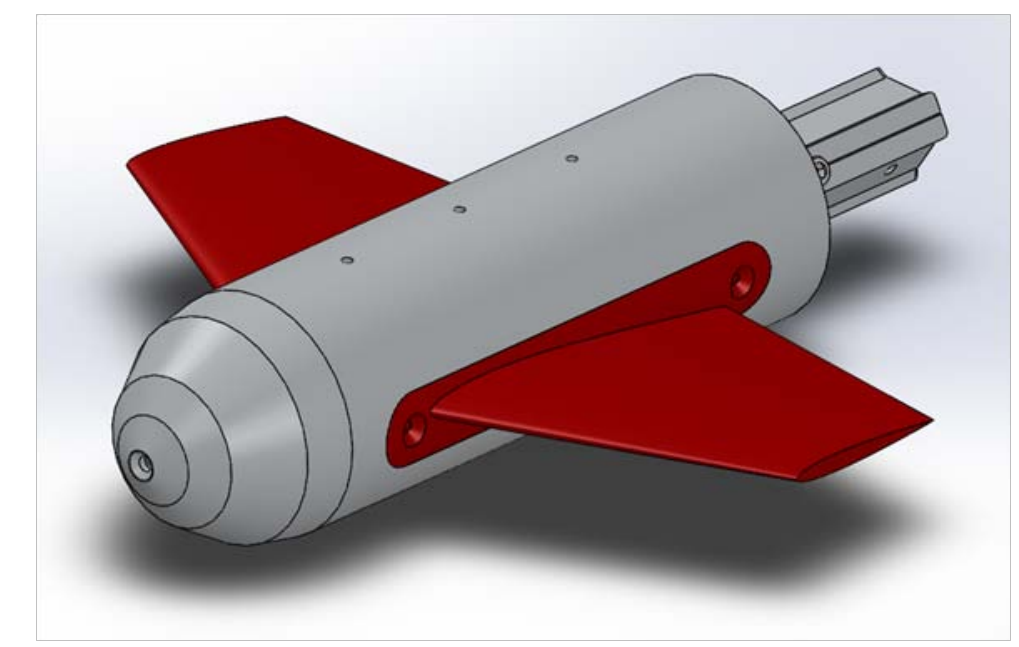

Figure 5-1 Wind tunnel model with solid NACA 0009 wings installed

Three wing test configurations were used to collect the data needed to evaluate the wing's performance along with three additional MAV component buildup test configurations to collect data for the qualitative estimates of component contributions to the overall MAV performance. Lastly, a high speed video camera was used to collect video and imagery to evaluate flutter in the 
membrane wing skin. This resulted in eight primary test configurations and two additional secondary test configurations which are summarized below.

1. MAV Fuselage Only

2. MAV Fuselage with tail fins

3. MAV Fuselage with wings

a. Solid NACA 0009 wing

b. Solid modified NACA 0009 wing

c. Solid-membrane modified NACA 0009 wing

i. Full TE deployment

ii. Partial TE deployment (Secondary)

iii. No TE deployment (Secondary)

4. MAV Fuselage with wings and tail fins
a. Solid NACA 0009 wing
b. Solid modified NACA 0009 wing
c. Solid-membrane modified NACA 0009 wing

\subsection{Test plan}

In order to evaluate the performance of the MAV and wings over the expected flight envelope, data was collected at three Re ranging from 75,000 to 150,000, and at AoA ranging from $-12^{\circ}$ to $+12^{\circ}$ in $2^{\circ}$ increments. To account for aerodynamic hysteresis during each test, the AoA is swept from $0^{\circ}$ up to $12^{\circ}$ and back to $0^{\circ}$, and then from $0^{\circ}$ down to $-12^{\circ}$ and back to $0^{\circ}$. Data collected at each AoA was then averaged to account for any aerodynamic hysteresis present. Mechanical hysteresis was accounted for during calibration and no significant mechanical hysteresis was observed.

To investigate the presence of flutter in the membrane skin for a fully deployed wing, a wing with a partially deployed trailing edge element, and a wing with no trailing edge deployment a high speed camera was set up and video was recorded at $\mathrm{AoA}=0^{\circ}, 6^{\circ}$, and $12^{\circ}$ at $\mathrm{Re}=125,000$. So that the camera position did not change for each test, the wings were changed between tests at each AoA rather than completing full sweeps with each wing before proceeding to the next.

The test plan presented in Appendix A accounts for the tested model configurations, Re ranges, and AoA sweeps, but does not account for the high speed camera footage collected. This 
plan was used during testing to ensure all necessary data was collected during testing and to help facilitate more efficient use of the time available for testing.

\subsection{Test Equipment}

\subsubsection{WVU Closed Loop Sub-Sonic Wind Tunnel}

The WVU closed loop subsonic wind tunnel is a low turbulence variable speed wind tunnel with two available test sections. For this experiment, only the primary test section was utilized. It has a 32" x 45" rectangular test section, and has a speed range of 0 - $76 \mathrm{~m} / \mathrm{s}$. The required velocity range for the testing conducted was 12.0 - $25.0 \mathrm{~m} / \mathrm{s}$, which is well within the tunnel's capabilities. Results of the most recent test section qualification, completed in late 2011, indicate that the flow quality in the test section is generally ok. The flow in the test section is angled slightly upward $\left(\tilde{+}+1.5^{\circ}\right)$, and has a highly unif orm velocity profile with variations of less than $1 \%$ outside the boundary layer. Turbulence intensity inside the test section was measured at $0.2 \%$, which is higher than ideal $(<0.1 \%)$, but is still acceptable. A photograph of the wind tunnel test section appears in Figure 5-2.

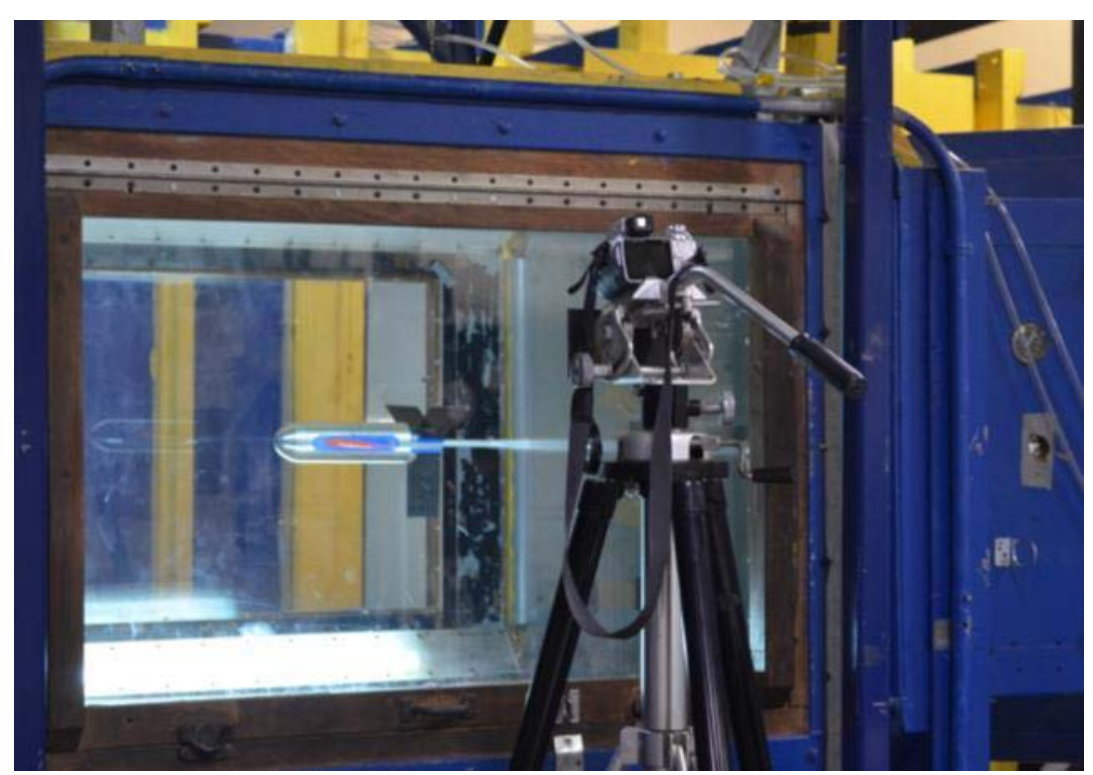

Figure 5-2 Primary Test Section of the WVU Closed Loop Subsonic Wind Tunnel

\subsubsection{Test Sting and Three-Component Balance}

The sting assembly used mounts downstream in the wind tunnel and is enclosed by an aerodynamic fairing. The model attaches to a sting arm that extends forward into the test section with a pivot point inside the fairing to adjust the model's angle of attack relative the tunnel free stream flow direction. A picture of the sting assembly appears in Figure 5-3. 


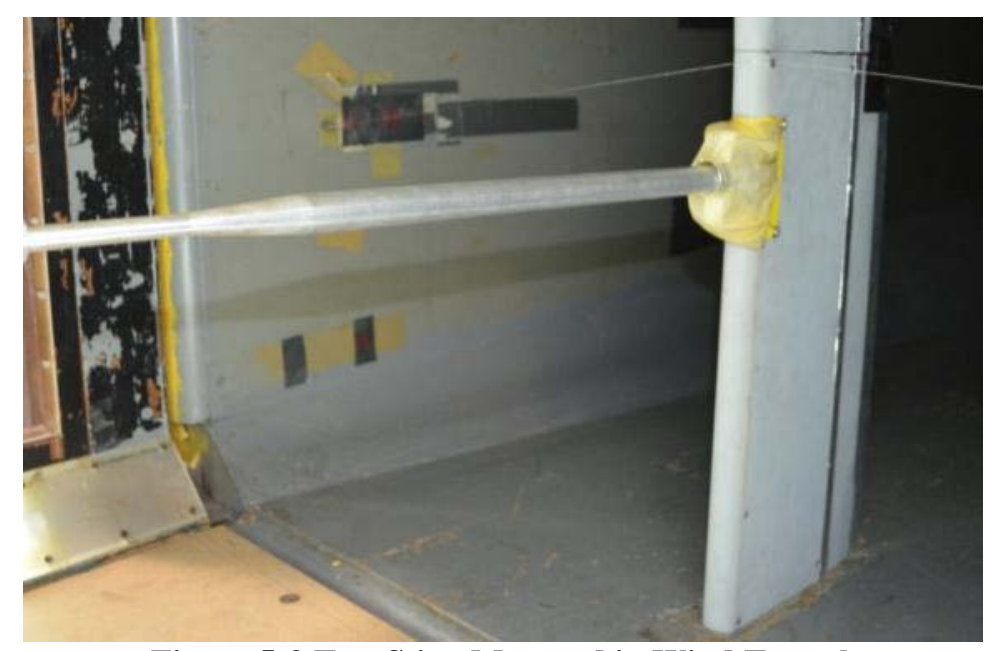

Figure 5-3 Test Sting Mounted in Wind Tunnel

A three-component balance with 25lb load cells in the L1 and L2 directions and a $1 \mathrm{~kg}$ load cell in the drag direction was used due to availability off the shelf. The 25lb load cells were used in the L1 and L2 directions primarily to ensure the weight of the model and sting assembly did not overstress the load cells. An image of the balance assembly mounted underneath the WVU Closed Loop Sub-sonic Wind Tunnel with the L1, L2, and D locations is presented in Figure 5-4.
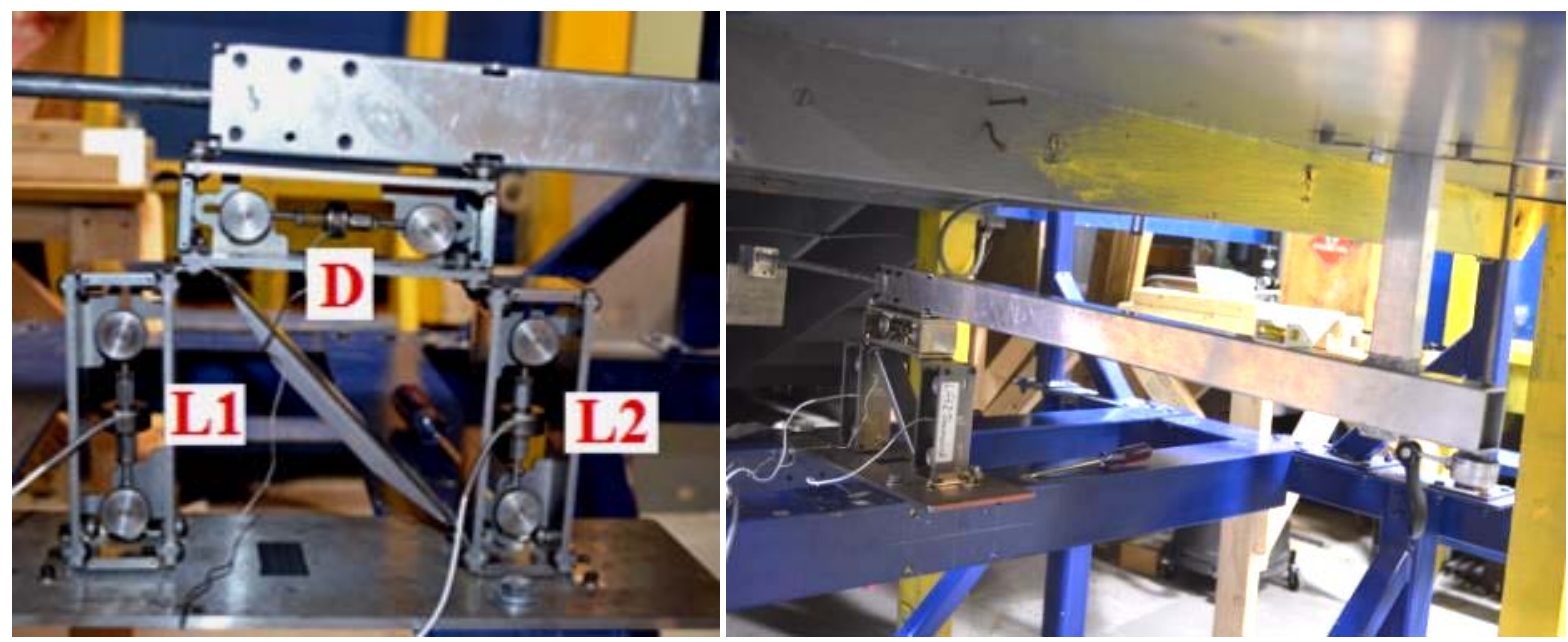

Figure 5-4 Three-component balance assembly (left) mounted under the wind tunnel (right)

\subsubsection{High Speed Camera}

To collect the high speed camera video, a Photron High Speed Camera capable of recording video at one million fps was used along with a Nikon lens. High intensity constant illumination lights were also used to help light the model in the wind tunnel. To prevent the need to constantly reposition the camera, video was collected at each AoA for all wings before moving on to the next AoA. Also, video was recorded at $1000 \mathrm{fps}$ for a period of 2-3 seconds. Due to the 
file sizes of the video, only 1/10th of a second of video was retained as this appeared to show a full cycle when the membrane skin fluttered.

\subsubsection{Data Acquisition and Processing}

To read and convert the analog electrical signals from the load cells, a Texas Instruments DAQ system was used along with a computer running Lab View to collect and record the raw data. A MATLAB software code, presented in Appendix B, was written and used to average the sampled data and then output the raw voltages, force data, and coefficient data for each test point into a *.txt file for further post-processing. Equipment calibration details for the process with the DAQ and 3-component balance are presented in Appendix D.

\section{Chapter 6. Data Analysis \& Discussion}

The complete set of lift and drag polars for the eight primary test configurations and two secondary test configurations are presented in Appendix $\mathrm{F}$ so as to not detract from the significance of the discussion of the results presented herein. Results presented within the current chapter are presented solely to provide supporting evidence of the analysis discussion points. An error analysis was also conducted and the results are presented first with analysis details appearing in Appendix E. Next, a brief discussion over the data collected including attempts at validating the results against other experimental results is presented followed with a discussion and analysis of the wind tunnel testing results.

\subsection{Uncertainty Analysis}

When taking flow measurements, two major types of error exist; systemic (bias) errors and random (precision) errors. These errors affect the results, but most can be minimized by ensuring the sensors and gauges are accurately calibrated or by using a gauge with higher graduation in the scales. As a rule of thumb, if more than 11 data points are available, a standard deviation should be used to describe the error in experimental results. Otherwise, an uncertainty analysis should be conducted to estimate the error in the results. Since only three sets of data for any one experiment was collected at most, an uncertainty analysis was conducted to estimate the error present in the data collected. The results of this analysis are within acceptable ranges for experimental data and are presented below in Table 6-1. Details of the analysis including a brief discussion of the general equations used, derivation of the individual Uncertainty equations, and the values used as inputs in the equations are presented in Appendix E. 
Table 6-1 Uncertainty Results (Maximum Uncertainties)

\begin{tabular}{|c|c|c|c|}
\hline \multirow{2}{*}{$\operatorname{Re}$} & \multicolumn{3}{|c|}{$\%$ Uncertainty } \\
\cline { 2 - 4 } & $\mathbf{C}_{\mathbf{L}}$ & $\mathbf{C}_{\mathbf{D}}$ & $\mathbf{L} / \mathbf{D}$ \\
\hline 75000 & $5.72 \%$ & $7.53 \%$ & $8.60 \%$ \\
\hline 100000 & $5.24 \%$ & $7.18 \%$ & $8.60 \%$ \\
\hline 125000 & $5.10 \%$ & $7.07 \%$ & $8.60 \%$ \\
\hline 150000 & $5.05 \%$ & $7.04 \%$ & $8.60 \%$ \\
\hline 250000 & $5.01 \%$ & $7.01 \%$ & $8.60 \%$ \\
\hline
\end{tabular}

\subsection{Data Overview, Validation, and Repeatability}

The general shape and appearance for most of lift and drag polars were as expected, and the collected data was within the anticipated ranges for each configuration. Some difficulties were encountered when attempting to collect data for the fuselage only configuration, most likely due to the forces being too small to accurately measure using the load cells used. This was confirmed by collecting data for the fuselage at $\mathrm{Re}=250,000$ (based on wing MAC). It was noted that the shapes of the curves and values were consistent with the expected results. This would normally call the data collected using the test setup into question, but the forces on the fuselage at $\operatorname{Re}=250,000$ were equivalent or slightly higher than those expected with the tail fins and wings installed.

To validate the data collected for the fuselage at $\mathrm{Re}=250,000$, it was compared to data collected for a similar fuselage tested in an ARDEC wind tunnel in August of 2010 by Mr. Hamburg. The ARDEC data was evaluated with respect the MAV wing rather than the fuselage diameter, and the resulting lift and drag polars at $\mathrm{Re}=250,000$ are presented in Figure 6-1 along with the fuselage test data from this study.

The comparison indicates that the collected drag data is a fairly acceptable match to the ARDEC data, since the fuselage used in this study is nearly $30 \%$ longer. If one assumes that the drag coefficient is proportional to the fuselage length, then the $30 \%$ increase in length would result in a 30\% increase in drag, which is approximately what the collected drag data shows. However, the lift data collected does not follow the data from the ARDEC study nearly as closely. It is possible that this increase in lift is due in part to the increased fuselage length, but it is equally as likely that the increased lift is the result of aerodynamic forces acting on the sting. It should be noted that the order of magnitude of the effects of the sting on the measured lift is less 
than $5 \%$ of the forces produced by the tail fins and wings, and that the effect of the sting on the lift and drag data should be consistent for all configurations at each Re. This allows for performance comparisons within the test group to be made to evaluate the relative performance of the wings.

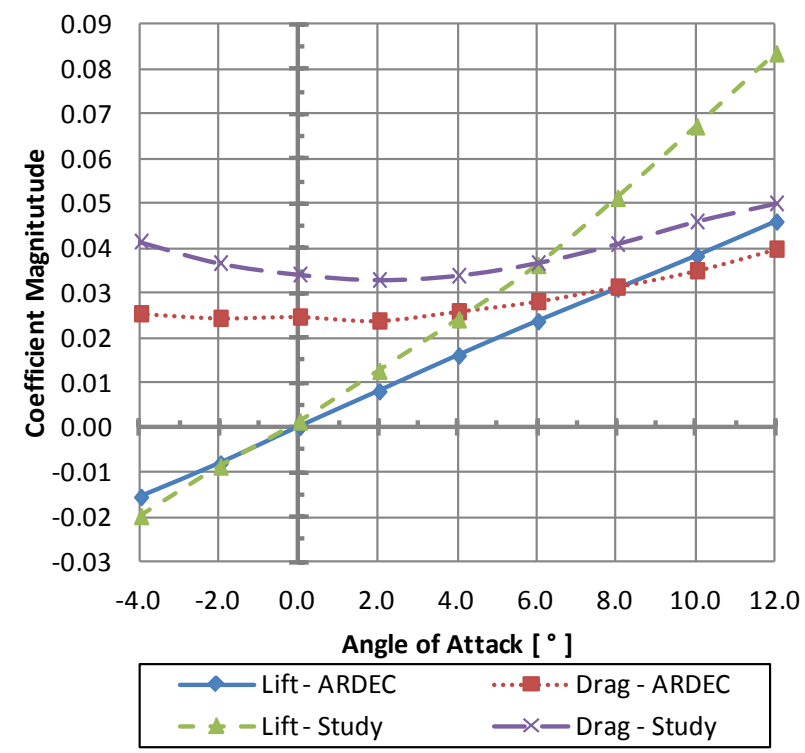

Figure 6-1 Lift and Drag data comparison at $\operatorname{Re}=250,000$ between data for a baseline fuselage in the ARDEC wind tunnel and the solid-membrane wing MAV fuselage.

Another important step in any experiment is to verify the repeatability of the data collected during the experiment. In general, repeatability requires the use of a separate test setup in a separate wind tunnel. Since no other tunnel sufficiently large enough was available in this case, testing was conducted to demonstrate the repeatability of results within the WVU closed loop wind tunnel. To accomplish this, three full sets of data were collected at $R e=125,000$ for the fuselage \& wing and fuselage, wing, \& tail cases. Three sets of data were also collected over three days for the fuselage only configuration at $R e=250,000$. The data was then plotted and compared to determine if any significant variances appeared between the tests. None were observed, and to show what the data looked like, plots of the lift and drag data for the fuselage, tail, \& wing configurations is presented below in Figure 6-2, and for the fuselage only configuration in Figure 6-3.

Error bars would normally be displayed on every plot to convey the uncertainty error, but due to the amount of data displayed on each plot, this was done only on one set of data so as to not clutter up the remaining plots. The lift, drag, and L/D polar plots with appropriate error bars for the Fuselage, Tail, \& Solid-Membrane Wing at $\mathrm{Re}=125,000$ is presented in Figure 6-4. 

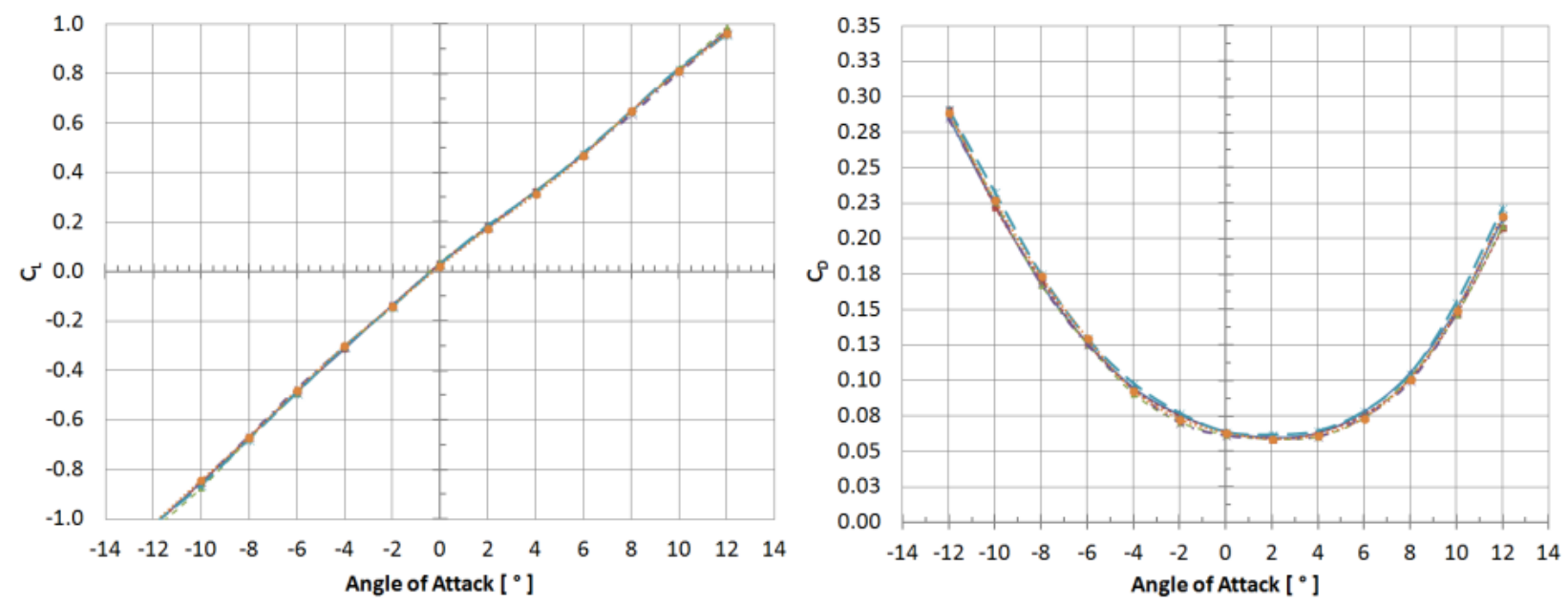

$\rightarrow$-Fuselage, Tail, \& Solid NACA 0009 Wing - Run $1-x \cdot$ Fuselage, Tail, \& Solid-Membrane NACA 0009m Wing - Run 1

$-\cdots$-Fuselage, Tail, \& Solid NACA 0009 Wing - Run $2 \rightarrow$ Fuselage, Tail, \& Solid-Membrane NACA 0009m Wing - Run 2

- - Fuselage, Tail, \& Solid NACA 0009 Wing - Run $3 \ldots$ Fuselage, Tail, \& Solid-Membrane NACA 0009m Wing - Run 3

Figure 6-2 Repeatability plots for Fuselage, Tail, and Wing Configurations at $\mathbf{R e}=125,000$.
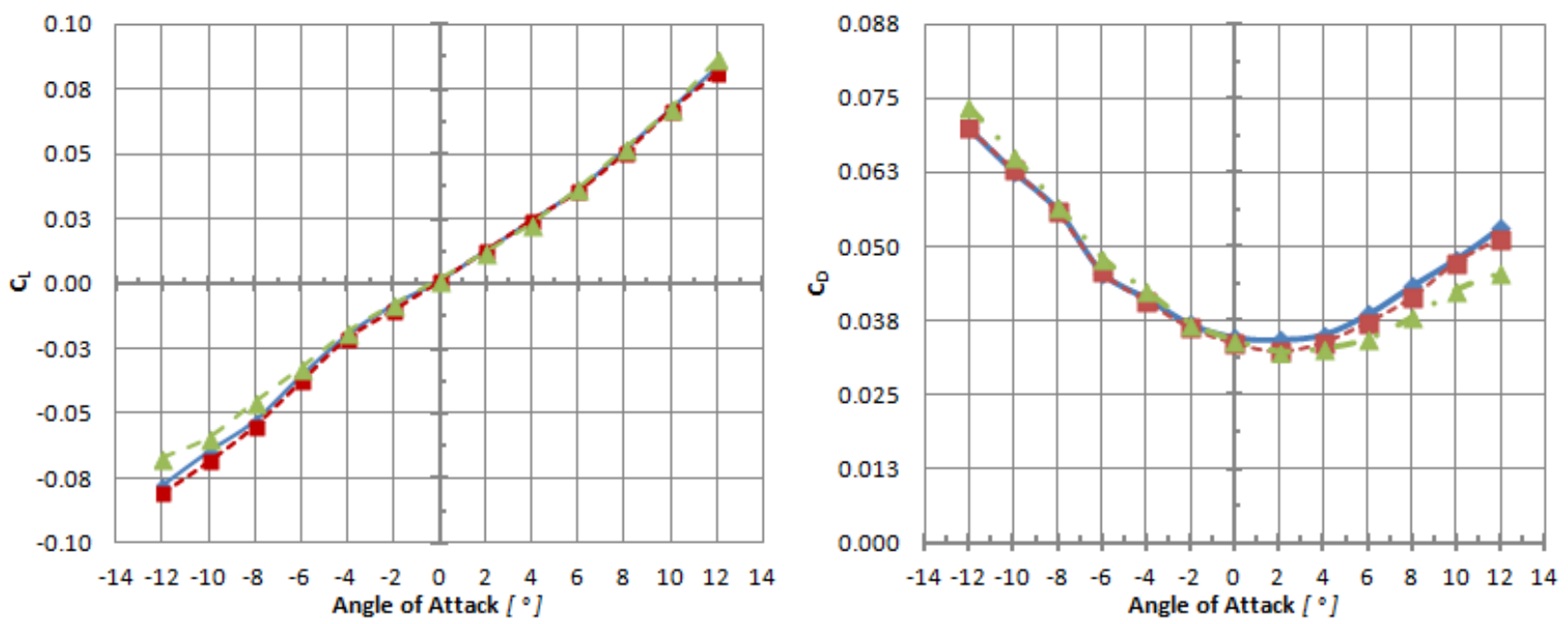

$$
\begin{array}{llll|}
\hline- \text { Fuselage, Run } 1 \quad-- \text { Fuselage, Run } 2 & -1 & \text { Fuselage, Run } 3 \\
\hline
\end{array}
$$

Figure 6-3 Repeatability plots for Fuselage only Configuration at $\mathbf{R e}=\mathbf{2 5 0 , 0 0 0}$. 

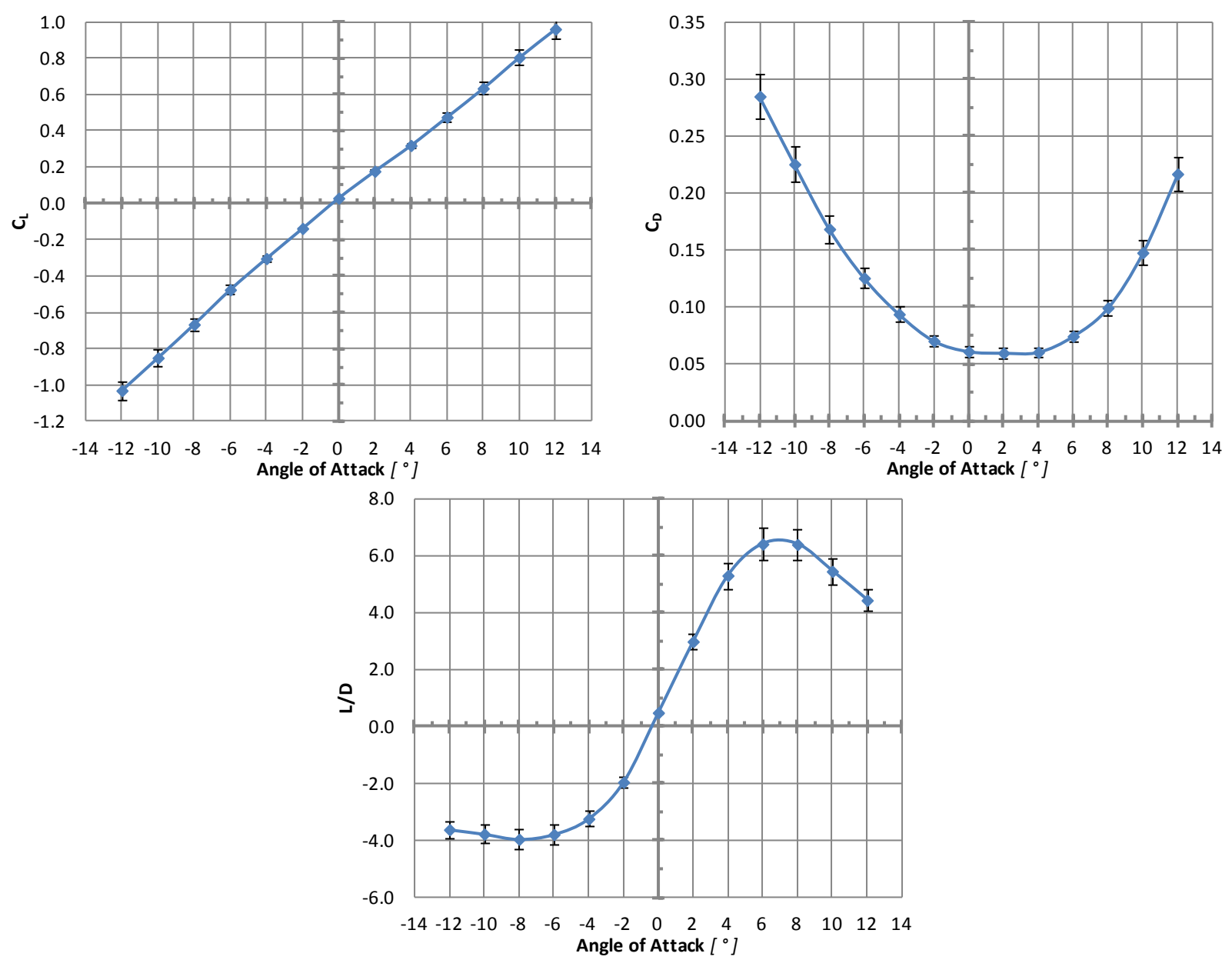

Figure 6-4 Fuselage, Tail, and Solid-Membrane Wing $C_{L}, C_{D}$, and $L / D$ data with vertical error bars at $\operatorname{Re}=125,000$.

\subsection{Analysis and Discussion}

Overall, only minor variations were observed in performance between the various wings and Re tested within each major test group (fuselage $\&$ wings, and fuselage, wings, \& tail). Also, the overall lift produced by each wing was very similar within test groups and Re ranges. The minor variability is more noticeable in the drag curves and resulting L/D curves than the lift curves, particularly at $\operatorname{Re}=75,000$ and 100,000 . At $\operatorname{Re}=125,000$ and 150,000, less variability within test groups was observed. Despite the variability, the quality of the data was sufficient to evaluate and compare the performance of the Solid-Membrane wing with a NACA 0009m airfoil to that of a Solid wing with the baseline NACA 0009 airfoil.

As discussed previously in the attempt to validate the fuselage data at Re below 125,000, collection of the fuselage drag and lift data presented some difficulty. This was especially true with drag at positive AoA and lift at negative AoA. The data at $\operatorname{Re}=150,000$ and 250,000 is 
believed to be more accurate, and indicates that the overall contributions to the lift and drag by the fuselage is very small when compared to that produced by the tail and wings. When the tail fins were added, the contributions to the overall lift and drag of the MAV were increased. The lift, drag, and L/D polars for the fuselage and fuselage and tail configurations are presented in Appendix F.

Data quality for the Fuselage \& Wing, and Fuselage, Wing, \& Tail configurations was generally good with some difficulty experienced in adequately capturing the drag data for $R e=75,000$. This also had an effect on the $L / D$ results at $R e=75,000$, especially for the solid NACA 0009 and NACA 0009m wings. Additionally, the drag data at $\operatorname{Re}=100,000$ appeared to have some minor discrepancies that affected the L/D results yielding higher than expected values. For the $\mathrm{Re}=125,000$ and 150,000 results, the drag data appears to have stabilized with respect to Re. This behavior is best demonstrated in the lift, drag, and L/D polars for the Fuselage \& Solid NACA 0009 Wing configuration presented in Figure 6-5. The overall effect of Re on the drag and L/D also appears to have had less of an effect on the Fuselage, Wings, \& Tail configuration. As a result of this and the repeatability work completed the $\operatorname{Re}=125,000$ data was primarily used in the performance comparisons with $\mathrm{Re}=150,000$ data used as needed. The complete data for $\mathrm{Re}=75,000,100,000,125,000$, and 150,000 is presented in Appendix $\mathrm{F}$ for completeness. 

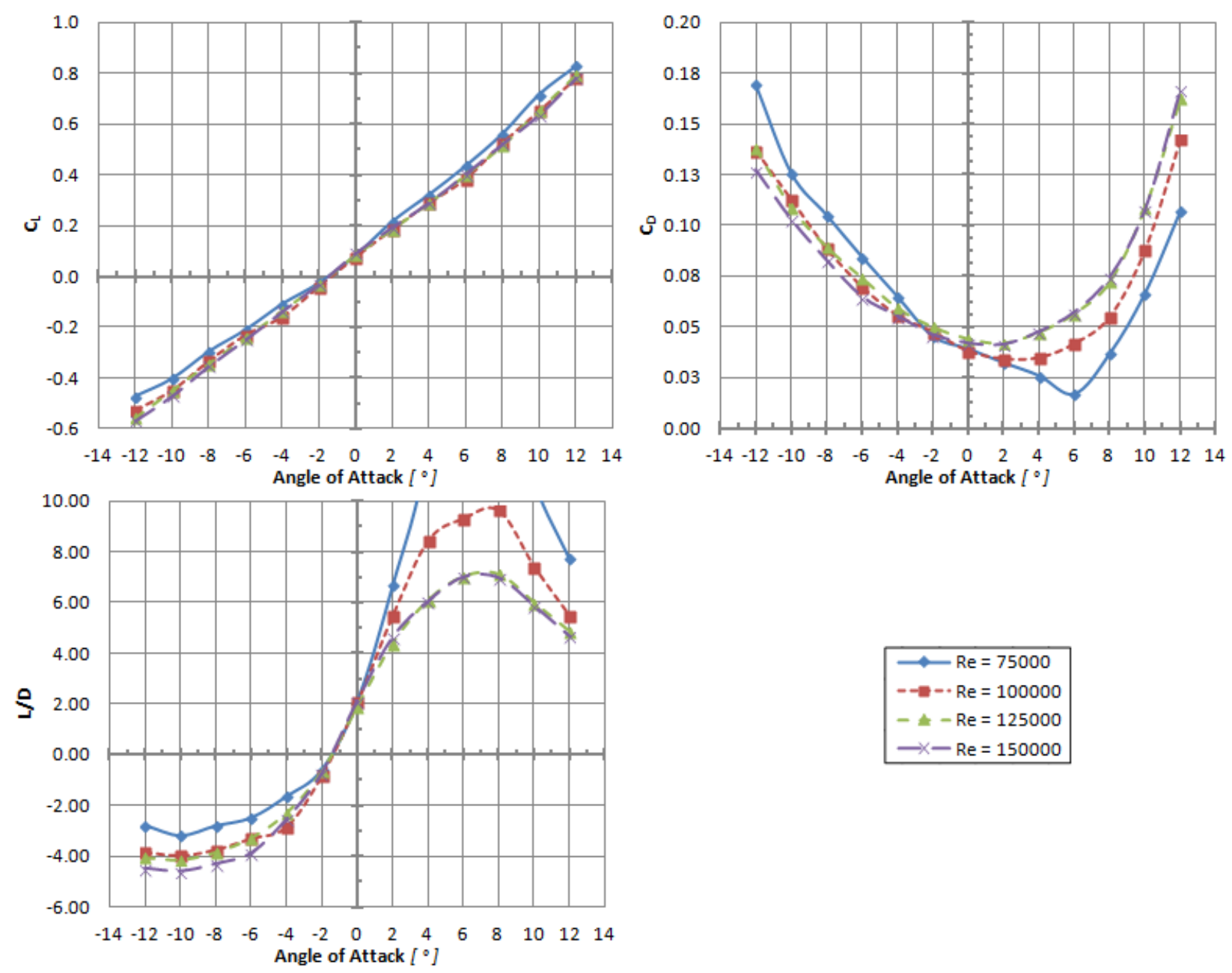

Figure 6-5 Lift, Drag, \& L/D Polars for the Fuselage \& Solid NACA 0009 Wing Configuration

Data comparing the different wings in the Fuselage \& Wing and Fuselage, Wing, \& Tail configurations at $\operatorname{Re}=125,000$ is presented in Figure 6-6. It should be clearly visible that the overall lift and drag performance of the wings were very similar, and that the L/D performance of the Solid-Membrane Wings with NACA 0009m airfoils is slightly higher than the solid wings with NACA 0009 or NACA 0009m airfoils. This strongly suggests that the overall performance of the Solid-Membrane Wing with the NACA 0009m airfoil is equivalent to or better than the performance of a similar semi-rigid solid wing with a NACA 0009 airfoil.

For the Solid-Membrane NACA $0009 \mathrm{~m}$ wing, the $\mathrm{L} / \mathrm{D}_{\max } \approx 6.1$ with the tail fins and $L / D_{\max } \approx 6.9$ without the tail fins. These values are significantly higher than the $L / D$ of the fuselage alone $\left(L / D_{\max } \approx 1.75\right)$ or the fuselage with tail fins $\left(L / D_{\max } \approx 3.0\right)$. This suggests that a gliding MAV utilizing the Solid-Membrane wings and tail fins could achieve a 200\% range increase over a finned MAV with a ballistic trajectory or nearly a 350\% increase over an 
unfinned MAV. Using the data collected from the wind tunnel testing, further performance estimates for a MAV utilizing the Solid-Membrane Wing and tail fins were calculated using classical aerodynamics with the results and accompanying pre-test estimates presented in Table 6-2.
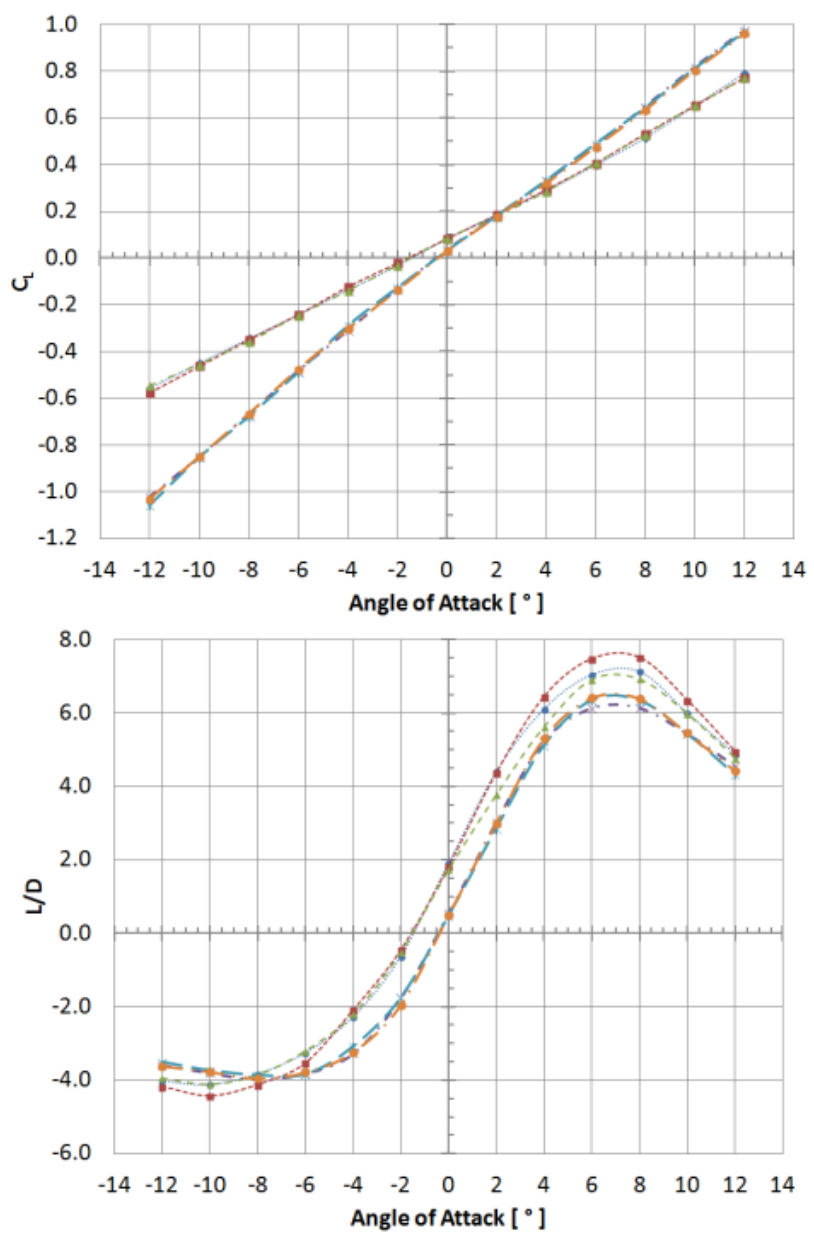

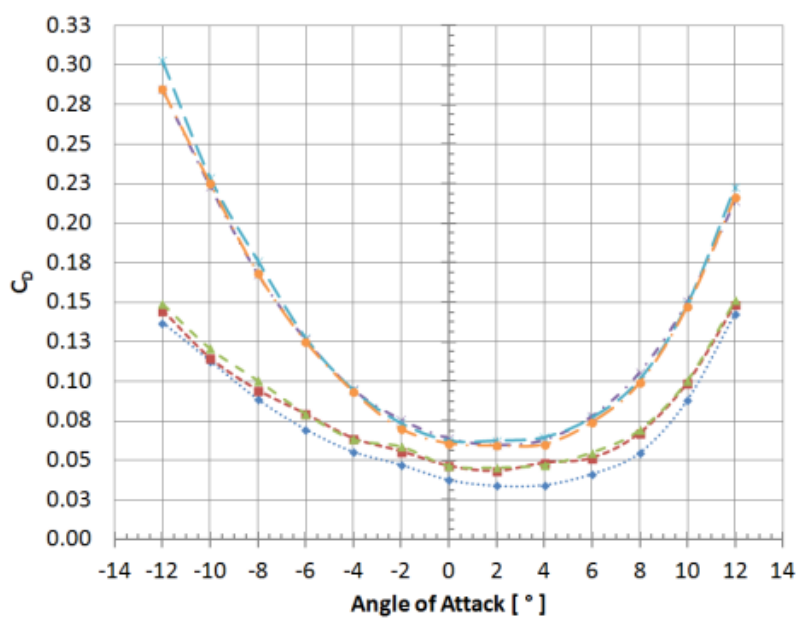

$$
\begin{aligned}
& - \text { Fuselage \& Solid NACA } 0009 \\
& - \text {-Fuselage \& Solid NACA 0009m } \\
& - \text { Fuselage \& Solid-Membrane NACA 0009m } \\
& - \text { Fuselage, Tail, \& Solid NACA } 0009 \\
& \rightarrow \text { Fuselage, Tail, \& Solid NACA } 0009 \mathrm{~m} \\
& \text { - Tail, \& Solid -Membrane NACA 0009m }
\end{aligned}
$$

Figure 6-6 Fuselage \& Wing and Fuselage, Wing, \& Tail Configuration Results at $\operatorname{Re}=125,000$.

Table 6-2 Solid-Membrane Wing MAV Performance Estimates

\begin{tabular}{|c|c|c|c|}
\hline Parameter & $\begin{array}{c}\text { Original } \\
\text { Value }\end{array}$ & $\begin{array}{c}\text { Experimental } \\
\text { Value }\end{array}$ & Units \\
\hline$R e_{S T A L L}$ & 100,000 & $>80,000$ & - \\
\hline$C_{L_{S T A L L}}$ & 0.60 & $>1.0$ & - \\
\hline$C_{D_{S T A L L}}$ & 0.048 & $>.25$ & - \\
\hline Stall Speed & 25.91 & 20.1 & $\mathrm{~m} / \mathrm{s}$ \\
\hline$C_{L_{G L I D E}}$ & 0.44 & 0.50 & - \\
\hline$C_{D_{G L I D E}}$ & 0.040 & 0.08 & - \\
\hline Glide Speed & 30.00 & 30.0 & $\mathrm{~m} / \mathrm{s}$ \\
\hline Glide Angle & -10.91 & -9.31 & $\circ$ \\
\hline$L / D_{M A V}$ & 5.19 & 6.10 & - \\
\hline
\end{tabular}


To evaluate the presence of flutter in the flexible membrane skin and its potential effect on the drag and lift performance of the MAV, high speed video was collected at $\mathrm{AoA}=0^{\circ}, 6^{\circ}$, and $12^{\circ}$ at a $\operatorname{Re}=125,000$ for the Fuselage and Solid-Membrane Wing configuration. Still captures from the video over a 1/10 second time step are presented below in Table 6-3. Analysis of the video showed that no visible flutter was observed over the AoA range tested, indicating that the slightly flexible nature of the ripstop nylon membrane skin did not affect the drag force on the wing. The effect of the roughness of the membrane skin itself on the drag and lift of the wing was not investigated, but warrants further investigation in the future, along with an investigation into the use of alternative membrane skin materials.

Table 6-3 Fuselage \& Fully Deployed Wing Membrane Skin High Speed Video Frame Captures

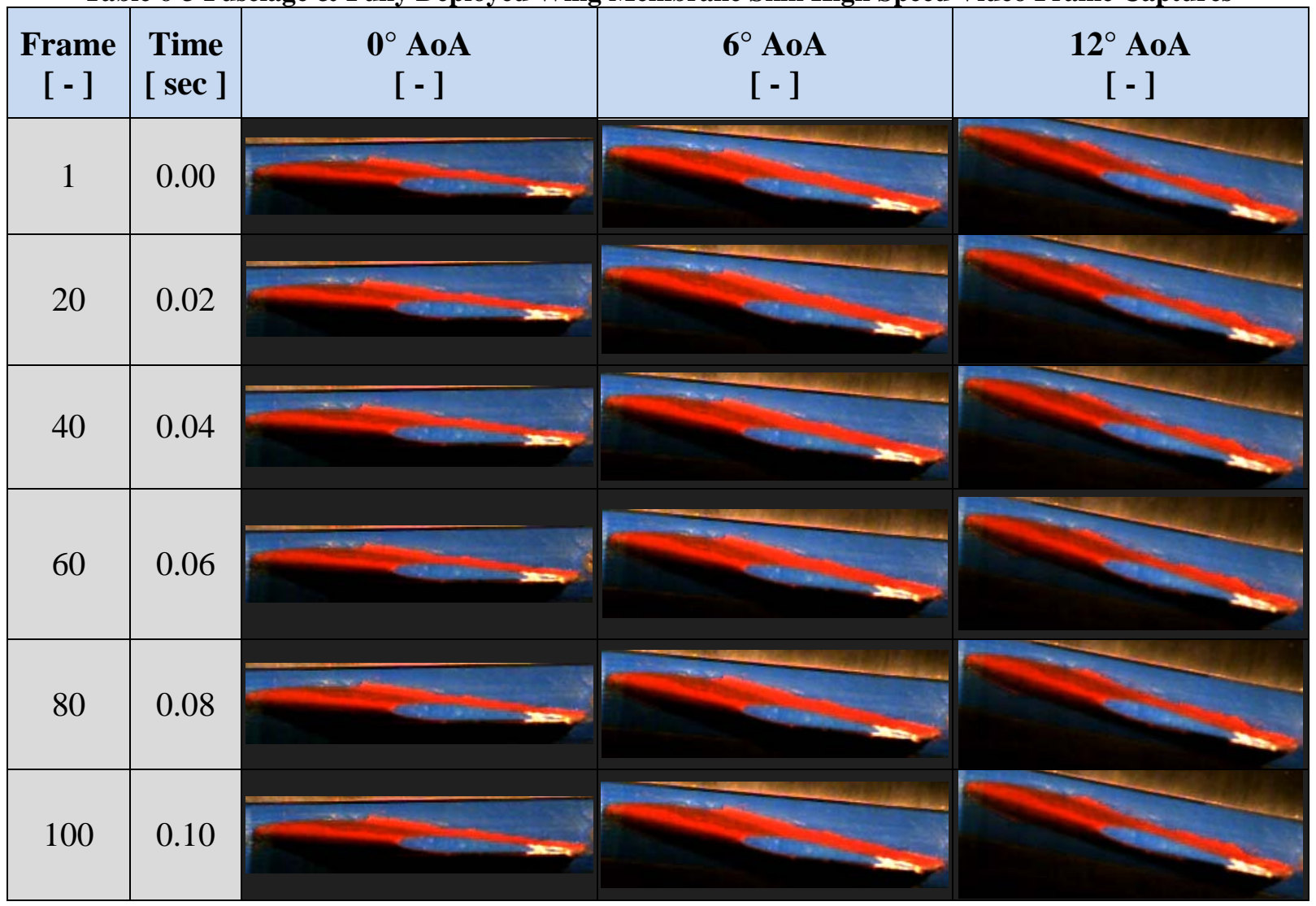

Comparing the lift and drag data for the Fuselage, Fuselage \& Tail, Fuselage \& Wing, and Fuselage, Wing, \& Tail configurations allows one to generate a qualitative sense of the contributions of each component to the overall performance of the MAV. Lift and drag polars with lift and drag curves for each configuration at $\mathrm{Re}=125,000$ are presented $(\mathrm{Re}=250,000$ for the Fuselage only case) in Figure 6-7. The resulting data indicates that the order of significance 
of the contributions from most significant to least significant was tail fins, wings, and fuselage. This ordering is different from what is normally seen on larger vehicles, but once the size of the tail fins with regards to the main wing are accounted for, the ordering makes sense as the surface area of the tail fins on the MAV model is similar to the area of the main wings due to the close coupling of the fins and wing.
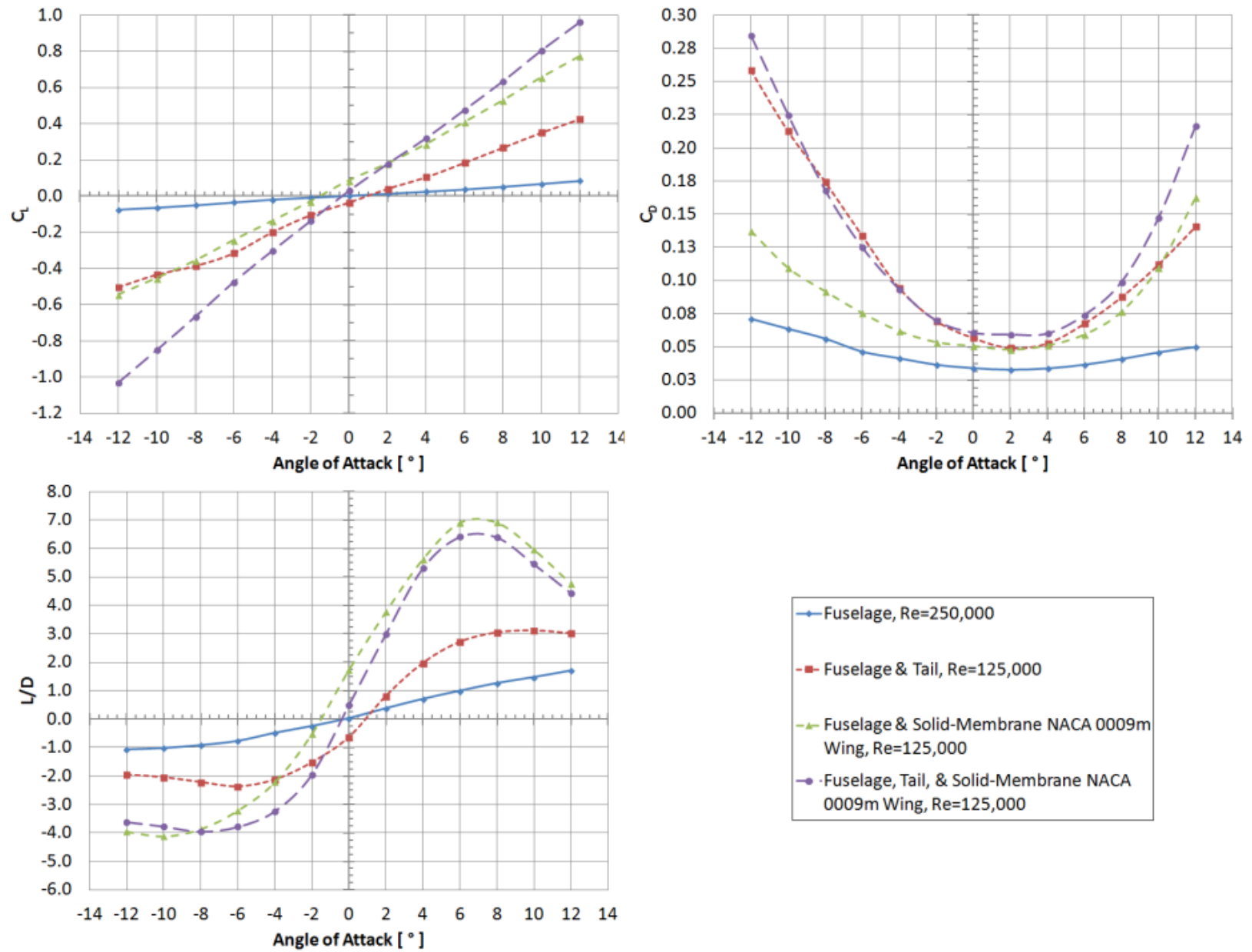

Figure 6-7 Lift, Drag, and L/D Comparison of Fuselage, Fuselage \& Tail, Fuselage \& Solid-Membrane Wing, and Fuselage, Tail, \& Solid-Membrane Wing Configurations.

In addition to evaluating the performance of the Solid-Membrane Wing with a NACA 0009m airfoil to that of the Solid wing with a NACA 0009 airfoil, the performance of the SolidMembrane wing was also evaluated at two different "failed" deployment conditions in the Fuselage \& Wing configuration. This was done to determine when and how the wing would fail to provide the necessary aerodynamic performance. For the first condition, a incomplete deployment of the trailing edge element was simulated by allowing the membrane skin to remain loose. For the second condition, a failed deployment of the trailing edge element was simulated 
by removing the trailing edge element entirely and leaving the membrane skin loose behind the leading edge element.

Lift and drag data was collected for the partial trailing edge deployment condition at $\mathrm{Re}=125,000$ along with high speed video data at $\mathrm{AoA}=0^{\circ}, 6^{\circ}, 10^{\circ}$ and $12^{\circ}$. Additional lift and drag data was also collected at $\operatorname{Re}=150,000$ and is displayed with the $\operatorname{Re}=125,000$ data in Figure 6-8. As expected, the drag roughly doubled. Surprisingly, the wing continued to produce a significant amount of lift reducing by only approximately $10 \%$. This yielded a $L / \mathrm{D}_{\max } \approx 3.5$, which would still result in a 50-100\% range extension compared to the range of an unfinned MAV.

In addition, according to the data collected with the high speed video camera, the loosened membrane skin did not begin to flutter until an AoA $>10.0^{\circ}$ was achieved. Even at AoA $>10^{\circ}$ only the top surface of the membrane skin fluttered and appeared to have a regular intermediate pattern which repeated itself every few seconds. For clarity, some frames from the high speed video at $\mathrm{AoA}=0^{\circ}, 6^{\circ}$, and $12^{\circ}$ are presented below in Table 6-4.

Table 6-4 Fuselage and Wing Partial Trailing Edge Deployment High Speed Video Frame Captures

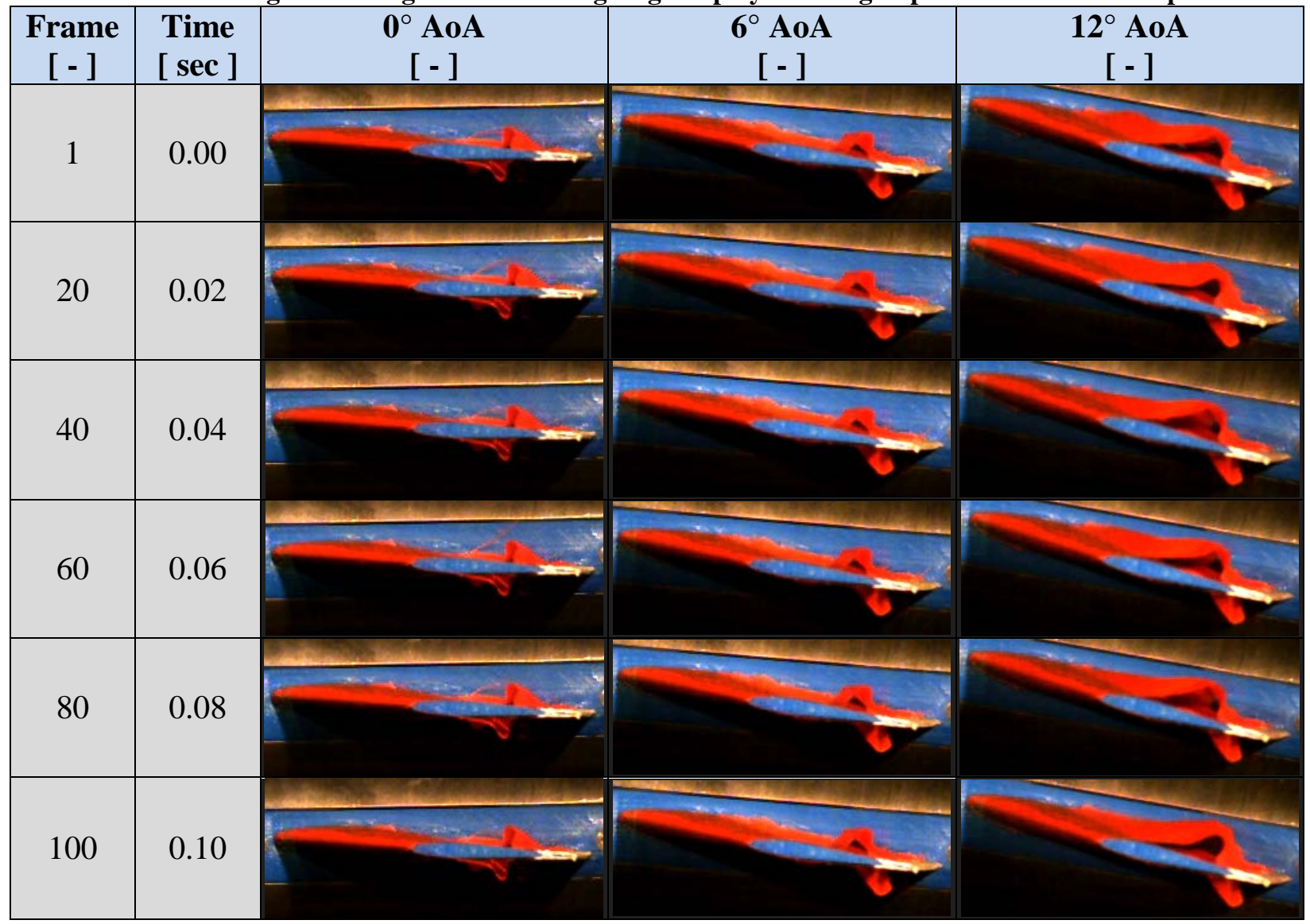


For the no trailing edge deployment condition, lift and drag data was collected at three Re $\left(100,000,125,000\right.$, and 150,000) along with high speed video data at $\operatorname{Re}=125,000$ at $A o A=0^{\circ}, 6^{\circ}$, and $12^{\circ}$. The lift and drag data is presented for the $\mathrm{Re}=125,000$ and 150,000 cases in Figure 6-8. Overall, the lift performance of the wing was reduced by $50 \%$ while the drag was increased nearly tenfold, resulting in a $L / D_{\max } \approx 1.2$, which was $30 \%$ less than the $L / D_{\max }$ of the fuselage alone. The increased drag was about as expected, although significantly more lift was still produced than expected. This indicates that the LE element alone may be responsible for a significant portion of the lift production and may warrant some further study in the future.

The high speed video showed that the loose membrane wing skin fluttered in such a way at all AoA that the vortices coming off the wing were nearly completely visible in the flutter pattern of the membrane skin. This increased flutter definitely explains the increase in drag, as the skin friction from the fluttering membrane skin paired with the vortex separation behind the leading edge element caused the drag force to drastically increase. To illustrate these vortices, some frames from the high speed video at $0^{\circ}, 6^{\circ}$, and $12^{\circ}$ are presented below in Table 6-5.
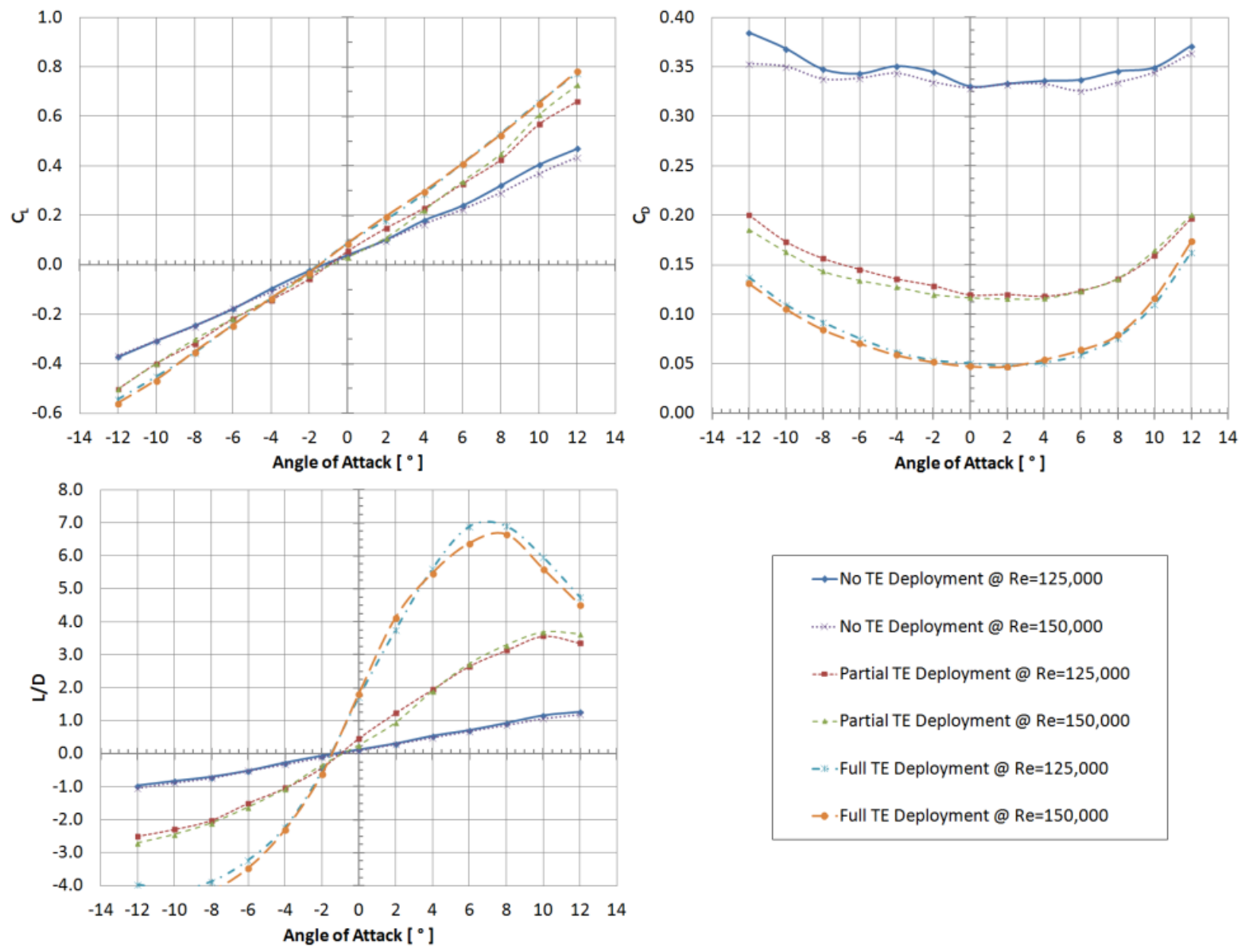

Figure 6-8 Fuselage and Wing Full, Partial, and Failed TE Deployment Comparison 
Table 6-5 Fuselage and Wing Failed Trailing Edge Deployment High Speed Video Frame Captures.

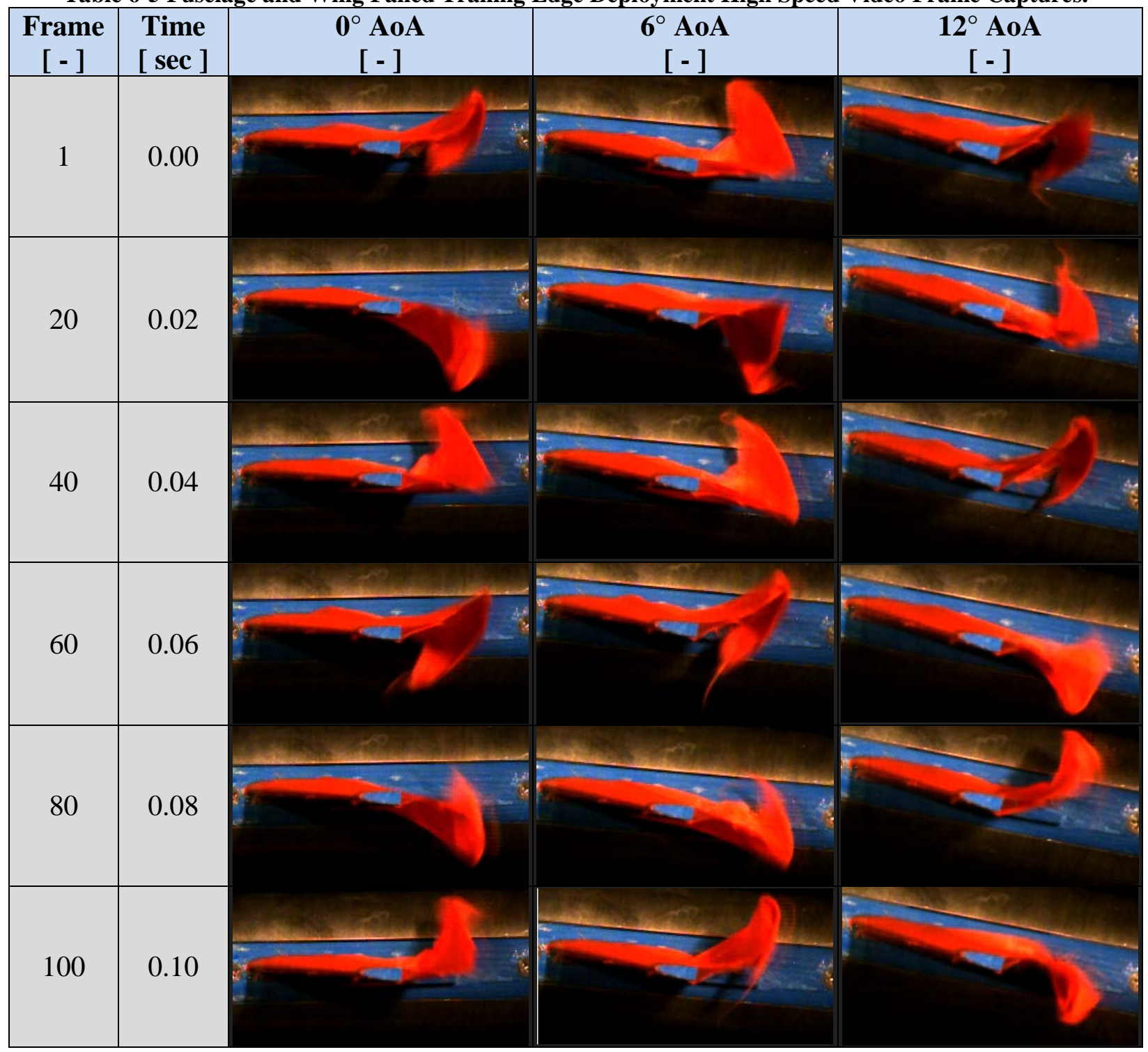

The above data for the failed deployment scenarios investigated suggests that a partially deployed trailing edge element will provide reduced but acceptable performance whereas a completely failed deployment of the trailing edge element will result in a significant reduction of performance to a level worse than having no wing installed on the MAV at all. These results suggest that further study of the effect on MAV performance by the failed states of deployment should be conducted along with a study to determine the conditions that cause incomplete deployments. 


\section{Chapter 7. Summary and Recommendations}

The work presented herein provides strong evidence that a folding solid-membrane wing has the potential to allow small projectile launched MAVs to utilize a wing with higher efficiency full profile airfoils while maintaining the packing efficiency required to successfully stow the wing in the fuselage along with all the necessary control system and payload components required to carry out the MAV's mission. The accomplishments of the research, conclusions based upon the design and experimental work, and recommendations for future work are outlined in the subsequent sections.

\subsection{Accomplishments}

- A review of the conceptual and preliminary design work including an analysis of the MAV mission profile, a sensitivity study by various parameters on the glide ratio, and development of initial high speed and maximum range concepts was presented. A review of some MAV and UAV systems which demonstrate useful concepts were also presented.

- The solid-membrane wing concept was selected from a field of five concepts presented herein based upon its probability of striking the best balance between aerodynamic efficiency, available internal MAV volume, low cost, and low technical risk.

- A solid-membrane folding wing design was presented and included the folding mechanism and a release and locking mechanism.

- An inviscid flow analysis of the NACA 0009 airfoil and the modified NACA 0009 airfoil was conducted to evaluate the performance similarities between the airfoils.

- A functional proof of concept demonstration model used to identify and correct potential design issues was developed and assembled.

- Issues with forming and attaching the flexible membrane skin to the solid elements of the wing were solved using patterns to cut the material and molds to properly bond the material together.

- An engineering MAV model was developed to prove the feasibility of integrating the wing and other necessary components and payloads into a representative MAV fuselage.

- Extensive wind tunnel testing was conducted to evaluate the lift, drag, and glide performance of the airfoils, and MAV model configurations using wings in full and 
partial deployment conditions. High speed video was also collected to evaluate the presence of surface motion in the membrane skin.

\subsection{Conclusions From Study}

- After integration of the solid-membrane wing presented into the fuselage of the gliding tube launched MAV, more than $80 \%$ of the fuselage volume remains for integration of other system components and payloads.

- The experimental results suggest the performance of the NACA 0009 and modified NACA 0009 airfoils are very similar.

- Performance of the solid and solid-membrane wings with the modified NACA 0009 airfoil were nearly identical indicating that the flexible membrane skin does not have a negative effect on the wing's performance.

- A qualitative review of contributions to the lift and drag indicate that for a similarly sized $\mathrm{MAV}$, the tail fins contribute most significantly to the drag while the wings contribute most significantly to the lift.

- Experimental results suggest a MAV similar to the engineering model developed herein would have a 200\% greater range than that of the MAV fuselage and fins alone.

- Partial deployments of the wing trailing edge elements cause slight-moderate reductions in the lift produced by the wing, and moderate-significant increases in drag.

- A review of the high speed video footage collected indicated that across the AoA range studied, no discernible surface motion was present in the membrane skin of a fully deployed wing with increasing levels of surface motion becoming apparent with decreasing levels of trailing edge element deployment.

\subsection{Recommendations for Future Work}

- To confirm that the NACA 0009 and modified NACA 0009 airfoils truly have similar performance, more studies need to be conducted. These should include an investigation of the effect of wing geometry on the airfoil performance and an investigation of each airfoil's pitching moment.

- Further investigation to quantify the interaction effects between the individual MAV components (fuselage, tail fins, and wings) should be conducted using a variety of flow visualization techniques as well as further collection of force data. 
- Transient deployment studies should be conducted to investigate the effects of successful and partial wing deployments on the flight characteristics of the wing and a representative MAV. This study should also investigate and determine conditions that will cause issues with deployment of the solid-membrane wing.

- An investigation into the capability of the solid-membrane wing components to survive the high G-force launches anticipated needs to be conducted.

\subsection{Closing Remarks}

Although much work remains before attempting full integration into a flight test model, the Solid-Membrane Wing concept presented herein is a viable technological solution to placing a relatively small to mid size folding wing in a tube launched MAV. Initial steps demonstrating the feasibility and benefits of the wing were presented, but further study of the stability of the wing, the deployment dynamics of the wing, deployment failure modes, and survivability of solidmembrane wing system components under the high G-force launch conditions are required. 


\section{Chapter 8. References}

1. Hamburg, Shanti Don. Conceptual and Preliminary Design of Stowable Ruggedized Micro Air Vehicles. West Virginia University. Morgantown, WV : s.n., 2010. Thesis.

2. Miley, S.J. A Catalog of Low Reynolds Number Airfoil Data for Wind Turbine Applications. Department of Aerospace Engineering, Texas A\&M University. College Station, Texas : s.n., 1982.

3. Liebeck, R. and Blackwelder, R. Low Reynolds Number - Separation Bubble. 1987.

4. Simpson, Andrew D. Design and Evaluation of Inflatable Wings for UAVs. University of Kentucky. 2008. Doctoral Dissertation.

5. Low-Reynolds-Number Airfoils. Lissman, P. B. S. Annual Review of Fluid Mecanics, Vol. 15, pp. 223-239.

6. Airfoil Lift Augmentation at Low Reynolds Number. Traub, Lance W. and Akerson, Adrian. 6, 2010, Journal of Aircrafht, Vol. 47.

7. Inflatable and rigidizable wings for unmanned aerial vehicles. Cadogan, David, Graham, William and Smith, Tim. San Diego: AIAA, 2003. 2nd AIAA "Unmanned Unlimited" Systems, Technologies, and Operations Conference.

8. Deflections of an Inflated Circular Cylindrical Cantilever Beam. Comer, R. and Levy, S. 7, s.l. : AIAA, 1963, AIAA Journal, Vol. 1, pp. 1652-1655.

9. Aeroelastic Behaviour of a Non-Rigidizable Inflatable UAV Wing. Rendall, T., et al. s.l. : AIAA. 47th AIAA/ASME/ASCE/AHS/ASC Structures, Structural Dynamics and Materials Conference. AIAA-2006-2161.

10. In-Flight Deployment Dynamics of Inflatable Wings. Ben Loh, Jamey D. Jacob. 2009, American Institute for Aeronautics and Astronautics.

11. Loh, W. Deployment Dynamics of Inflatable Wings. Oklahoma State University. 2008. MS Thesis.

12. Gaddam, Pradeep, Hill, Jeremy and Jacob, Jamey D. Aerostructural Interaction and Optimization of Inflatable Wings. Aerospace Engineering, Oklahoma State University. s.l. : AIAA, 2010. AIAA-2010-4610. 
13. Light Curing Resin Systems for Use in Inflatable Wing Applications. Hoyt-Haight, Andrea E., Harrah, Larry A. and Allred, Ronald E. 2005. Prc. 50th International SAMPE Symphosium and Exhibition.

14. Ground and Flight Evaluation of a Small-Scale Inflatable Winged Aircraft. Murray, J., et al. Reno, NV : s.n., 2002. 40th AIAA Aerospace Sciences Meeting and Exhibit.

15. Fixed Membrane Wings for Micro Air Vehicles: Experimental Characterization, Numerical Modeling, and Tailoring. Stanford, Bret, et al. 4, 2008, Progress in Aerospace Sciences, Vol. 44, pp. 258-294.

16. Prioria Embedded Intelligence. Maveric UAS. [Online] 2012. [Cited: August 29, 2012.] http://www.prioria.com/products/maveric-uas.

17. Applied Research Associates. ARA :: Robotics :: Nighthawk. [Online] 2012. [Cited: August 29, 2012.] http://www.ara.com/robotics/Nighthawk.html.

18. Experimental In-Flight Rolling MAV Wing Deployment and Aerodynamic Characterization. Coffin, Peter, et al. 2, s.l.: SAE International, 2011, SAE International Journal of Aerospace, Vol. 4.

19. Woodland, Richard L.K. Sonotube Compatible Unmanned Aerial Vehicle and System. 6056237 United States, May 2, 2000. United States Patent.

20. Martorana, Richard T, et al. Flyer Assembly. US 2003/0089820 A1 United States of America, May 15, 2003. Patent Application Publication.

21. Spektrum RC. Spektrum - The Leader in Spread Spektrum Technology. [Online] 2013. [Cited: 11 14, 2013.] http://www.spektrumrc.com/default.aspx.

22. Guiler, Richard W. Control of a Swept Wing Tailless Aircraft Through Wing Morphing. Department of Mechanical and Aerospace Engineering, West Virginia University. Morgantown, WV : s.n., 2007. Doctoral Dissertation.

23. Design and Wind-Tunnel Analysis of a Fully Adaptive Aircraft Configuration. Neal, David A., et al. Palm Springs, CA : s.n., 2004. 45th AIAA/ASME/ASCE/AHS/ASC Structures, Structural Dynamics \& Materials Conference. AIAA-2004-1727.

24. Rafael Advanced Defense Systems LTD. FIREFLY, Ground Assault Tactical Intelligence. [Online] 2010. [Cited: August 29, 2012.] http://www.rafael.co.il/marketing/SIP_STORAGE/FILES/0/730.pdf. 
25. Defense Update. FIREFLY - Miniature "Video Grenade". [Online] 2004. [Cited: August 29, 2012.] http://defense-update.com/products/f/Firefly.htm.

26. Aerovironment. Switchblade: UAS Advanced Development. [Online] 2012. [Cited: September 25, 2012.] http://www.avinc.com/uas/adc/switchblade/.

27. Future Solutions - ISR. Grabowsky, John. 2007. Pacific Theater Operational Science and Technology Conference.

28. Aerovironment. Nano Air Vehicle (NAV) - Aerovironment, Inc. (AV). [Online] 2012. [Cited: September 25, 2012.] http://www.avinc.com/nano/.

29. —. Black Widow (UAV): UAS Advanced Development Center - Aerovironment, Inc.

(AV). [Online] 2012. [Cited: September 25, 2012.] http://www.avinc.com/uas/adc/black_widow/.

30. Wind Tunnel Tests of Wings at Reynolds Numbers Below 70000. Laitone, E. V. 1997, Experiments in Fluids, pp. 405-409.

31. BIG BLUE: High-Altitude UAV Demonstrator of Mars Airplane Technology. Simpson, A.D., et al. Crystal City, Va. : s.n., 2005. Aerospace Conference, 2005 IEEE.

32. Behavior and Control of the Deployment Dynamics of Inflatable Wings. Loh, Ben and Jacob, Jamey D. Orlando, FL : AIAA, 2009. 47th AIAA Aerospace Sciences Meeting and Exhibit. AIAA-2009-1291. 


\section{Appendix A: Full Test Plan}

Table A-1 Wind Tunnel Test Plan Configuration Descriptions

\begin{tabular}{|c|c|c|}
\hline \multicolumn{3}{|r|}{ Test Configuration Descriptions } \\
\hline Test 1 & & Fuselage Only \\
\hline Test 2 & & Fuselage \& Tail \\
\hline \multirow{4}{*}{ Test 3} & & Fuselage \& Wings \\
\hline & $\mathrm{a}$ & Solid NACA 0009 \\
\hline & $\mathrm{b}$ & Solid NACA 0009m \\
\hline & c & Membrane NACA 0009m \\
\hline \multirow{4}{*}{ Test 4} & & Fuselage, Wings, \& Tail \\
\hline & a & Solid NACA 0009 \\
\hline & b & Solid NACA 0009m \\
\hline & c & Membrane NACA 0009m \\
\hline \multirow{4}{*}{ Test 5} & & Fuselage \& Wings - High Speed Video \\
\hline & $\mathrm{a}$ & Membrane NACA 0009m \\
\hline & $\mathrm{b}$ & Membrane NACA 0009m w/ non-fully deployed TE element \\
\hline & c & Membrane NACA 0009m w/ non deployed TE element \\
\hline \multirow{3}{*}{ Test 6} & & Fuselage \& Wings - AoA Sweeps \\
\hline & a & Membrane NACA 0009m w/ non-fully deployed TE element \\
\hline & b & Membrane NACA 0009m w/ non deployed TE element \\
\hline
\end{tabular}


Table A-2 Wind Tunnel Test Plan - Run 1

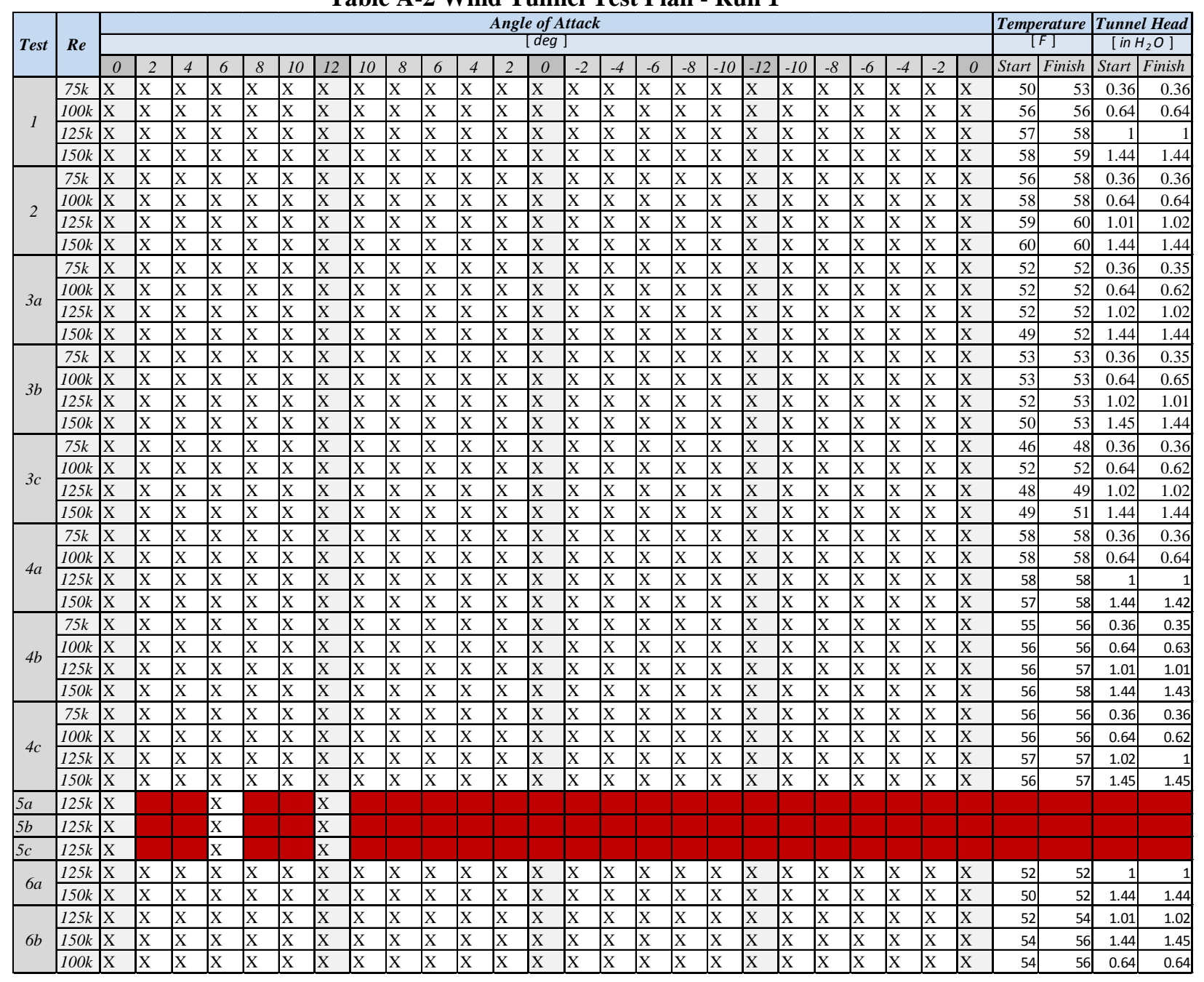


Table A-3 Wind Tunnel Test Plan - Run 2

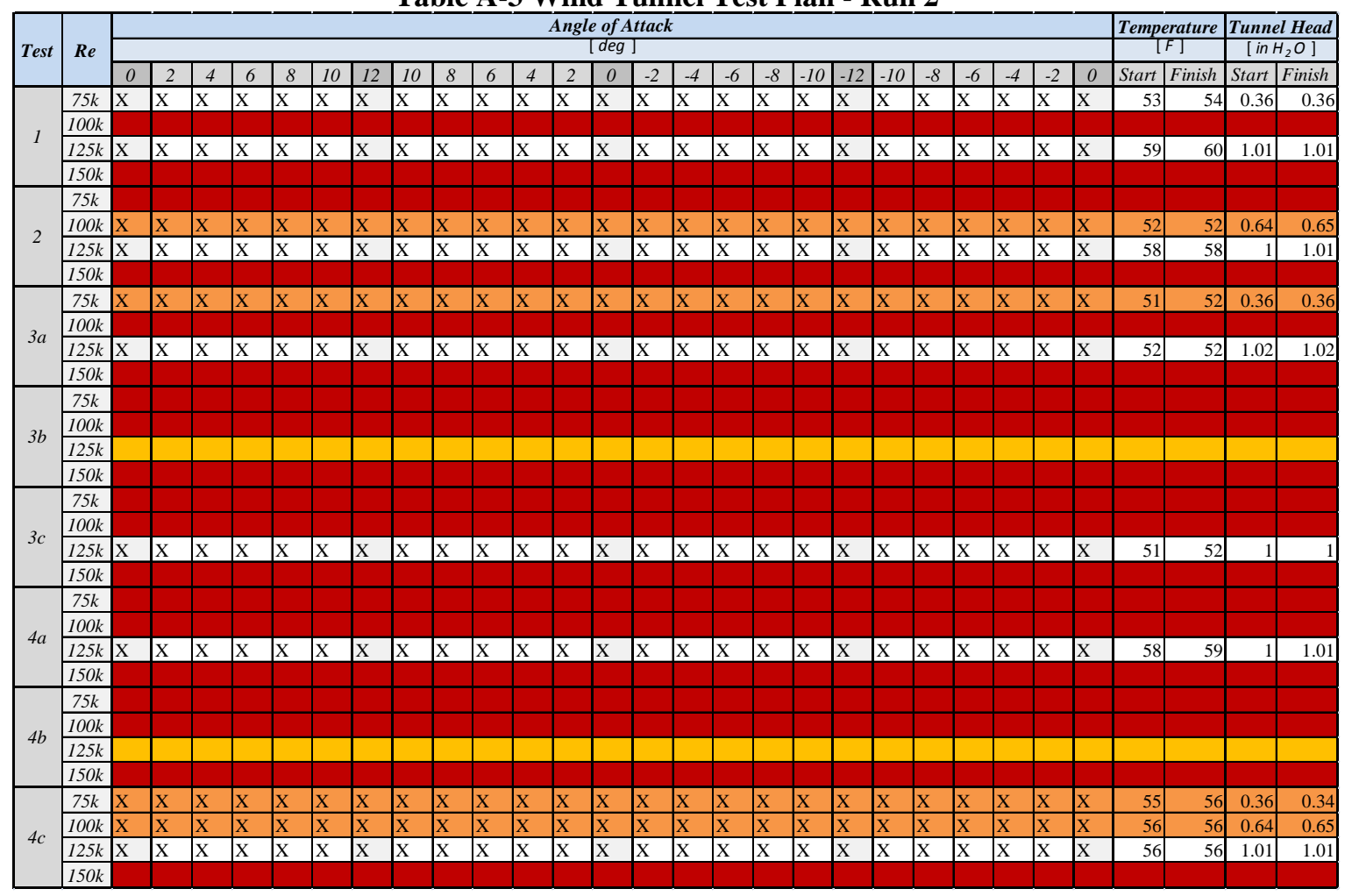

Table A-4 Wind Tunnel Test Plan - Run 3

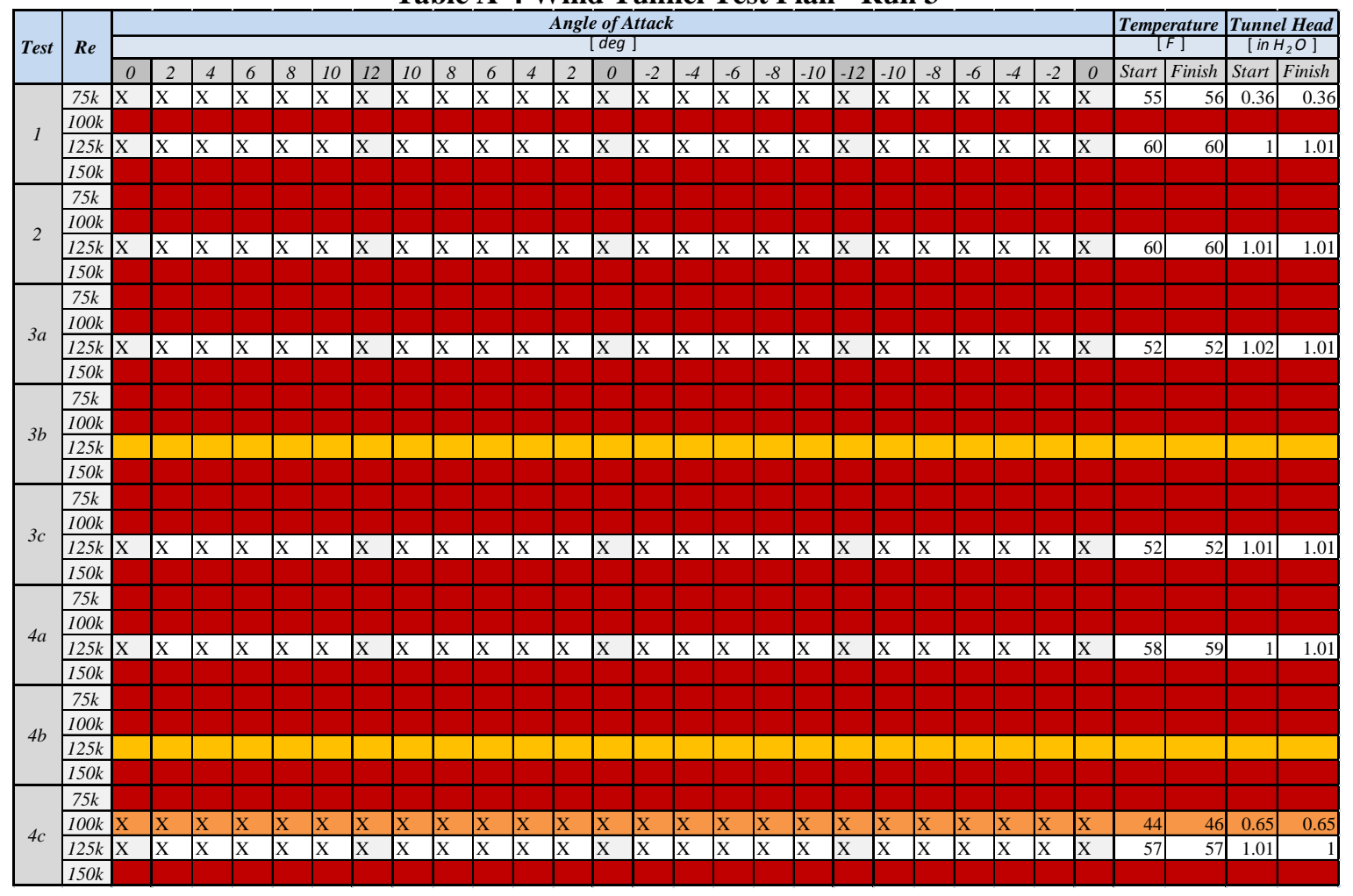




\section{Appendix B: Data Analysis Codes}

\section{Wind Tunnel Data Averaging and Calibration Code}

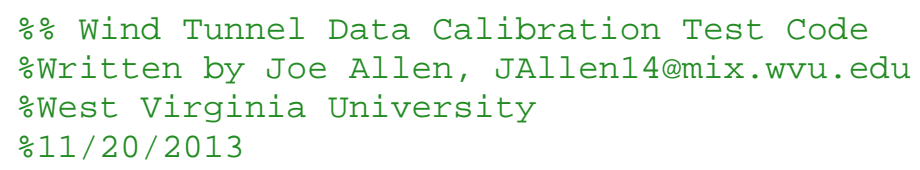




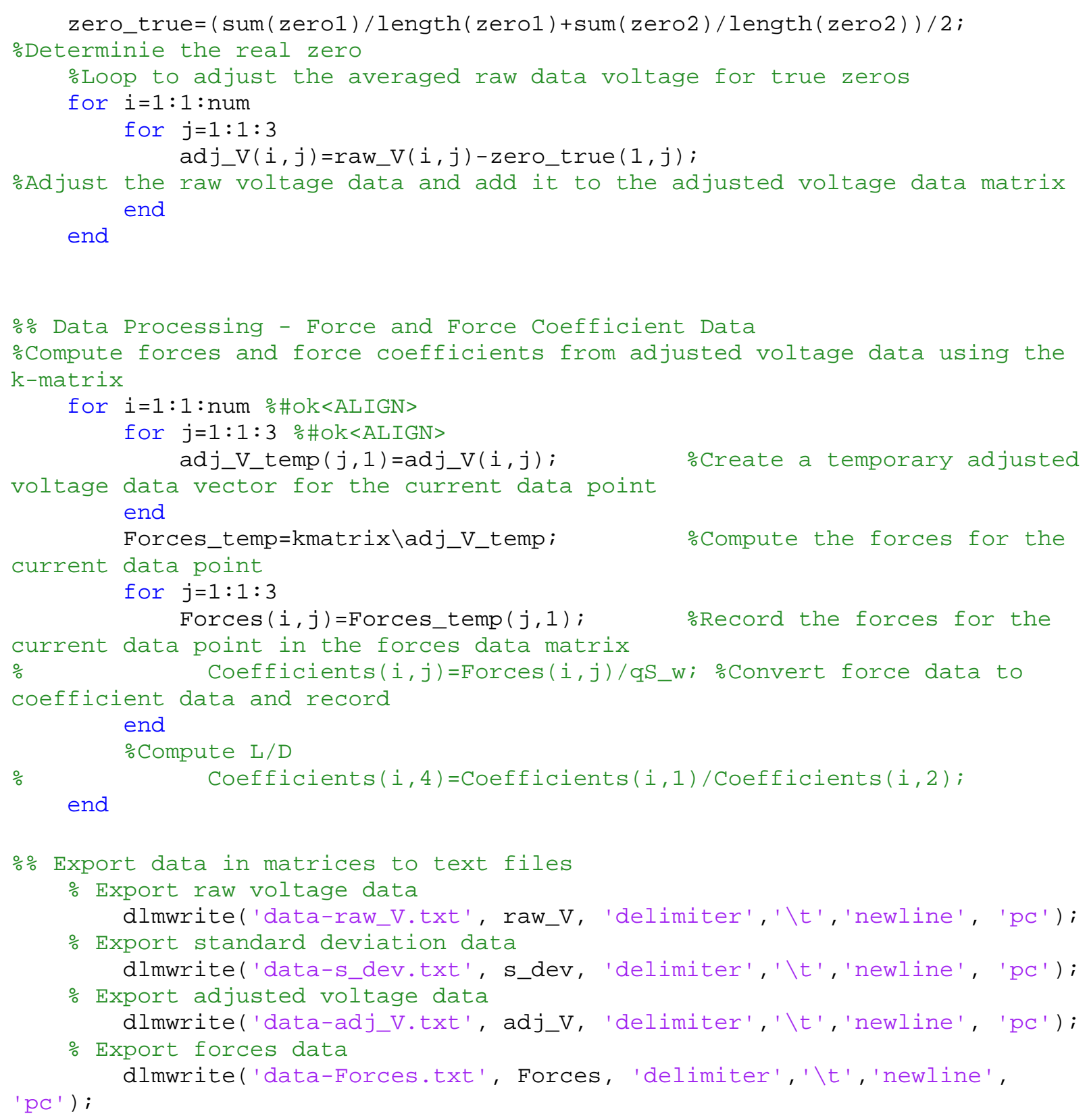

\section{Wind Tunnel Data Averaging and Calibration Test Code}

\%\% Wind Tunnel Data Calibration Test Code

\%Written by Joe Allen, JAllen14@mix.wvu.edu

\%West Virginia University

$\% 11 / 20 / 2013$

$\%$ Housekeeping

clear;

format long $g$;

clc;

\% Description \& Instructions: 
\%This program uses inputs from a user file sequence for 3 load cells to

\%output force data for use in building a mV-Force transformation matrix

$\%$ Instructions:

$\%{ }^{*}$ The working directory must be set to the same directory as the location

of

$\%$ the data files.

$\%{ }^{*}$ One additional text file is needed in the working directory:

$\% \quad+$ k-matrix

$\%$ format: 3 rows, 3 columns of the load cell force transformation

$\% \quad$ matrix

$\%{ }^{*}$ Once all files are in the appropriate locations, run the program and

$\%$ evaluate the quality of the results in Figures 1 - 3

$\%$ Inputs \& Calculation of Fixed Variables

$\%$ Constants

$\mathrm{g}=9.80665$;

$\%\left[\mathrm{~m} / \mathrm{s}^{\wedge} 2\right]$

num=1;

\%Import data from text files

kmatrix=dlmread('k-matrix.txt'); \%[ - ]

$\%$ Data Processing - Raw data

\% Import and average the raw voltage data

for $i=1: 1:$ num

fn_ip=sprintf('\%d.lvm',i); $\quad$ \%Iterate to the file to import

$M=d l m r e a d\left(f n \_i p\right)$;

\%Import the file

s_dev $(i, 1: 3)=\operatorname{std}(M)$;

\%Compute the standard deviation of the

raw voltage data

data_point=sum(M)/length(M); \%Find the average of the raw voltage data

for $j=1: 1: 3$

matrix

raw_V $(i, j)=$ data_point $(1, j) ; \%$ Add the result to the raw voltage data

end

end

\% Adjust the averaged raw voltage data for zeros zero1=dlmread ( '०. lvm');

\%Read

the initial zero load values

zero2=dlmread ( '००. lvm');

\%Read

the final zero load values zero_true $=(\operatorname{sum}($ zero1 $) /$ length $($ zero1 $)+\operatorname{sum}($ zero2 $) /$ length $($ zero2 $)) / 2$;

\%Determinie the real zero

\%Loop to adjust the averaged raw data voltage for true zeros

for $i=1: 1:$ num

for $j=1: 1: 3$

adj_V $(i, j)=r a w \_V(i, j)-\operatorname{zero} \_t r u e(1, j)$;

\%Adjust the raw voltage data and add it to the adjusted voltage data matrix end

end

$\%$ Data Processing - Force and Force Coefficient Data

\%Compute forces and force coefficients from adjusted voltage data using the

k-matrix

for $i=1: 1:$ num $\% \#$ ok<ALIGN>

for $j=1: 1: 3 \% \#$ ok<ALIGN> 


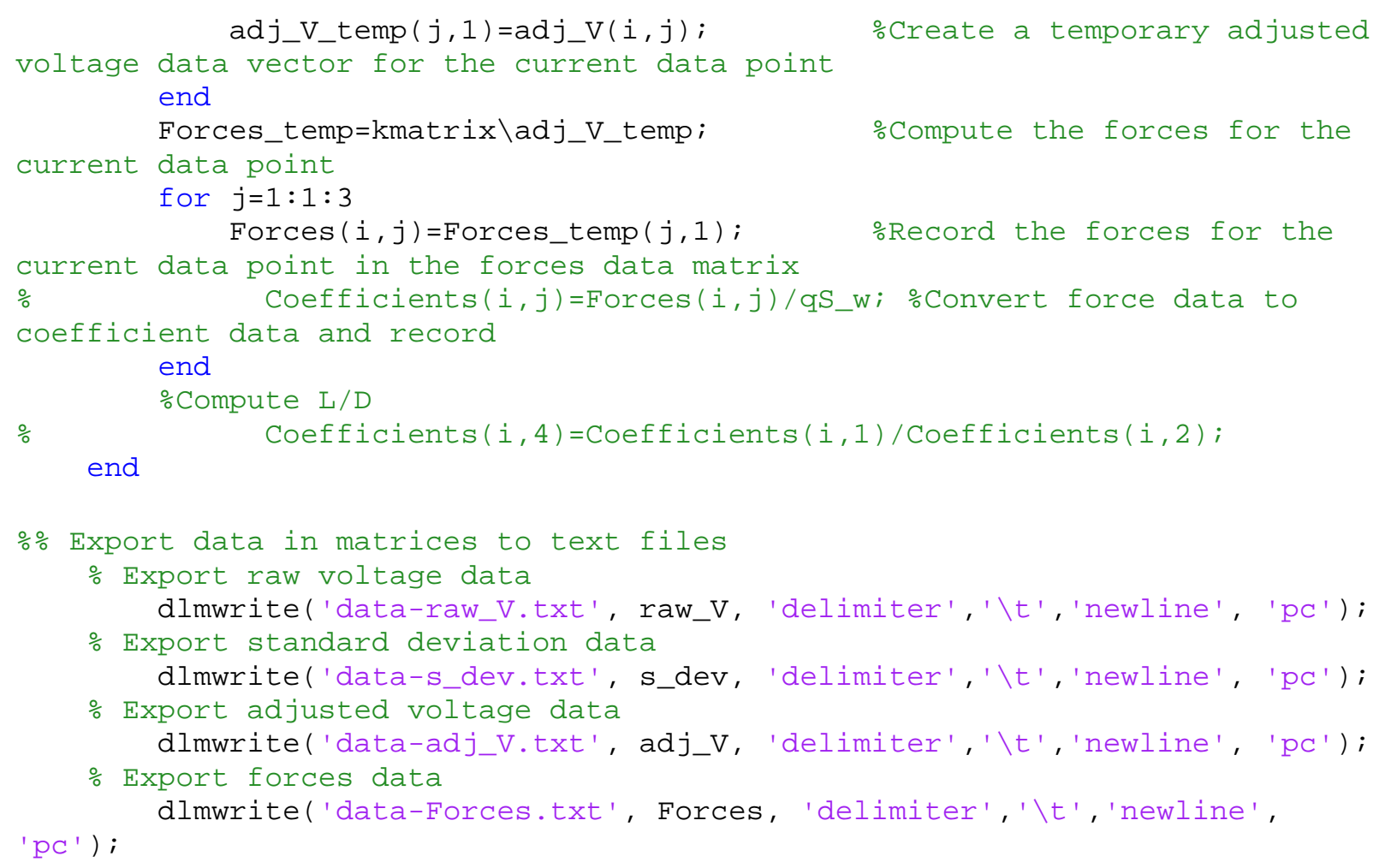

\section{Wind Tunnel Data Averaging and Force Computation Code}

$\% \%$ Wind Tunnel Data Processing Code

\%Written by Joe Allen, JAllen14@mix.wvu.edu

\%West Virginia University

$\% 11 / 19 / 2013$

$\% \%$ Housekeeping

clear;

format long $g$;

clc;

$\%$ Description \& Instructions:

\%This program uses inputs from a user file sequence for 3 load cells to \%output force and coefficient data using a k-matrix developed during \%calibration.

$\%$ Instructions:

$\%{ }^{* *}$ The working directory must be set to the same directory as the location of 


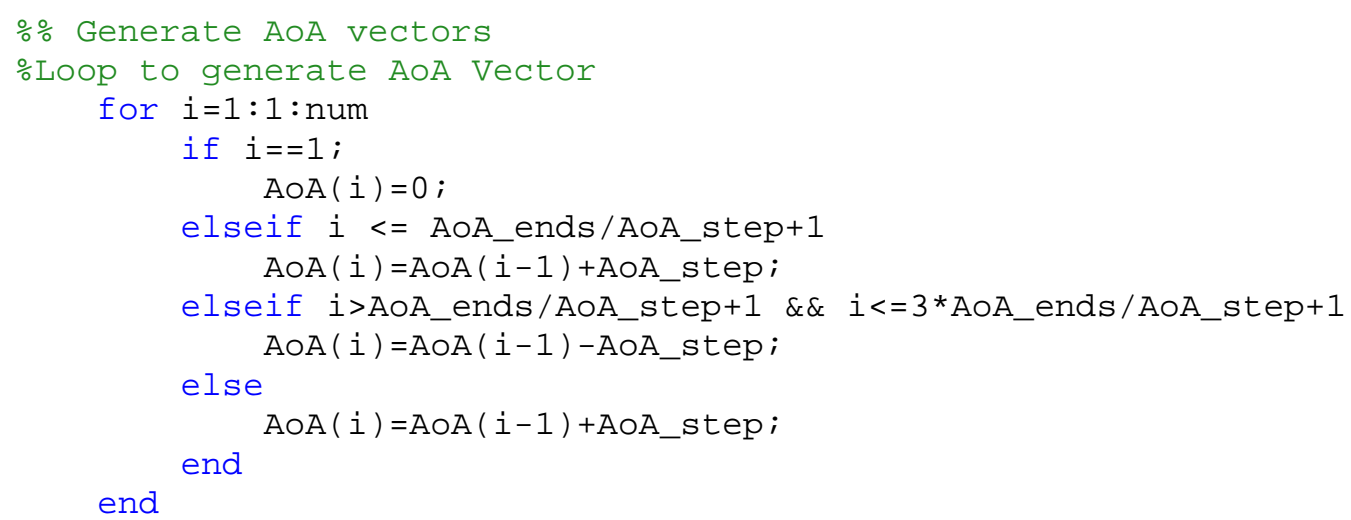


$\operatorname{adj} v_{-} t \operatorname{temp}(j, 1)=\operatorname{adj} v(i, j)$;

voltage data vector for the current data point end

Forces_temp=kmatrix \adj_v_temp;

current data point

for $j=1: 1: 3$

$\operatorname{Forces}(i, j)=$ Forces_temp $(j, 1)$;

current data point in the forces data matrix

Coefficients $(i, j)=$ Forces $(i, j) / q s \_w$; \%Convert force data to

coefficient data and record

end

\%Compute L/D

end

\%Average neccessary force and coefficient data according to AoA data to

\%have 1 set of AoA data

for i=1:1:length(AoA_avg);

Forces_temp $=0$;

Coeff_temp $=0$;

count $=0$;

for $j=1: 1:$ length $(A \circ A)$;

if $\operatorname{AoA}(j)==A o A \_a v g(i)$

Forces_temp=Forces_temp+Forces $(j, 1: 3)$;

Coeff_temp=Coeff_temp+Coefficients $(j, 1: 4)$; count $=$ count +1 ;

end

end

Forces_avg $(i, 1: 3)=$ Forces_temp/count ;

end

Coeff_avg $(i, 1: 4)=$ Coeff_temp/count ;

\%\% Export data in matrices to text files

\% Export raw voltage data

dlmwrite('data-raw_V.txt', raw_v, 'delimiter', '\t', 'newline', 'pc');

$\%$ Export standard deviation data

dlmwrite('data-s_dev.txt', s_dev, 'delimiter', '\t', 'newline', 'pc');

\% Export adjusted voltage data

dlmwrite('data-adj_V.txt', adj_v, 'delimiter','\t', 'newline', 'pc');

\% Export forces data

'pc'); dlmwrite('data-Forces.

dlmwrite('data-Coefficients.txt', Coefficients,

'delimiter', '\t', 'newline', 'pc');

\% Export experiment AoA vector

dlmwrite('data-AoA.txt', AoA, 'delimiter', '\t','newline', 'pc');

\% Export averaged AoA vector dlmwrite('data-AoA_avg.txt', AoA_avg, 'delimiter','\t','newline', ' $\left.p c^{\prime}\right) ;$

\% Export averaged AoA vector with true zero offset

dlmwrite('data-AoA_os_avg.txt', AoA_os_avg,

'delimiter','\t', 'newline', 'pc');

\% Export averaged Forces data 


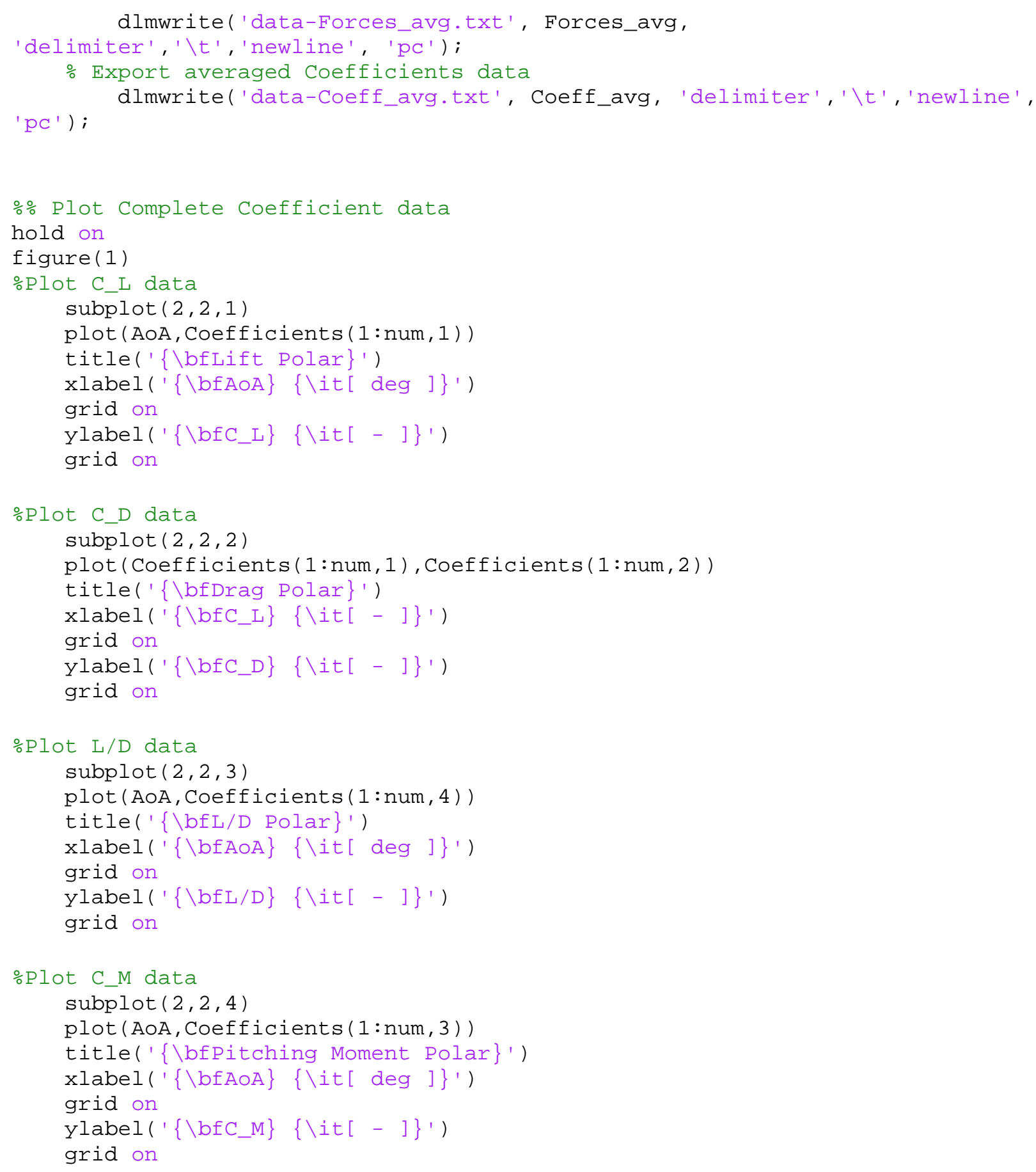




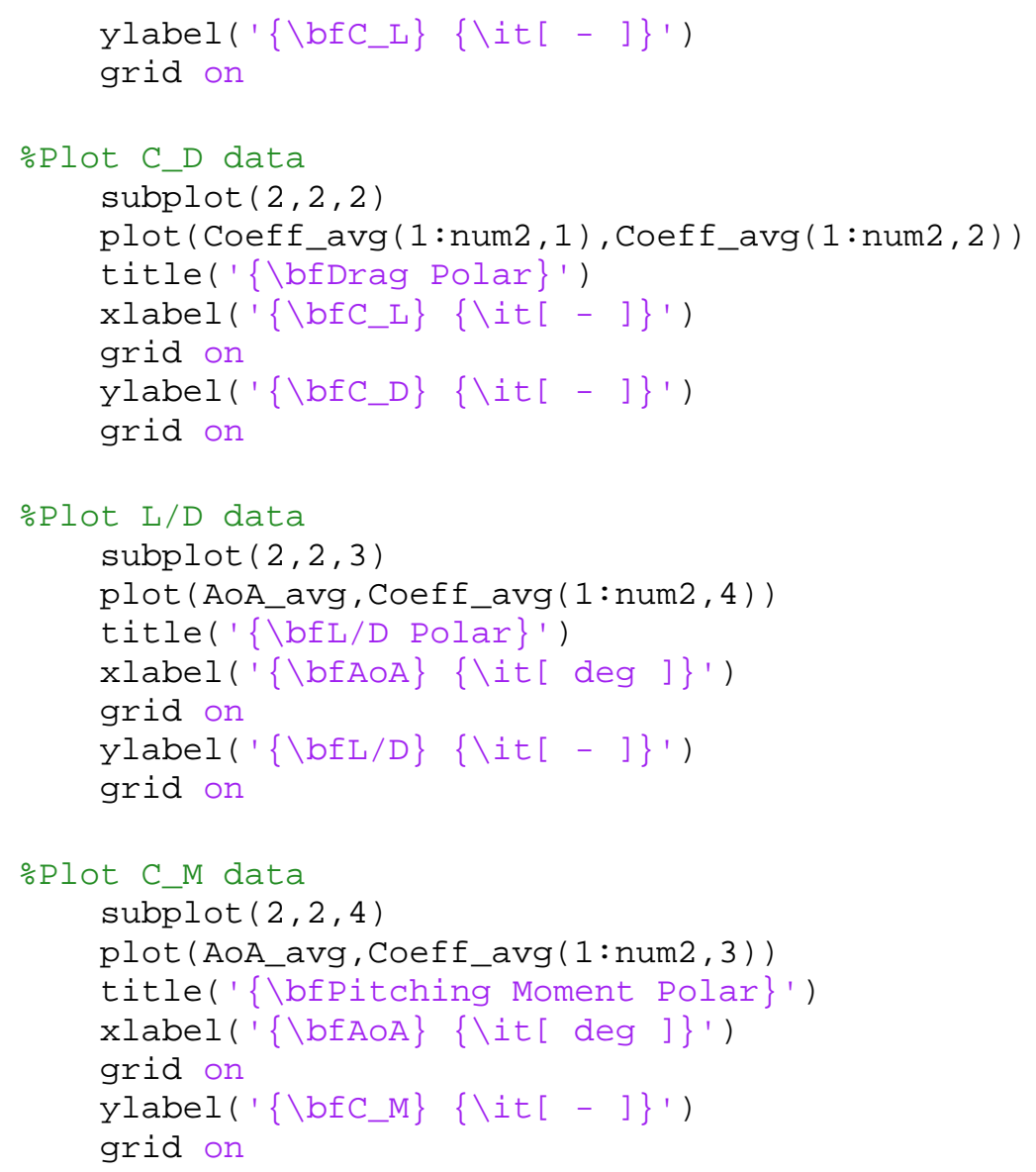




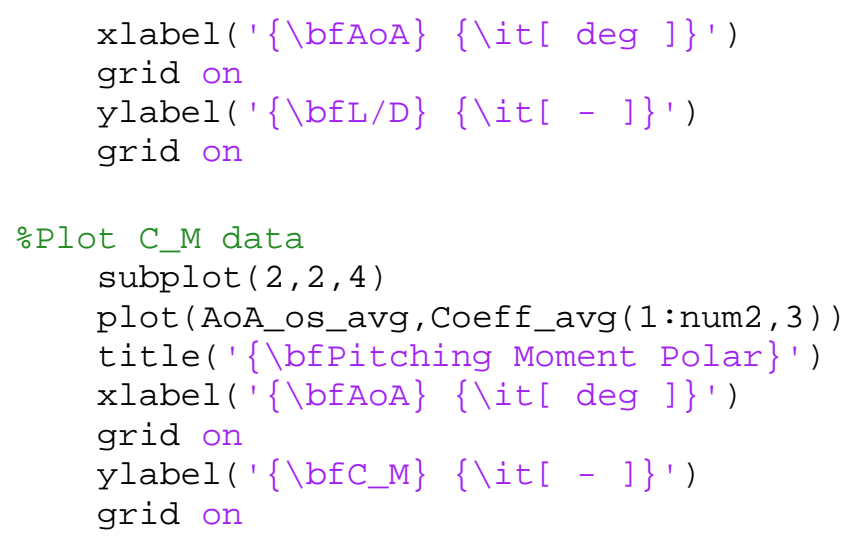




\section{Appendix C: Method for Forming and Application of Membrane Wing Skins}

The method developed to form and apply the membrane wing skin for the folding SolidMembrane wing mechanism presented herein primarily utilizes a cut pattern and a waxed mould along with Cyanoacrylate adhesives (CA). The steps to follow to skin one wing half (left or right) are outlined below.

1. Apply and buff a light coat of car wax or a spray on mould release to the male wing mould.

2. Prepare the wing skin material

a. Lay down the cutting pattern onto the membrane material (ripstop nylon in this case) and tape down the pattern to the material with a transparent tape. A sample cutting pattern is presented in Figure C-1.

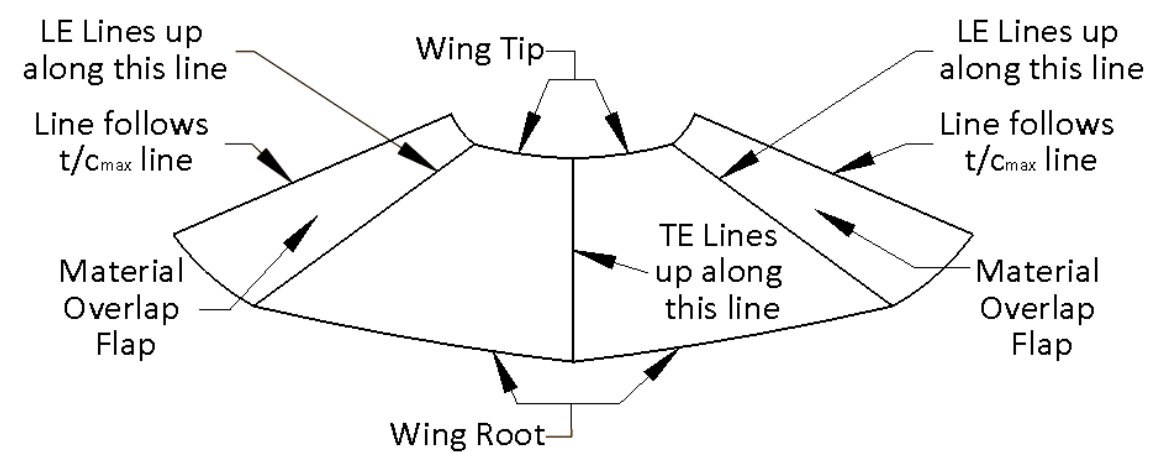

Figure C-1 Sample Membrane Wing Skin Material Pattern (Not to Scale)

b. Using a sharp blade (x-acto style hobby blade, single sided razor blade, etc.) cut out the material by tracing the edges of the pattern. Use a straight edge for the straight lines of the pattern if desired.

3. Form the wing skin

a. Using a few small drops of medium CA, lightly tack the membrane skin onto the mould so that the wing can be wrapped starting on the upper surface at the maximum thickness line around the LE, the lower surface, the TE, and back around the LE.

b. Pull the wing skin so there are no wrinkles and the skin is smoothly wrapped around the mould.

c. Once the skin has been wrapped entirely around the wing mould as described, peel back $6 \mathrm{~mm}$ of material and lay down a thin bead of medium CA along the lower surface of the wing skin where the material overlaps. 
d. Lay the material back down and smooth it out.

e. Quickly wipe away any CA that oozes from the seam.

f. Wait a few minutes and wait for the CA to fully dry.

4. Remove the completed wing skin from the mould.

a. Using a strip of paper or card stock, feed a thin string (fishing line works well) spanwise on the lower surface between the wing skin and the mold.

b. Pull the string towards and around the leading edge and then towards the trailing edge breaking the CA tack points in step 3a.

c. Slide the wing skin off of the mould.

5. Apply the wing skin to the Solid-Membrane wing mechanism

a. Remove the LE element from the mechanism

b. Test fit the skin to the LE element

c. Remove the skin and lay a thin bead of medium CA along the LE of the LE element and just forward of the maximum thickness locations on the upper and lower surface.

d. Evenly spread the CA along the outer surface of the leading edge element as quickly as possible.

e. Carefully slide and position the wing skin over the LE element and work the skin onto the leading edge element bonding it to the LE element. Be careful to properly align the LE, root, and tip sections.

f. Reinstall the LE element to the mechanism. While doing so, make sure to slide the membrane skin over the TE element (the carbon tube over the spring)

g. Bond only the root of the membrane skin to the TE element with a thin drop of CA to prevent the TE of the skin from sliding out along the TE during deployment. Make sure the root of the TE is positioned so as to not induce wrinkles in the membrane skin.

6. Fold and test the deployment of the wing. 


\section{Appendix D: Three-Component Balance Calibration}

Before data could be collected, the signals from the balance of the experimental setup needed to be calibrated using know forces so the experimental data could be interpreted. In order to complete the calibration, pure loads were applied to the model and the resulting signals from each load cell was recorded using the DAQ system. This data was then used to generate the calibration curves and the k-matrix.

After the calibration curves and k-matrix were generated, known uni-directional loads as well as combined loads were applied to the model to validate the calibration. Upon successful validation, data collection could begin. The k-matrix and resulting validated calibration curves are presented below in Table D-1 and Figure D-1, respectively.

Table D-1 Derived k-matrix from load cell calibration

\begin{tabular}{|c|c|c|c|}
\hline \multicolumn{4}{|c|}{ K-Matrix } \\
\hline & L & D & M \\
\hline L1 & $-5.14 \mathrm{E}-05$ & -0.000323 & -0.000357 \\
\hline L2 & 4.64E-05 & -0.000303 & -0.000382 \\
\hline D1 & $-3.54 \mathrm{E}-06$ & 0.000569 & $-2.91 \mathrm{E}-05$ \\
\hline
\end{tabular}

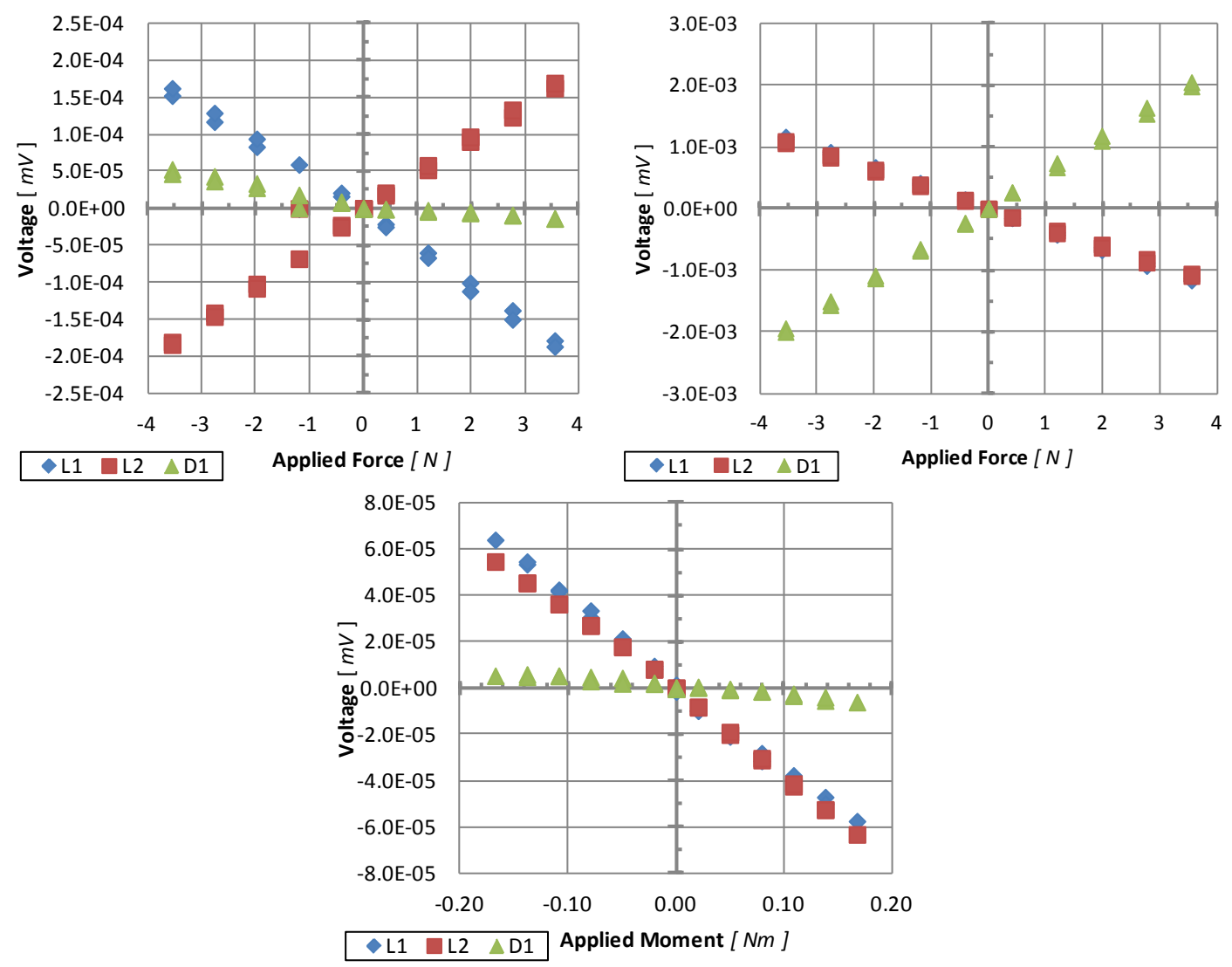

Figure D-1 Lift (top left), Drag (top right), and Moment (bottom) Load Cell Calibration Curves 


\section{Appendix E: Uncertainty Analysis}

The general equation to determine the uncertainty of a calculated value is shown in Equation E-1.

$$
\frac{U_{x}}{f(x)}=\sqrt{\sum_{i=1}^{n}\left(\frac{1}{f(x)} \frac{\partial f(x)}{\partial y_{i}} \omega_{y_{i}}\right)^{2}}
$$

where $U_{x}$ is the uncertainty in the calculation of a value, $f(x)$ is the equation used to calculate

the value, $\frac{\partial f(x)}{\partial y_{i}}$ is the partial derivative of $f(x)$ with respect to the measured value $y$, and $\omega_{y_{i}}$ is the instrument error in finding the value of $y$.

For this research, the three calculated parameters affected by uncertainty include the lift coefficient $\left(\mathrm{C}_{\mathrm{L}}\right)$, the drag coefficient $\left(\mathrm{C}_{\mathrm{D}}\right)$, and the $\mathrm{L} / \mathrm{D}$. Equations for each are presented below as Equation E-2 through Equation E-4.

$$
\begin{gathered}
C_{L}=\frac{\mathrm{L}}{\mathrm{h}_{\mathrm{w}} \rho_{\mathrm{w}} \mathrm{gbc}_{\mathrm{MAC}}} \\
C_{D}=\frac{\mathrm{D}}{\mathrm{h}_{\mathrm{w}} \rho_{\mathrm{w}} \mathrm{gbc}_{\mathrm{MAC}}} \\
\frac{\mathrm{L}}{\mathrm{D}}=\frac{C_{L}}{C_{D}}=\frac{\frac{\mathrm{L}}{\mathrm{h}_{\mathrm{w}} \rho_{\mathrm{w}} \mathrm{gbc}_{\mathrm{MAC}}}}{\frac{\mathrm{D}}{\mathrm{h}_{\mathrm{w}} \rho_{\mathrm{w}} \mathrm{gbc}_{\mathrm{MAC}}}}
\end{gathered}
$$

Equation E-2

Equation E-3

Equation E-4

where $L$ is the lift, $h_{w}$ is the tunnel head pressure, $\rho_{w}$ is the water density, $g$ is the gravitational acceleration constant on Earth, $\mathrm{b}$ is the wing span, $c_{M A C}$ is the mean aerodynamic chord of the wing, and $D$ is the drag.

For the research presented, major sources of error in calculating the lift and drag coefficients and the L/D values are:

- Tunnel Head Pressure Manometer (increments of 0.02 in $\mathrm{H}_{2} \mathrm{O}$ ) to determine $\mathrm{h}_{\mathrm{w}}$

- Calipers (increments of $0.01 \mathrm{~mm}$ )) to determine $\mathrm{b}$ and $\mathrm{c}_{\mathrm{MAC}}$.

- Density of water ( $0.2 \%$ variability over the Temperature range during testing) to determine specific weight of water.

- $\quad$ Error in the lift and drag forces $(\approx 5.0 \%$ for lift, $\approx 7.0 \%$ for drag)

Accounting for the major sources of error and applying them to the general form of the uncertainty equation presented in Equation E-1 results in the development of the complete 
uncertainty equation for lift, Equation E-5, for the data collected in this research. Further simplification yields the final lift uncertainty equation presented as Equation E-6. The uncertainty equation for drag is similar to the lift uncertainty equation and is thus not presented below in detail. The Uncertainty equation used for determining the $\mathrm{L} / \mathrm{D}$ is derived as Equation E-7 and presented in its final form as Equation E-8.

$$
\frac{U_{x}}{f(x)}=\sqrt{\mathrm{u}_{1}+\mathrm{u}_{2}+\mathrm{u}_{3}+\mathrm{u}_{4}+\mathrm{u}_{5}}
$$

where:

$$
\begin{aligned}
& \mathrm{u}_{1}=\left(\frac{\mathrm{h}_{\mathrm{w}} \rho_{\mathrm{w}} \mathrm{gbc}_{\mathrm{MAC}}}{\mathrm{L}} \frac{\partial}{\partial \mathrm{h}_{\mathrm{w}}}\left(\frac{\mathrm{L}}{\mathrm{h}_{\mathrm{w}} \rho_{\mathrm{w}} \mathrm{gbc}_{\mathrm{MAC}}}\right) \omega_{\mathrm{h}_{\mathrm{w}}}\right)^{2} \\
& =\left(\frac{\mathrm{h}_{\mathrm{w}} \rho_{\mathrm{w}} \mathrm{gbc}_{\mathrm{MAC}}}{\mathrm{L}} \frac{-\mathrm{L}}{\mathrm{h}_{\mathrm{w}}{ }^{2} \rho_{\mathrm{w}} \mathrm{gbc}_{\mathrm{MAC}}} \omega_{\mathrm{h}_{\mathrm{w}}}\right)^{2}=\left(\frac{\omega_{\mathrm{h}_{\mathrm{w}}}}{\mathrm{h}_{\mathrm{w}}}\right)^{2} \\
& \mathrm{u}_{2}=\left(\frac{\mathrm{h}_{\mathrm{w}} \rho_{\mathrm{w}} \mathrm{gbc}_{\mathrm{MAC}}}{\mathrm{L}} \frac{\partial}{\partial \mathrm{b}}\left(\frac{\mathrm{L}}{\mathrm{h}_{\mathrm{w}} \rho_{\mathrm{w}} \mathrm{gbc}_{\mathrm{MAC}}}\right) \omega_{\mathrm{b}}\right)^{2} \\
& =\left(\frac{\mathrm{h}_{\mathrm{w}} \rho_{\mathrm{w}} \mathrm{gbc}_{\mathrm{MAC}}}{\mathrm{L}} \frac{-\mathrm{L}}{\mathrm{h}_{\mathrm{w}} \rho_{\mathrm{w}} \mathrm{gb}^{2} \mathrm{c}_{\mathrm{MAC}}} \omega_{\mathrm{b}}\right)^{2}=\left(\frac{\omega_{\mathrm{b}}}{\mathrm{b}}\right)^{2} \\
& \mathrm{u}_{3}=\left(\frac{\mathrm{h}_{\mathrm{w}} \rho_{\mathrm{w}} \mathrm{gbc}_{\mathrm{MAC}}}{\mathrm{L}} \frac{\partial}{\partial \mathrm{c}_{\mathrm{MAC}}}\left(\frac{\mathrm{L}}{\mathrm{h}_{\mathrm{w}} \rho_{\mathrm{w}} \mathrm{gbc}_{\mathrm{MAC}}}\right) \omega_{\mathrm{c}_{\mathrm{MAC}}}\right)^{2} \\
& =\left(\frac{\mathrm{h}_{\mathrm{w}} \rho_{\mathrm{w}} \mathrm{gbc}_{\mathrm{MAC}}}{\mathrm{L}} \frac{-\mathrm{L}}{\mathrm{h}_{\mathrm{w}} \rho_{\mathrm{w}} \mathrm{gbc}_{\mathrm{MAC}}{ }^{2}} \omega_{\mathrm{c}_{\mathrm{MAC}}}\right)^{2} \\
& =\left(\frac{\omega_{\mathrm{c}_{\mathrm{MAC}}}}{\mathrm{c}_{\mathrm{MAC}}}\right)^{2} \\
& \mathrm{u}_{4}=\left(\frac{\mathrm{h}_{\mathrm{w}} \rho_{\mathrm{w}} \mathrm{gbc}_{\mathrm{MAC}}}{\mathrm{L}} \frac{\partial}{\partial \rho_{\mathrm{w}}}\left(\frac{\mathrm{L}}{\mathrm{h}_{\mathrm{w}} \rho_{\mathrm{w}} \mathrm{gbc}_{\mathrm{MAC}}}\right) \omega_{\rho_{\mathrm{w}}}\right)^{2} \\
& =\left(\frac{\mathrm{h}_{\mathrm{w}} \rho_{\mathrm{w}} \mathrm{gbc}_{\mathrm{MAC}}}{\mathrm{L}} \frac{-\mathrm{L}}{\mathrm{h}_{\mathrm{w}} \rho_{\mathrm{w}}{ }^{2} \mathrm{gbc}_{\mathrm{MAC}}} \omega_{\rho_{\mathrm{w}}}\right)^{2}=\left(\frac{\omega_{\rho_{\mathrm{w}}}}{\rho_{\mathrm{w}}}\right)^{2} \\
& \mathrm{u}_{5}=\left(\frac{\mathrm{h}_{\mathrm{w}} \rho_{\mathrm{w}} \mathrm{gbc}_{\mathrm{MAC}}}{\mathrm{L}} \frac{\partial}{\partial \mathrm{F}_{\mathrm{L}}}\left(\frac{\mathrm{L}}{\mathrm{h}_{\mathrm{w}} \rho_{\mathrm{w}} \mathrm{gbc}_{\mathrm{MAC}}}\right) \omega_{\mathrm{F}_{\mathrm{L}}}\right)^{2} \\
& =\left(\frac{\mathrm{h}_{\mathrm{w}} \rho_{\mathrm{w}} \mathrm{gbc}_{\mathrm{MAC}}}{\mathrm{L}} \frac{1}{\mathrm{~h}_{\mathrm{w}} \rho_{\mathrm{w}} \mathrm{gbc}_{\mathrm{MAC}}} \omega_{\rho_{\mathrm{w}}}\right)^{2}=\left(\frac{\omega_{\mathrm{F}_{\mathrm{L}}}}{\mathrm{L}}\right)^{2} \\
& \frac{U_{C_{L}}}{C_{L}}=\sqrt{\left(\frac{\omega_{\mathrm{h}_{\mathrm{w}}}}{\mathrm{h}_{\mathrm{w}}}\right)^{2}+\left(\frac{\omega_{\mathrm{b}}}{\mathrm{b}}\right)^{2}+\left(\frac{\omega_{\mathrm{c}_{\mathrm{MAC}}}}{\mathrm{c}_{\mathrm{MAC}}}\right)^{2}+\left(\frac{\omega_{\rho_{\mathrm{w}}}}{\rho_{\mathrm{w}}}\right)^{2}+\left(\frac{\omega_{\mathrm{F}_{\mathrm{L}}}}{\mathrm{L}}\right)^{2}}
\end{aligned}
$$

Equation E-5

Equation E-6 


$$
\frac{U_{x}}{f(x)}=\sqrt{\mathrm{u}_{1}+\mathrm{u}_{2}}
$$

where:

$$
\begin{gathered}
\mathrm{u}_{1}=\left(\frac{\mathrm{D}}{\mathrm{L}} \frac{\partial}{\partial \mathrm{L}}\left(\frac{\mathrm{L}}{\mathrm{D}}\right) \omega_{\mathrm{F}_{\mathrm{L}}}\right)^{2}=\left(\frac{\mathrm{D}}{\mathrm{L}} \frac{1}{\mathrm{D}} \omega_{\mathrm{F}_{\mathrm{L}}}\right)^{2}=\left(\frac{\omega_{\mathrm{F}_{\mathrm{L}}}}{\mathrm{L}}\right)^{2} \\
\mathrm{u}_{1}=\left(\frac{\mathrm{D}}{\mathrm{L}} \frac{\partial}{\partial \mathrm{D}}\left(\frac{\mathrm{L}}{\mathrm{D}}\right) \omega_{\mathrm{F}_{\mathrm{D}}}\right)^{2}=\left(\frac{\mathrm{D}}{\mathrm{L}} \frac{-\mathrm{L}}{\mathrm{D}^{2}} \omega_{\mathrm{F}_{\mathrm{D}}}\right)^{2}=\left(\frac{-\omega_{\mathrm{F}_{\mathrm{D}}}}{\mathrm{D}}\right)^{2} \\
\frac{U_{L} / D}{\mathrm{~L} / \mathrm{D}}=\sqrt{\left(\frac{\omega_{\mathrm{F}_{\mathrm{L}}}}{\mathrm{L}}\right)^{2}+\left(\frac{-\omega_{\mathrm{F}_{\mathrm{D}}}}{\mathrm{D}}\right)^{2}}
\end{gathered}
$$

The values used for each necessary parameter during the Uncertainty Analysis using Equation E-6 and Equation E-8 are presented below in Table E-1. Values for the water density were assumed to have only a $0.20 \%$ precision error based on the resistance to changes in water density over the temperature ranges $\left(9-13^{\circ} \mathrm{C}\right)$ at which testing occurred. Lift and drag force error percentages were estimated using the maximum error returned from validation of the calibration data and k-matrix. During the validation of the k-matrix from calibration, the maximum recorded error in lift was $4.7 \%$ (rounded to 5.0\%) and the maximum recorded error in drag was 6.9\% (rounded to $7.0 \%$ ).

Upon determining the individual $\mathrm{u}_{\mathrm{x}}$ values in Equation E-5 and Equation E-7 necessary to compute the uncertainty of the lift and drag coefficients as well as the $\mathrm{L} / \mathrm{D}$, the uncertainties for the data at each Re were calculated and are shown in Table E-2. The resulting uncertainties are within the acceptable bounds for experimentally collected data. It would be possible to reduce the uncertainties further by producing additional calibration curves with a higher resolution at lower force values. 
Table E-1 Parameter Values Used in Uncertainty Analysis

\begin{tabular}{|c|c|c|c|c|}
\hline Parameter & $\begin{array}{l}\text { Measured } \\
\text { Value }\end{array}$ & Unit & $\begin{array}{l}\text { Value } \\
\text { Used }\end{array}$ & Unit \\
\hline $\mathrm{b}$ & 118.40 & {$[\mathrm{~mm}]$} & 0.11840 & {$[m]$} \\
\hline $\mathrm{C}_{\mathrm{MAC}}$ & 88.97 & {$[\mathrm{~mm}]$} & 0.08897 & {$[m]$} \\
\hline$\rho_{\mathrm{w}}$ & - & {$[-]$} & 998.20000 & {$\left[\mathrm{~kg} / \mathrm{m}^{3}\right]$} \\
\hline $\mathrm{h}_{\mathrm{w}, \mathrm{Re}}=75,000$ & 0.36 & [ in $\mathrm{H}_{2} \mathrm{O}$ ] & 0.00914 & {$\left[\mathrm{~m} \mathrm{H}_{2} \mathrm{O}\right]$} \\
\hline$h_{w, R e}=100,000$ & 0.64 & [ in $\mathrm{H}_{2} \mathrm{O}$ ] & 0.01626 & {$\left[\mathrm{~m} \mathrm{H}_{2} \mathrm{O}\right]$} \\
\hline $\mathrm{h}_{\mathrm{w}, \mathrm{Re}=150,000}$ & 1.00 & [ in $\left.\mathrm{H}_{2} \mathrm{O}\right]$ & 0.02540 & {$\left[\mathrm{~m} \mathrm{H}_{2} \mathrm{O}\right]$} \\
\hline $\mathrm{h}_{\mathrm{w}, \mathrm{Re}=125,000}$ & 1.42 & [ in $\mathrm{H}_{2} \mathrm{O}$ ] & 0.03607 & {$\left[\mathrm{~m} \mathrm{H}_{2} \mathrm{O}\right]$} \\
\hline $\mathrm{h}_{\mathrm{w}, \mathrm{Re}=250,000}$ & 3.96 & [ in $\mathrm{H}_{2} \mathrm{O}$ ] & 0.10058 & {$\left[\mathrm{~m} \mathrm{H}_{2} \mathrm{O}\right]$} \\
\hline$\omega_{\mathrm{h}, \mathrm{w}}$ & 0.01 & [ in $\mathrm{H}_{2} \mathrm{O}$ ] & 0.00025 & {$\left[\mathrm{~m} \mathrm{H}_{2} \mathrm{O}\right]$} \\
\hline$\omega_{\mathrm{c}, \mathrm{MAC}}$ & 0.01 & {$[\mathrm{~mm}]$} & 0.00001 & {$[m]$} \\
\hline$\omega_{\mathrm{b}}$ & 0.01 & {$[\mathrm{~mm}]$} & 0.00001 & {$[m]$} \\
\hline$\omega_{\rho, \mathrm{w}}$ & 0.02 & [ \% ] & 1.99640 & {$\left[\mathrm{~kg} / \mathrm{m}^{3}\right]$} \\
\hline$\omega_{\mathrm{F}, \mathrm{L}}$ & $5.0 \%$ & {$[-]$} & 0.07350 & {$[N]$} \\
\hline$\omega_{\mathrm{F}, \mathrm{D}}$ & $7.0 \%$ & {$[-]$} & 0.19880 & {$[N]$} \\
\hline
\end{tabular}

Table E-2 Experimental Measurement Uncertainty

\begin{tabular}{|c|c|c|c|}
\hline \multirow{2}{*}{$\operatorname{Re}$} & \multicolumn{3}{|c|}{ \% Uncertainty } \\
\cline { 2 - 4 } & CL & CD & L/D \\
\hline 75000 & $5.72 \%$ & $7.53 \%$ & $8.60 \%$ \\
\hline 100000 & $5.24 \%$ & $7.18 \%$ & $8.60 \%$ \\
\hline 125000 & $5.10 \%$ & $7.07 \%$ & $8.60 \%$ \\
\hline 150000 & $5.05 \%$ & $7.04 \%$ & $8.60 \%$ \\
\hline 250000 & $5.01 \%$ & $7.01 \%$ & $8.60 \%$ \\
\hline
\end{tabular}




\section{Appendix F: Complete Wind Tunnel Data Plots}

\section{Fuselage Only}
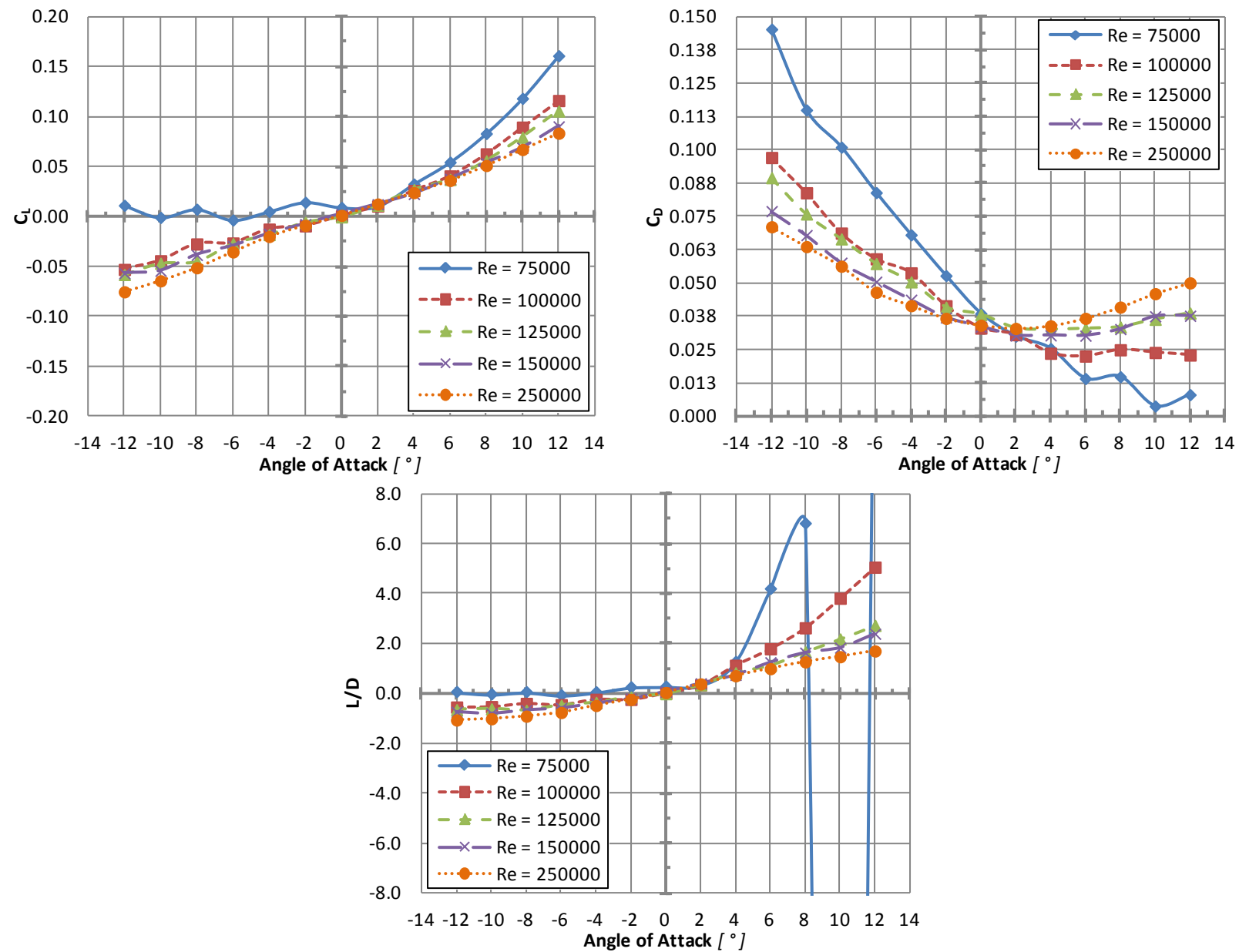

Figure F-1 Fuselage Only - Lift, Drag, and L/D Polars 

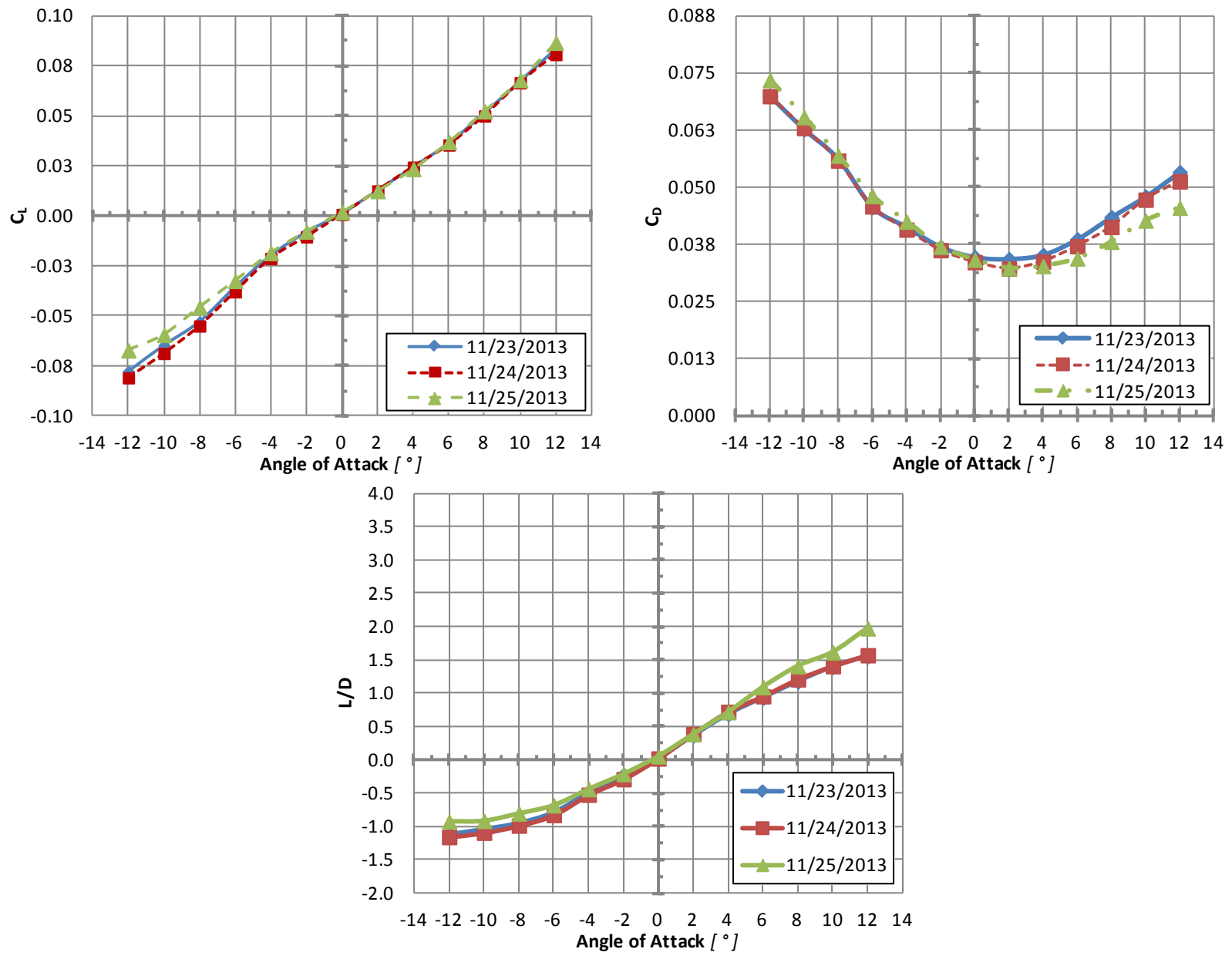

Figure F-2 Fuselage Only- Lift, Drag, and L/D Polars from Repeatability Testing at $R e=250,000$ 


\section{Fuselage \& Tail}
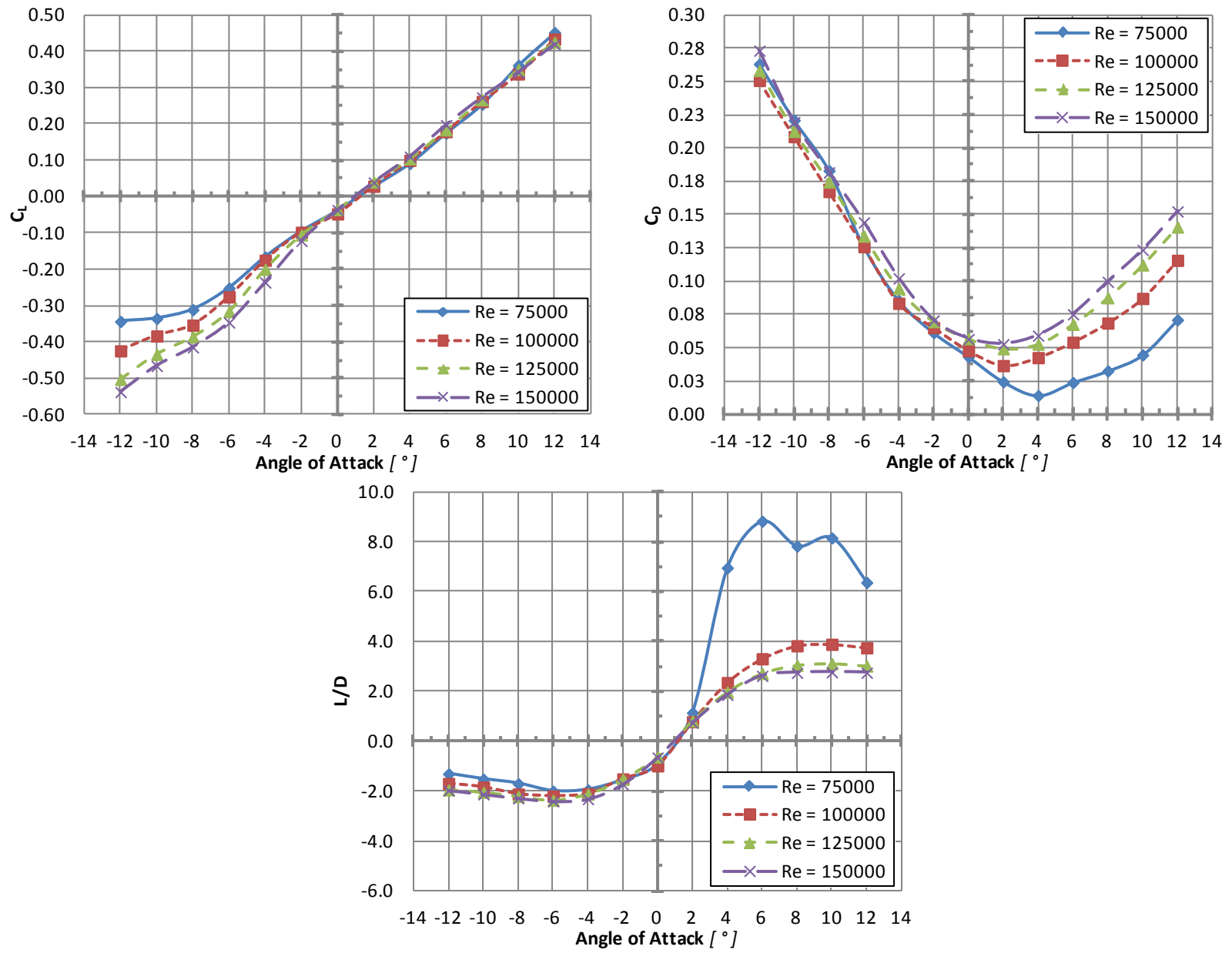

Figure F-3 Fuselage \& Tail - Lift, Drag, and L/D Polars 


\section{Fuselage and Wing}

\section{Solid NACA 0009}
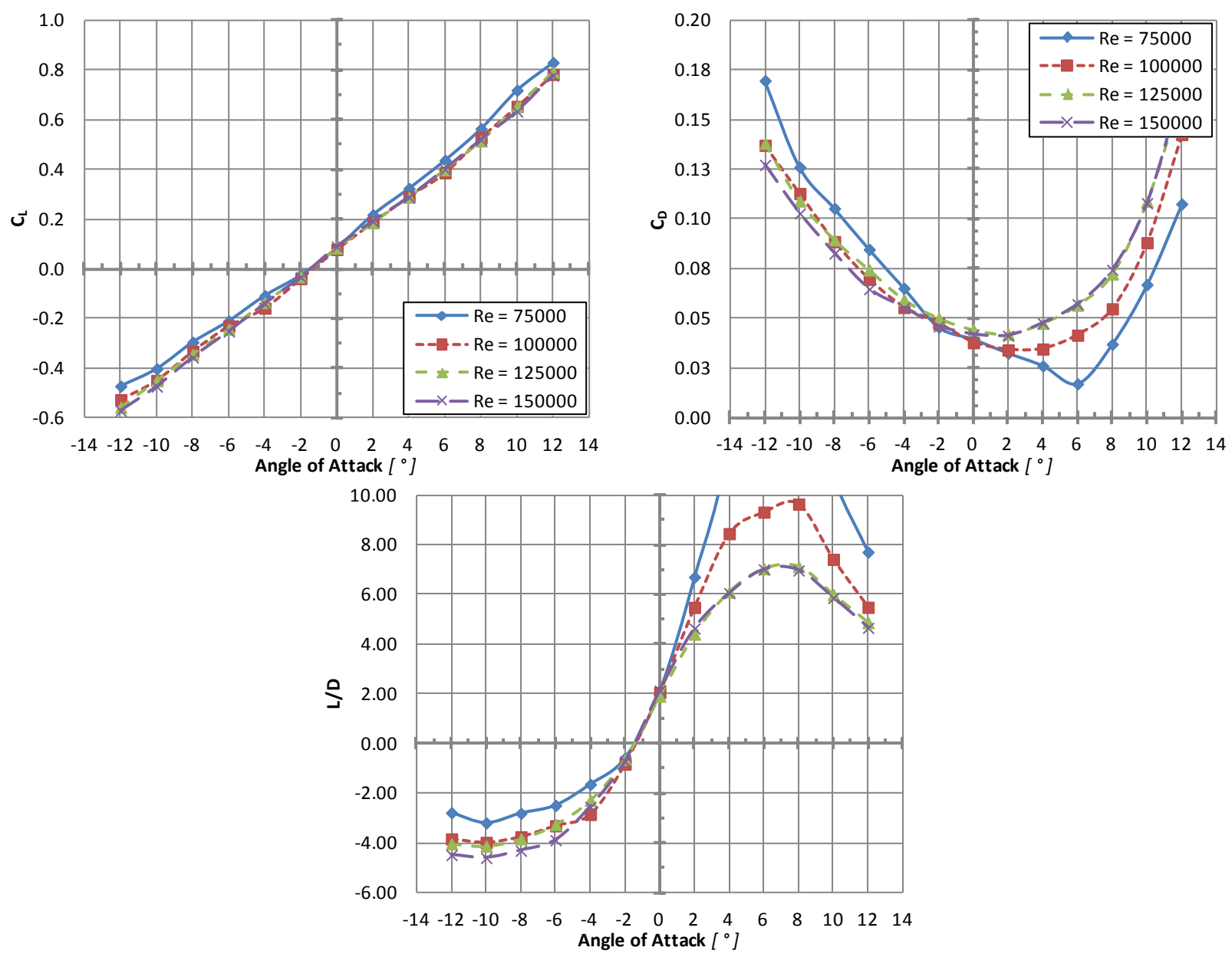

Figure F-4 Fuselage \& Solid NACA 0009 Wing - Lift, Drag, and L/D Polars 

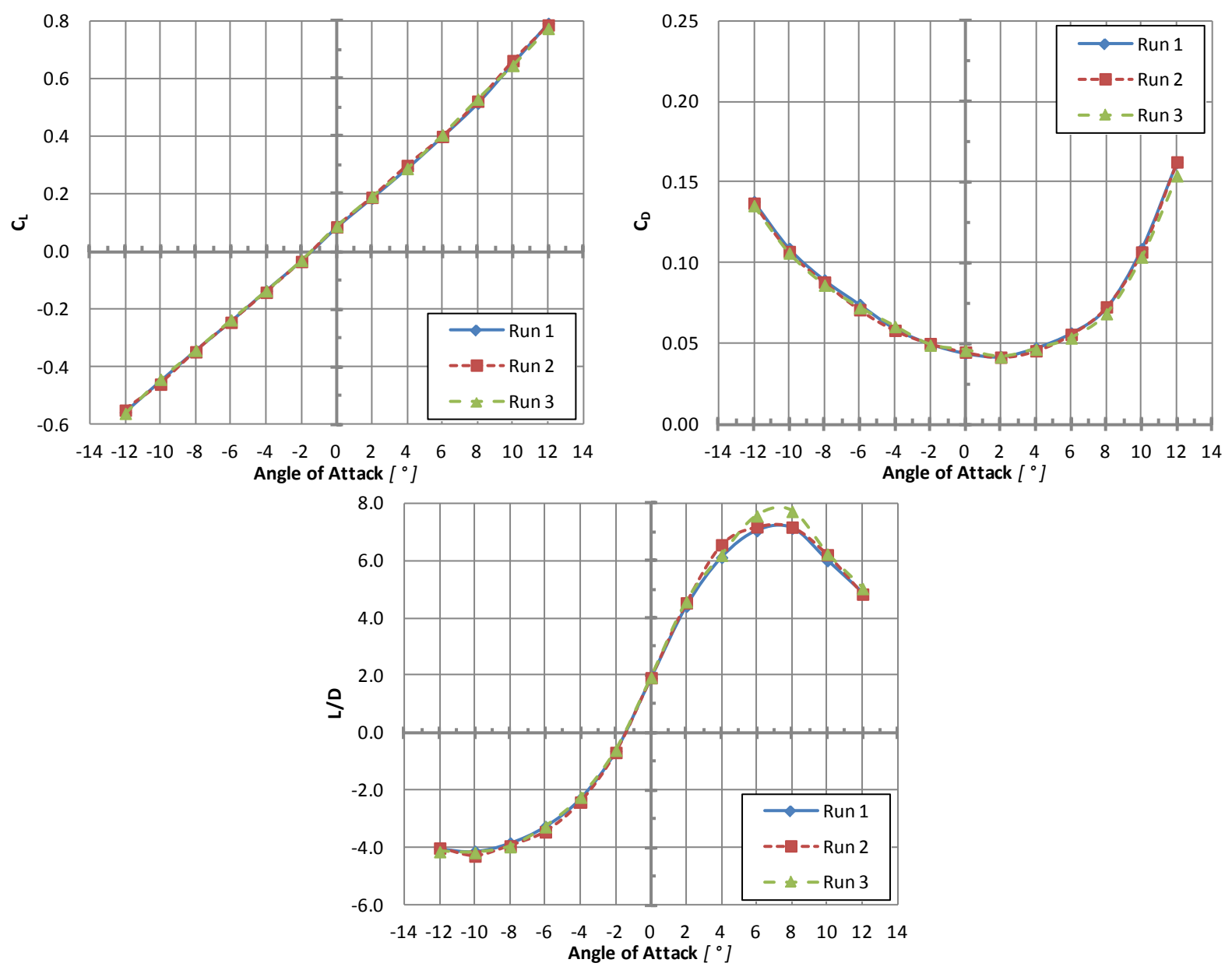

Figure F-5 Fuselage \& Solid NACA 0009 Wing - Lift, Drag, and L/D Polars from Repeatability Testing at $\operatorname{Re}=125,000$ 
Solid NACA 0009m
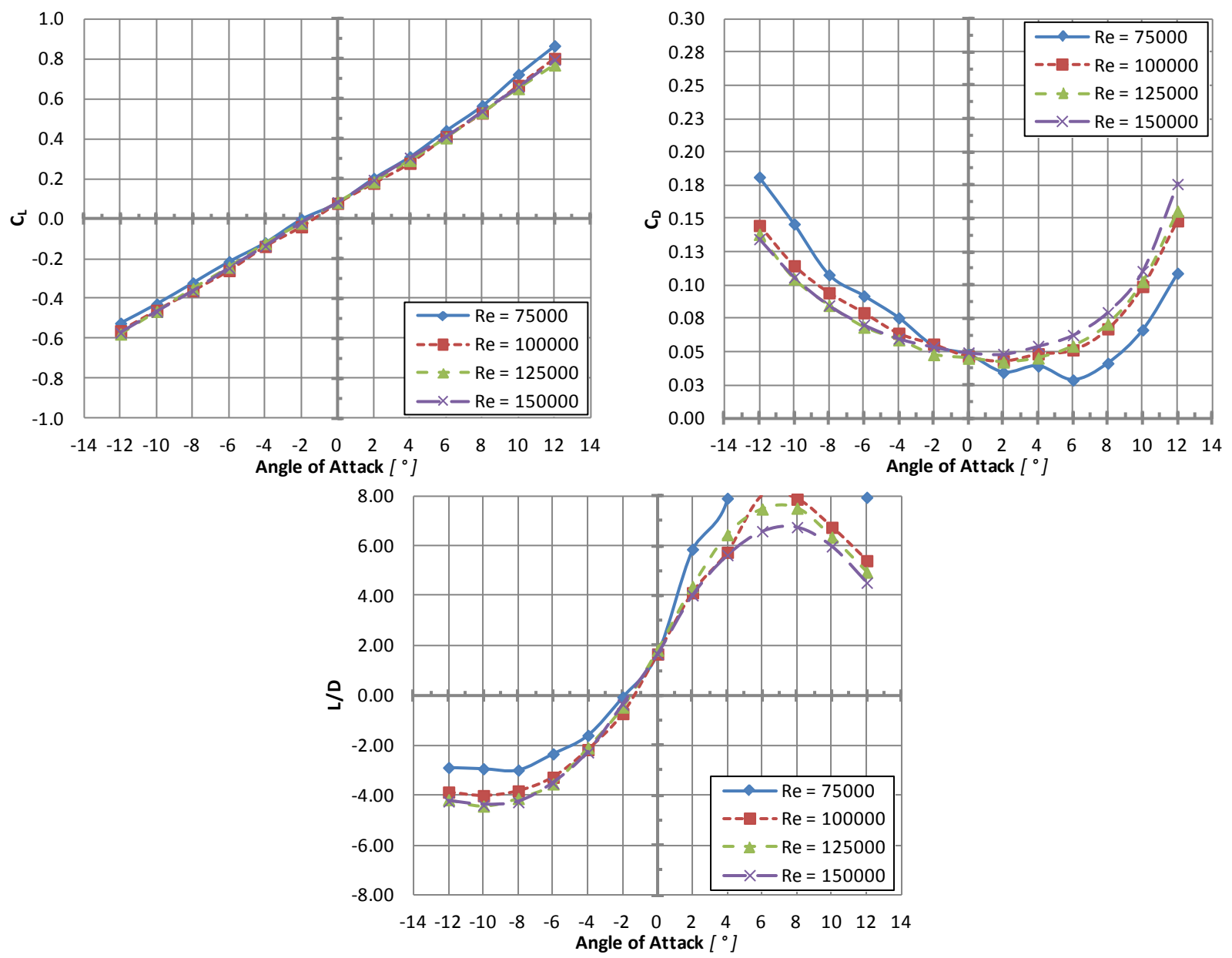

Figure F-6 Fuselage \& Solid NACA 0009m Wing - Lift, Drag, and L/D Polars 
Solid-Membrane NACA 0009m

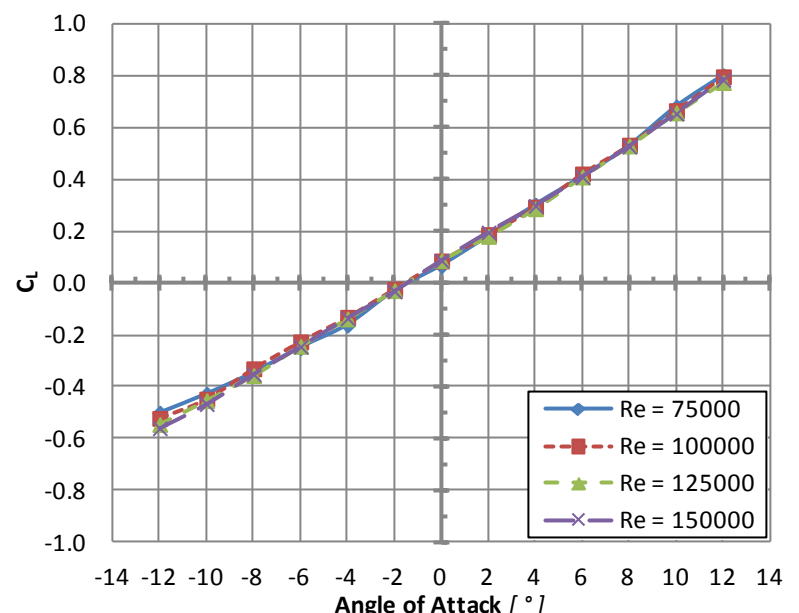

Angle of Attack $\left[{ }^{\circ}\right.$ ]

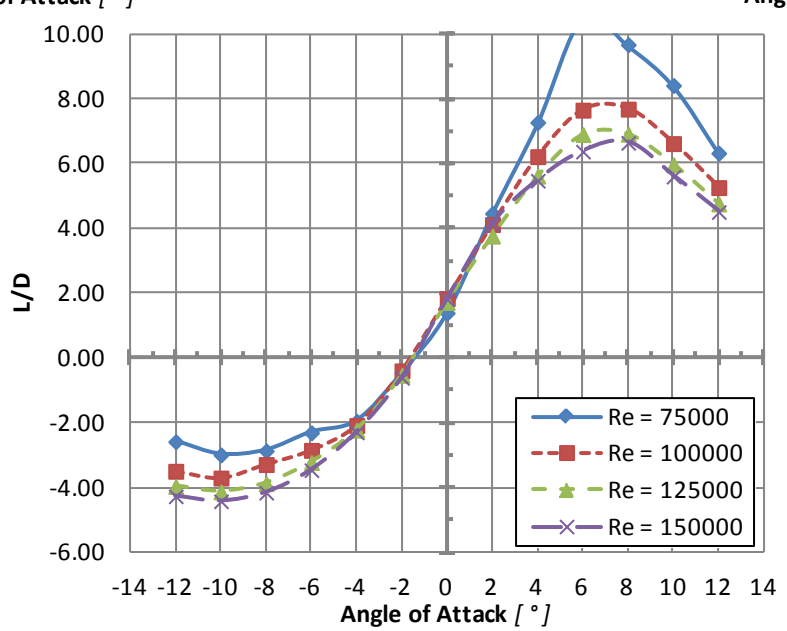

Figure F-7 Fuselage \& Solid-Membrane NACA 0009m Wing - Lift, Drag, and L/D Polars

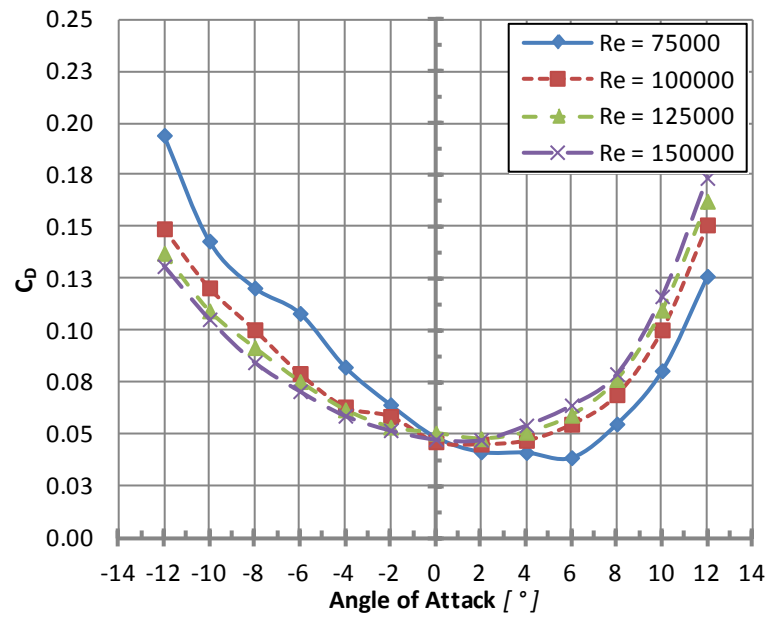

$$
\text { . }
$$



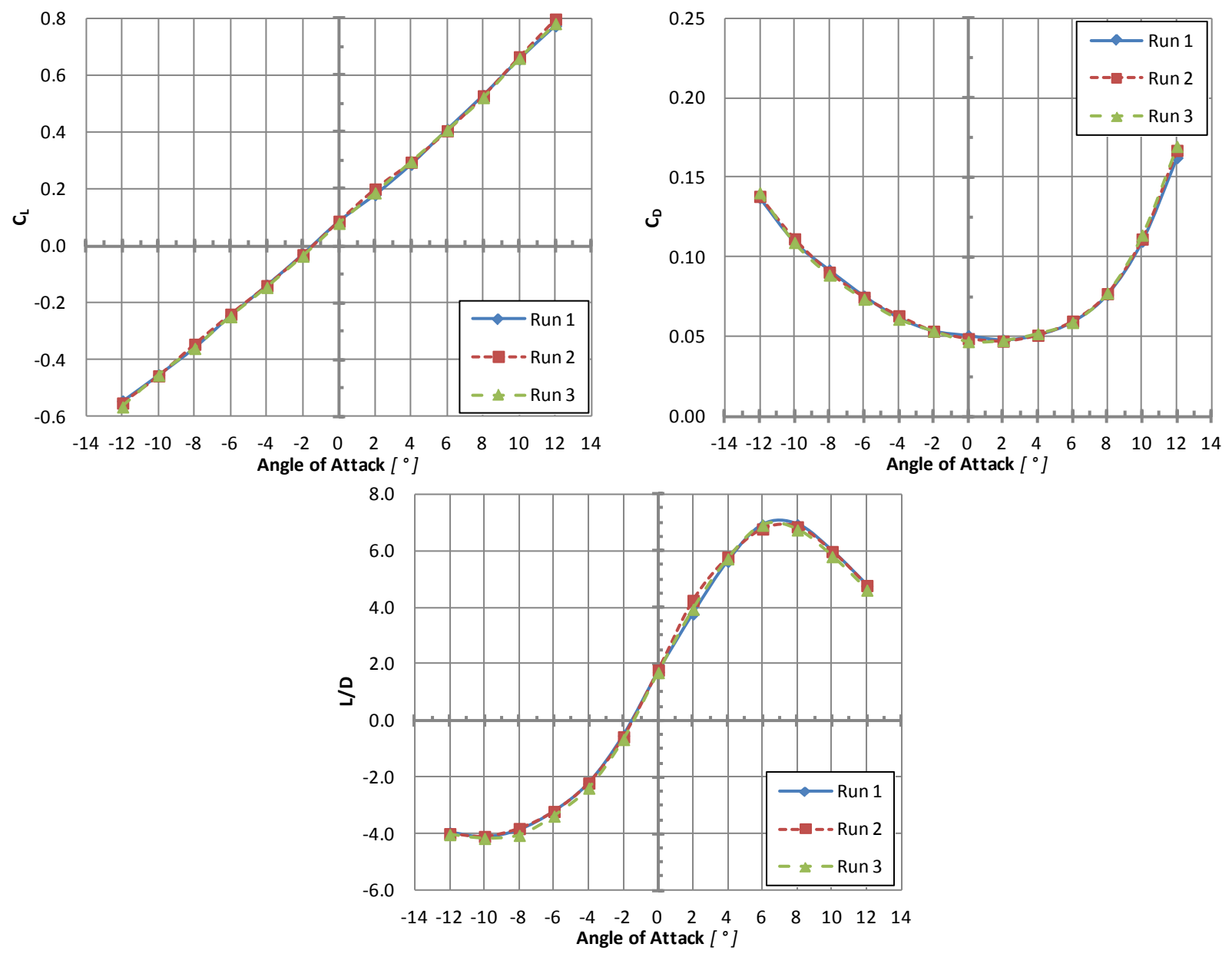

Figure F-8 Fuselage \& Solid-Membrane NACA 0009m Wing - Lift, Drag, and L/D Polars from Repeatability Testing at $\operatorname{Re}=125,000$ 


\section{Partial Deployment Cases - Solid-Membrane NACA 0009m}
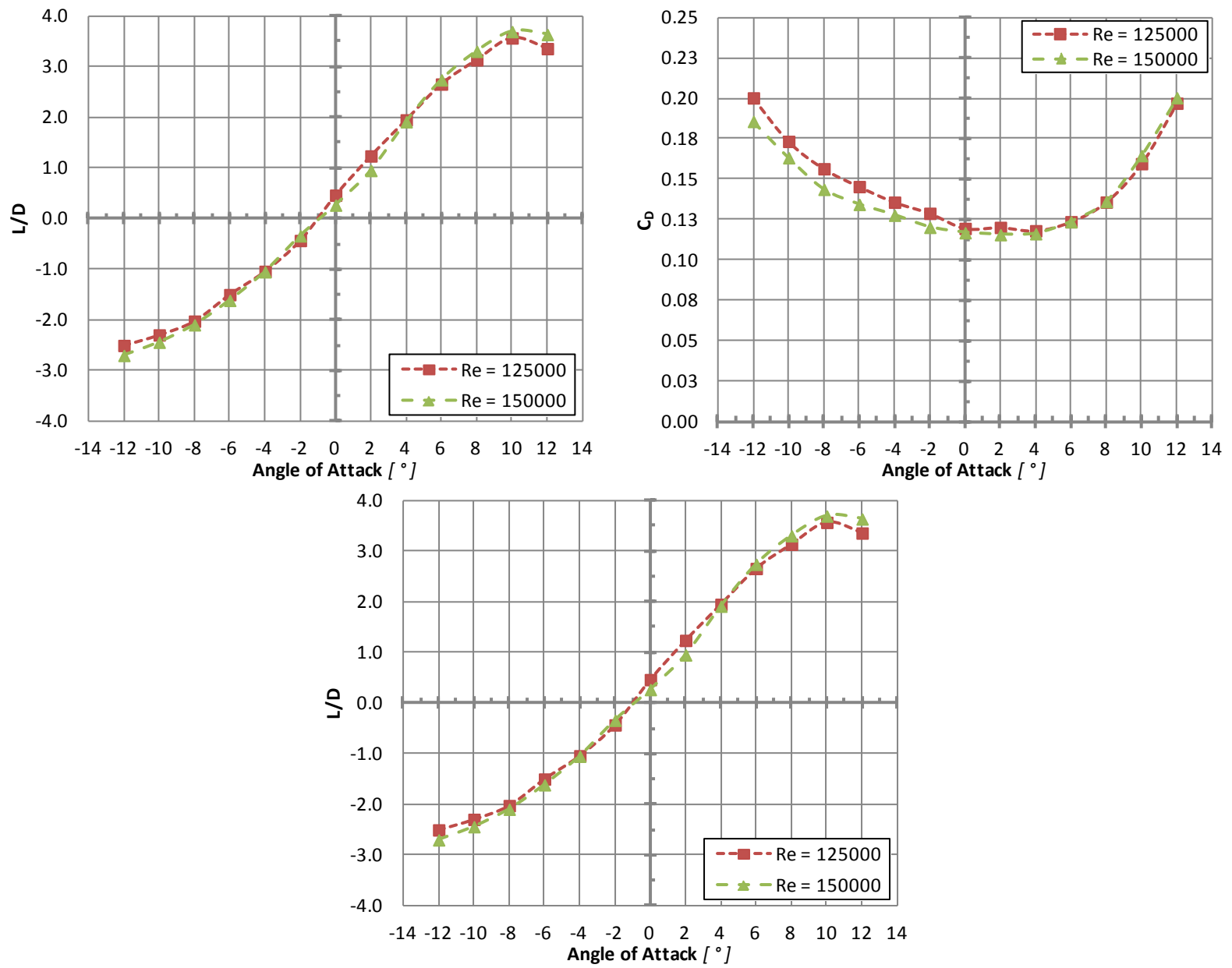

Figure F-9 Fuselage \& Solid-Membrane NACA 0009m Wing - Partial Trailing Edge Element Deployment Lift, Drag, and L/D Polars 

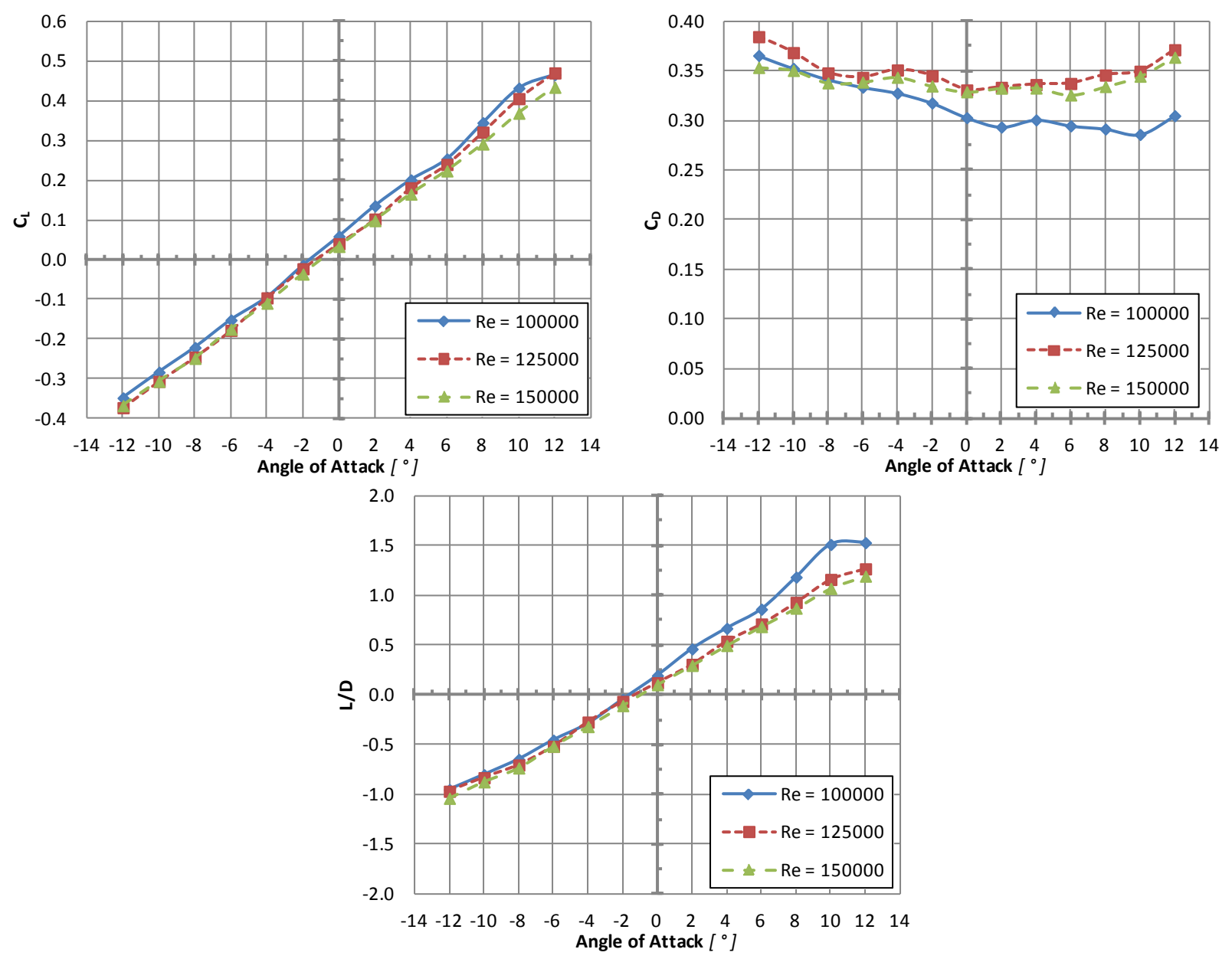

Figure F-10 Fuselage \& Solid-Membrane NACA 0009m Wing - No Trailing Edge Element Deployment - Lift, Drag, and L/D Polars 
Fuselage, Tail, and Wing

\section{Solid NACA 0009}
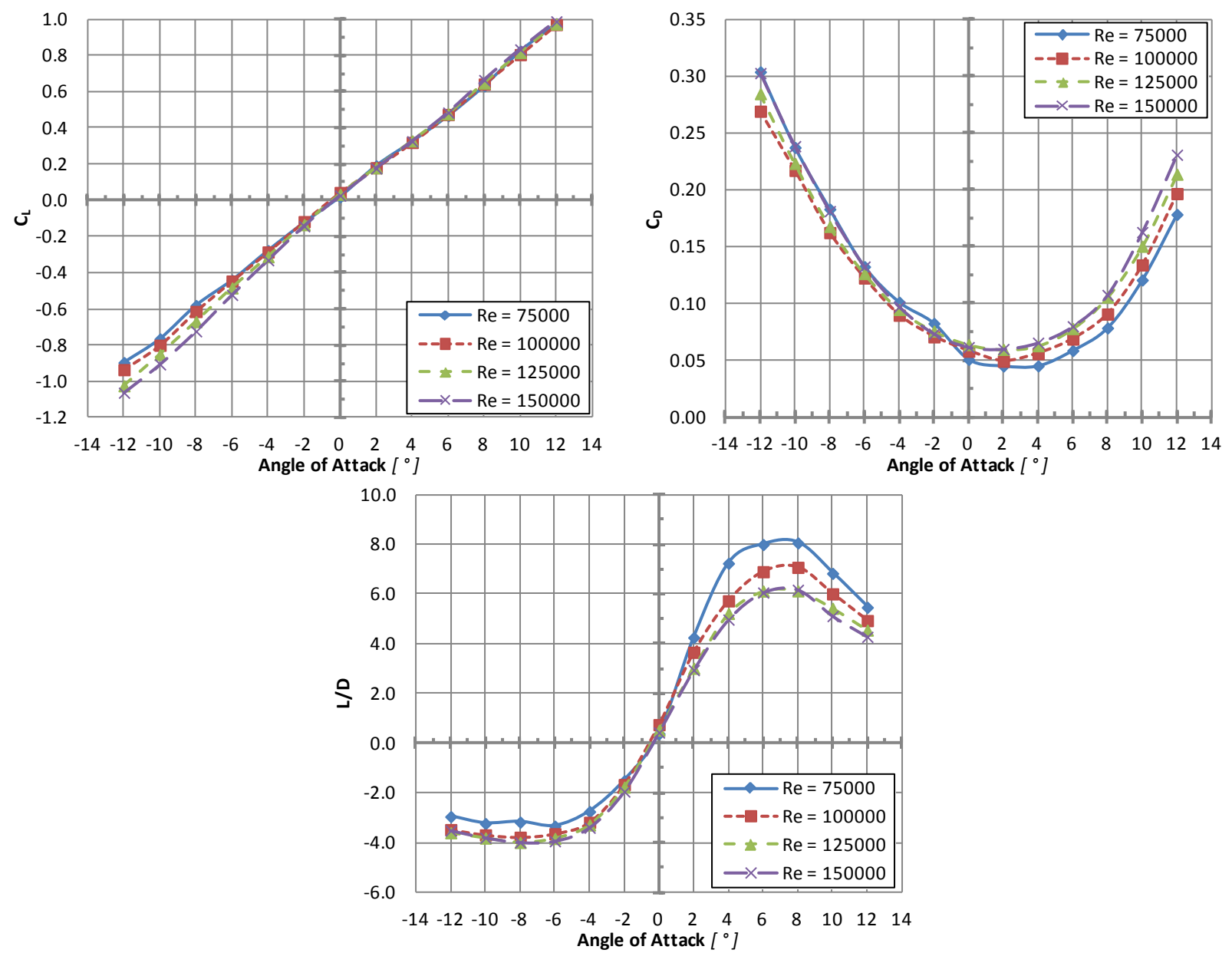

Figure F-11 Fuselage, Tail, \& Solid NACA 0009 Wing - Lift, Drag, and L/D Polars 

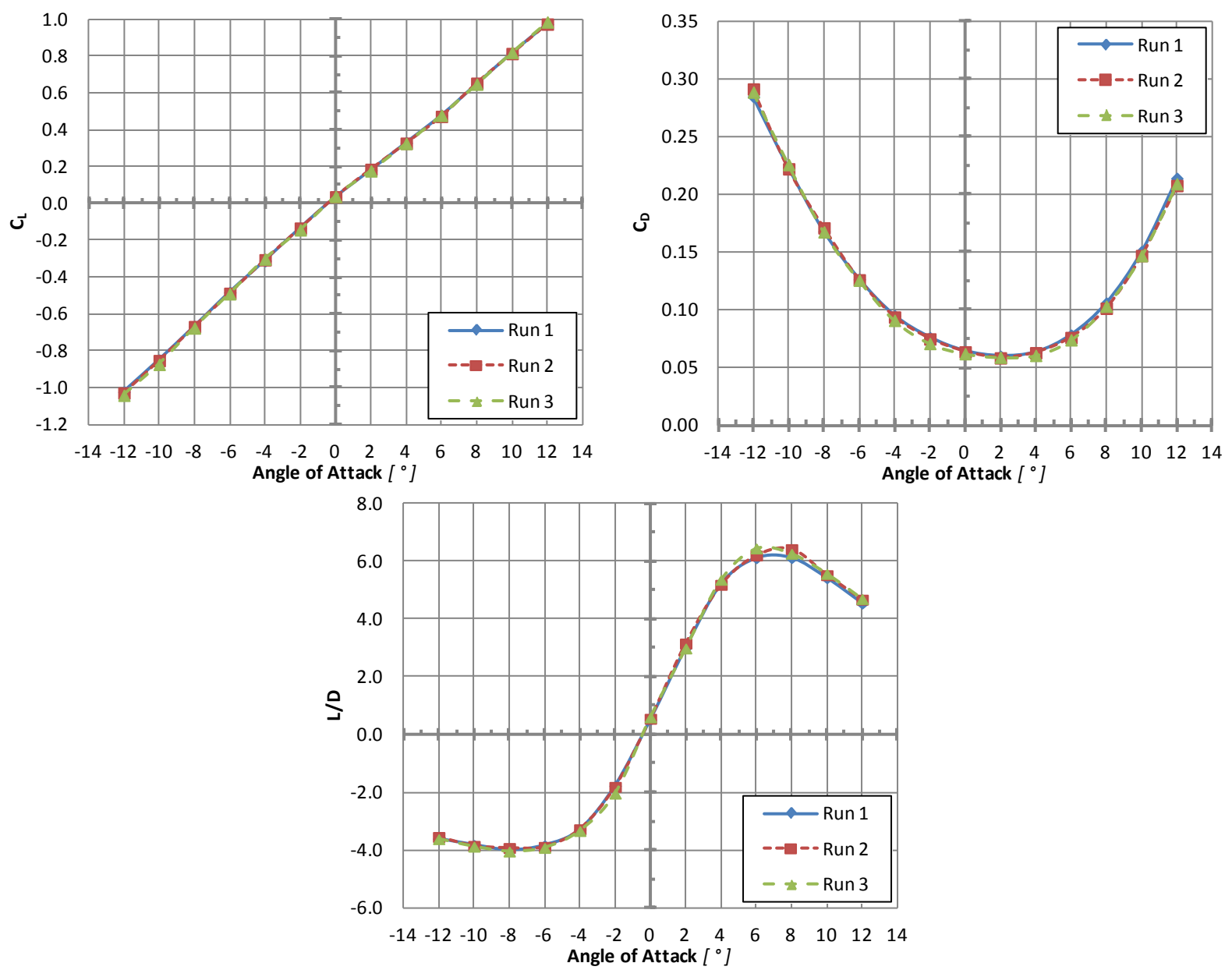

Figure F-12 Fuselage, Tail, \& Solid NACA 0009 Wing - Lift, Drag, and L/D Polars from Repeatability Testing at $\mathbf{R e}=125,000$ 
Solid NACA 0009m
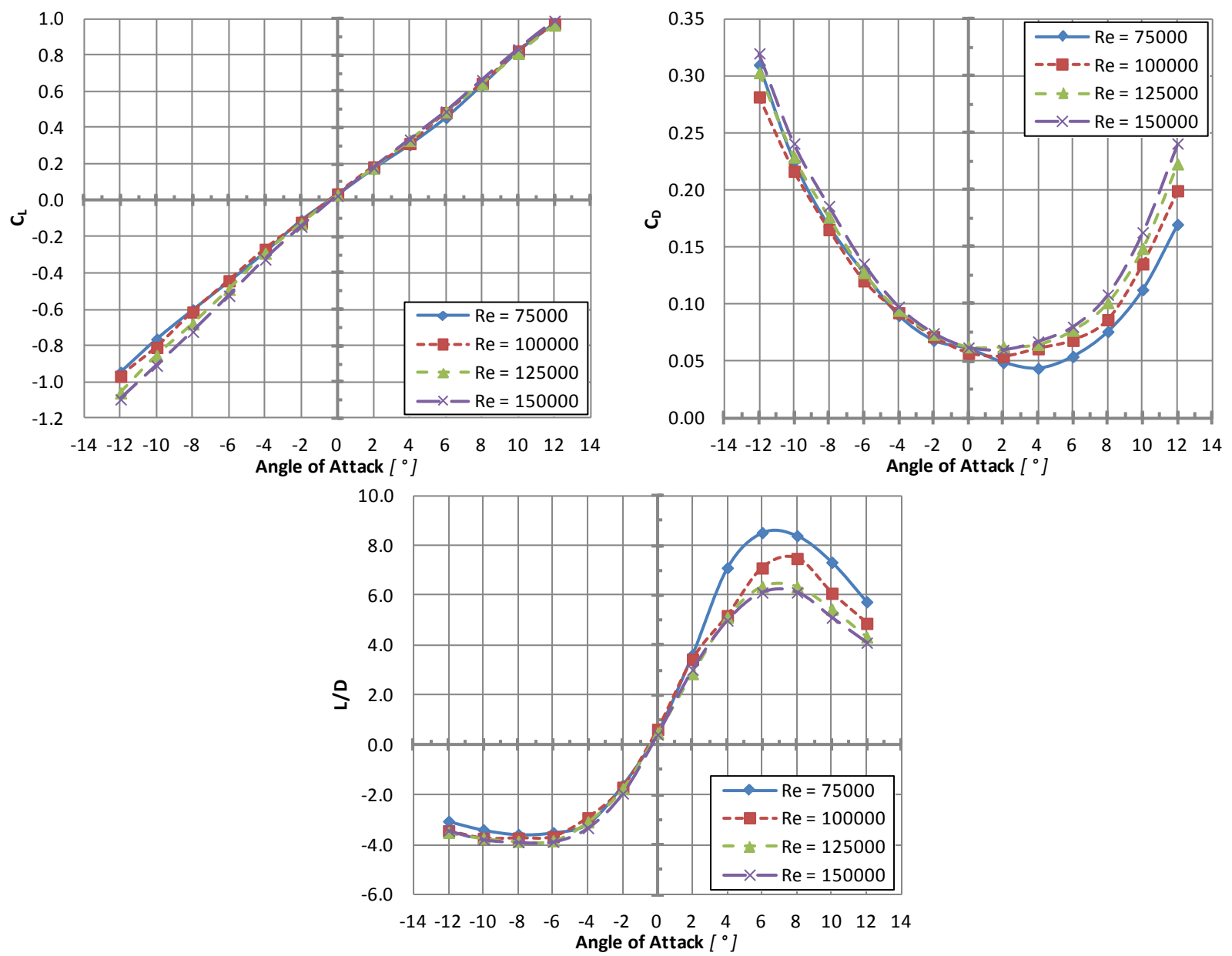

Figure F-13 Fuselage, Tail, \& Solid NACA 0009m Wing - Lift, Drag, and L/D Polars 


\section{Solid-Membrane NACA 0009m}
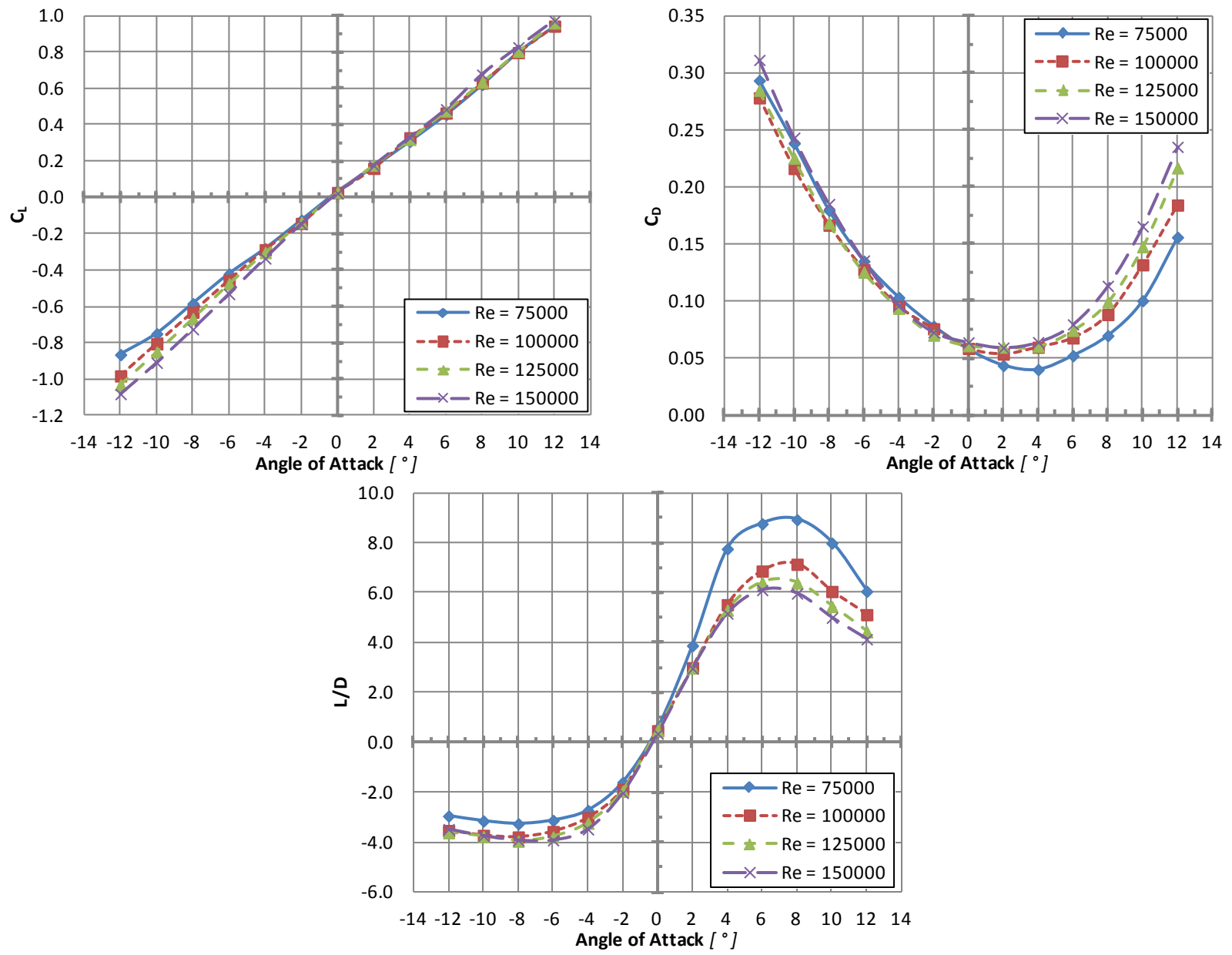

Figure F-14 Fuselage, Tail, \& Solid-Membrane NACA 0009m Wing - Lift, Drag, and L/D Polars 

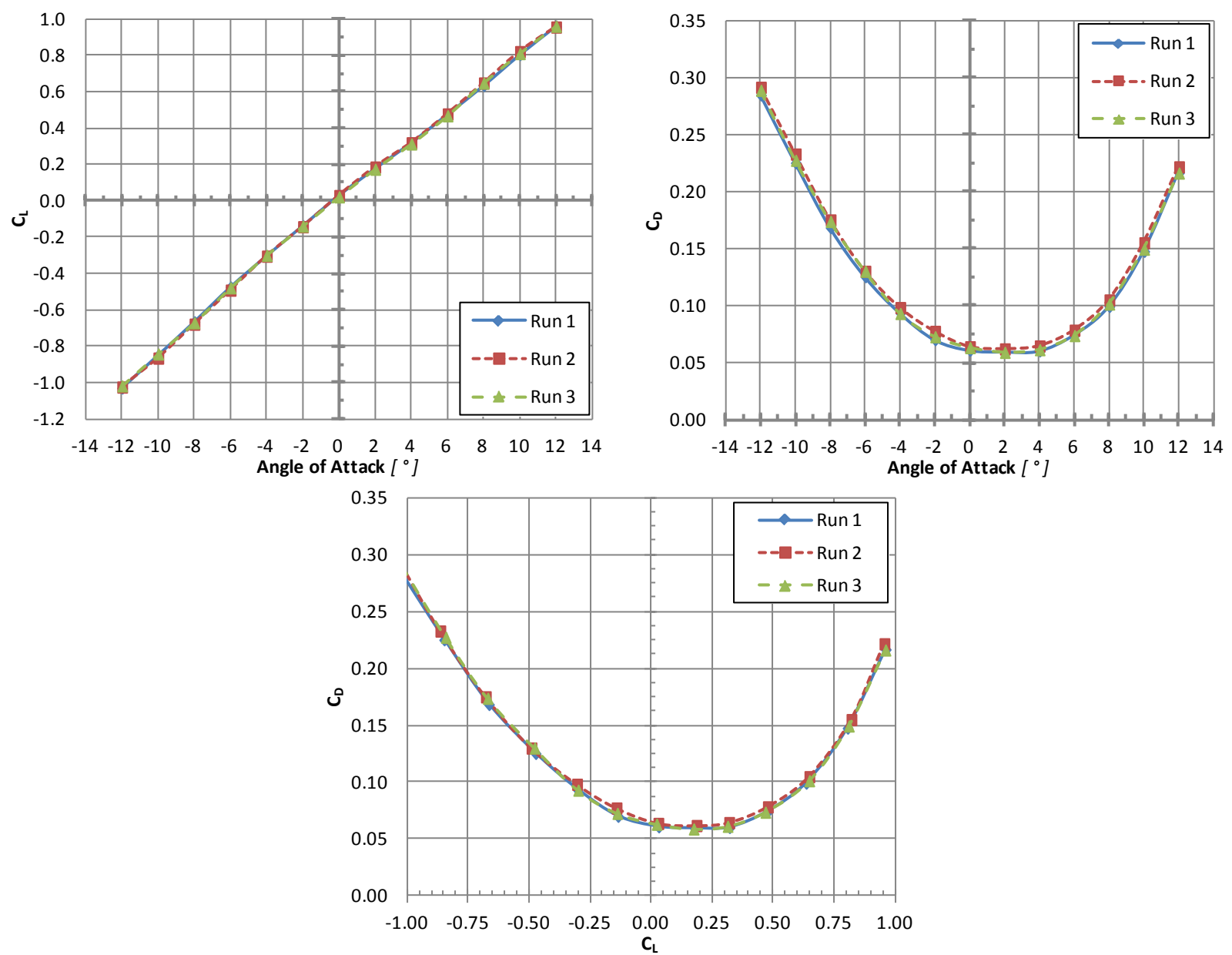

Figure F-15 Fuselage, Tail, \& Solid-Membrane NACA 0009m Wing - Lift, Drag, and L/D Polars from Repeatability Testing at $\operatorname{Re}=125,000$ 